\title{
ANÁLISE HARMÔNICA APLICADA A DADOS DE TEMPERATURAS MÉDIAS MENSAIS DE CAMPINAS, SP
}

INESS FUMIKO UBUKATA YADA

Orientador: Prof. Dr. IZAIAS RANGEL NOGUEIRA

Dissertação apresentada à Escola Superior de Agricultura "Luiz de Queiroz", da Universidade de São Paulo, para obtenção do título de Mestre em Agronomia. Área de concentração: "Estatística $\theta$ Experimentação Agronômica".

\author{
PIR A CICABA \\ Estado de São Paulo - Brasil \\ Maio - 1986
}


.ii.

$\bar{A}$ meus pais (in memoriam)

meus irmãos e cunhadas

ofereço

Ao meu esposo

George,

Dedico 


\section{AGRADECIMENTOS}

- Ao Dr. Izaias Rangel Nogueira, Professor Tí tular do Departamento de Matemática e Estatistica da ESALQ, pela valiosa orientação e incentivos durante o curso e na elaboração do trabalho.

- Ao Dr. F. Pimentel Gomes, Professor Catedrá tido do Departamento de Matemática e Estatistica da ESALQ, pela acolhida e ensinamentos prestados durante o curso.

- Ao Dr. Humberto de Campos, Dr. Débio Barbin, Professores Titulares do Departamento de Matemática e Estatistica da ESALQ, pelo apoio e estimulo.

- Ao corpo Docente do Departamento de Matemática e Estatistica da ESALQ, pelos ensinamentos transmitidos.

- Ao Conselho Nacional de Desenvolvimento Cientifico e Tecnológico (CNPq), pelas bolsas concedidas, durante o curso.

- Ao Dr. João Baptista da Silva, Professor Tí tular do Departamento de Matemática e Estatistica da Universidade Federal de l'elotas, RS, pelas valiosas sugestões, incentivos e colaboração na execução do trabalho.

- Ao Dr. Vivaldo Francisco da Cruz, Professor Assistente Doutor do Departamento de Matemática e Estatística da ESALQ, pelas sugestões na elaboração final do trabalho. 
iv.

- A Profa Vanderci Aguilera da Universidade Estadual de Londrina, pela revisão do portugués.

- Aos colegris da ärea de Biometria e Processa

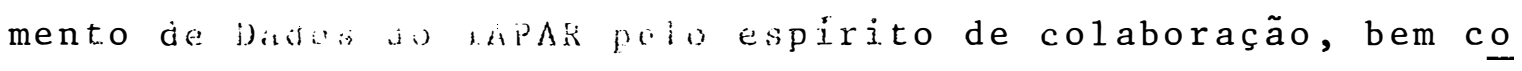
mo aos colegas Antonio Fernando Megumi Tazima e Jaime Gera1do da Silva, pela execução dos programas.

- A Srta. Maria Izalina Ferreira Alves, Rosa Maria Alves e familia pelo companheirismo, incentivos e ami$z$ ade

- Ao meu esposo, George Mitsuo Yada, pe 1 o apoio e incentivos.

- Aos colegas do curso de Pós-graduação, pelo excelente convívio.

- A todos que direta ou indiretamente colaboraram para a execução deste trabalho. 


\section{INDICE}

pägina

RESUMO $\ldots \ldots \ldots \ldots \ldots \ldots \ldots \ldots \ldots \ldots \ldots \ldots \ldots \ldots \ldots \ldots \ldots \ldots \ldots \ldots$

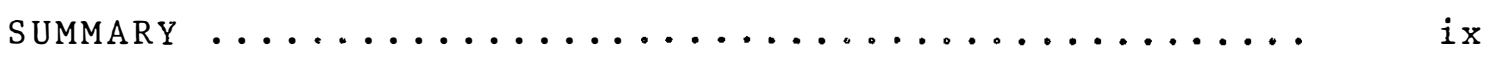

1. INTRODUÇAO $\ldots \ldots \ldots \ldots \ldots \ldots \ldots \ldots \ldots \ldots \ldots \ldots \ldots \ldots \ldots \ldots \ldots$

2. REvisão da literatura $\ldots \ldots \ldots \ldots \ldots \ldots \ldots \ldots \ldots$

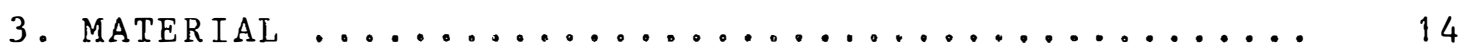

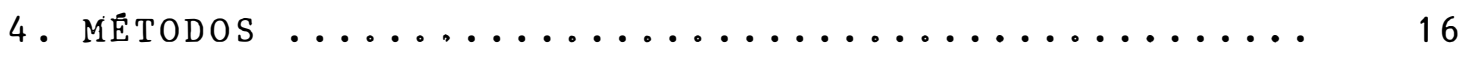

4.1. Desenvolvimento teórico ............... 16

4.2. Modelo matematico .................... 20

4.3. listimativas dos parämetros, suas variāncias

e covariâncias $\ldots \ldots \ldots \ldots \ldots \ldots \ldots \ldots \ldots \ldots \ldots$

4.4. Intervalo de confiança ................ 34

4.5. Transformação dos dados ............... 35

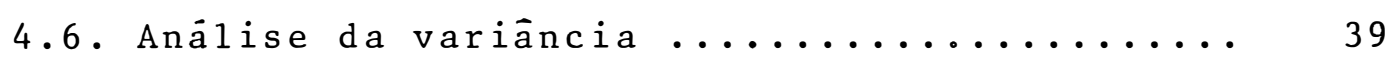

4.6.1. Teste de homogeneidade de variāncias. 40

4.6.2. Teste de normalidade .......... 41

4.6.3. Teste de aditividade de Tukey ...... 43

4.7. Quadros de anālise de variância ......... 46

5. REsultados E discussao $\ldots \ldots \ldots \ldots \ldots \ldots \ldots \ldots \ldots \ldots$

5.1. Transformação dos dados ............... 51

5.2. Análise harmönica .................. 53

5.3. Anjise de variancia $\ldots \ldots \ldots \ldots \ldots \ldots \ldots \ldots$. 106

5.4. Variáncia dos parāmetros estimados ....... 120

5.5. Intervalo de confiança .............. 120 
.$v i$.

pàgina

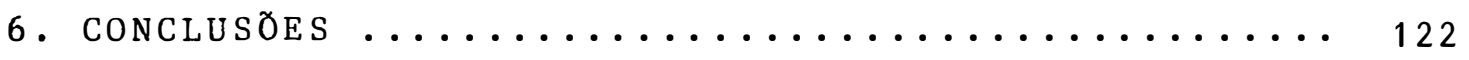

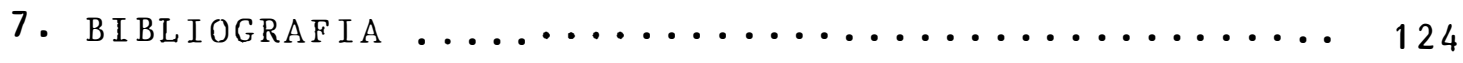

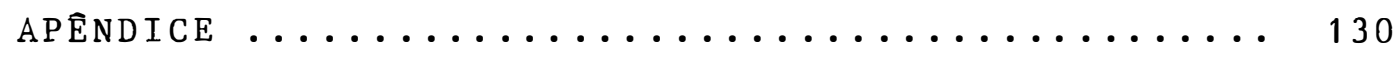




\title{
ANÁLISE HARMONNICA APLICADA À DADOS DE TEMPERATURAS \\ MÉDIAS MENSAIS DE CAPIPINAS; SP
}

\author{
Autor: INES FUMIKO UBUKATA YADA \\ Orientador: Prof. Dr. Izaias Rangel Nogueira
}

\section{RESUMO}

0 presente trabalho tem q.omo objetivo estudar as temperaturas médias mensais de Campinas, SP, através de seus componentes harmônicos e sintetizar aqueles componentes que se mostrarem significativos.

Aos dados de temperaturas médias mensais apli cou-se a anälise harmōnica para cada ano e para o conjunto to tal dos anos, ajustados a um ano médio referentes ao Municipio de Campinas, SP, num periodo de 91 anos (1890 a 1980).

Como os dados originais de temperaturas mëdias não apresentaram as pressuposições da análise de variāncia, estudou-se uma transformação conveniente aos dados e verificou-se que $Y=X^{1,84216}$ satisfaz estas condições.

A estabilidade dos componentes harmōnicos das temperaturas médias mensais foi testada pelo método da análi- 
se de variância, revelando-se significativas as ondas com periodo anual, semestral e trimestral.

A equação de regressão obtida pelos resultados da anailise himönusa do lotal dos 91 anos foi ajustada a um ano médio e ë apresentada por:

$$
\begin{aligned}
\hat{Y}_{t}=257,5209 & +67,3803 \operatorname{sen}\left(30^{\circ} t+93,1827^{\circ}\right)+ \\
& +16,0434 \operatorname{sen}\left(60^{\circ} t+331,5798^{\circ}\right)+ \\
& +2,4962 \operatorname{sen}\left(120^{\circ} t+209,0092^{\circ}\right) .
\end{aligned}
$$

A equação ora determinada explica $99,8 \%$ das variaçoes devidas a meses. Somente a onda anual explicou pra ticamente $94,5 \%$. Estimou-se um máximo durante o mês de fevereiro $\left(\vec{Y}_{1}=321,03\right)$ equivalente à temperatura de $\vec{Y}_{1}=22,94^{\circ}$ e um minimo durante o mês de julho $\left(\widehat{Y}_{6}=181,40\right)$, equivalente à temperatura de $\overline{\mathrm{Y}}_{6}=16,83^{\circ}$. 


\section{HARMONIC ANALYSIS APPLIED TO MONTHLY \\ MEAN TEMPERATURES DATE OF CAMPINAS; SP}

Author: INES FUMIKO UBUKATA YADA

Adviser: Prof. Dr. IZAIAS RANGEL NOGUEIRA

\section{SUMPARY}

The purpose of the present paper was to study the monthly mean temperatures of Campinas Municipality (SP) through their harmonic components and to synthesize those components which showed significance.

It was applied the harmonic analysis to the monthly mean temperatures of each year and to the total of 91 years adjusted to one average studied (1890 to 1980).

As the original data of mean temperatures didn't showed the presuppositions of the analyses of variance, a convenient transformation was calculated and it was found that $Y=X^{1.84216}$ satisfied these conditions.

The stability of the harmonic components of the monthly mean temperatures was tested through the method of analysis of variance showing significant those waves with periods of three, six and twelve months. 
The regression equation obtained by the results of the harmonic analysis from the total of 91 years studied was adjusted to one year average and is presented:

$$
\begin{aligned}
\hat{\mathrm{Y}}_{\mathrm{t}}=257.5209 & +67.3803 \operatorname{sen}\left(30^{\circ} \mathrm{t}+93.1827^{\circ}\right)+ \\
& +16.0434 \operatorname{sen}\left(60^{\circ} \mathrm{t}+331.5798^{\circ}\right)+ \\
& +2.4962 \operatorname{sen}\left(120^{\circ} t+209.0092^{\circ}\right) .
\end{aligned}
$$

The model here determinate explains $99.8 \%$ of the monthly variations. The one year period wave explained itself $94.5 \%$ of those variations. During february it was estimated a maximum of $\hat{\mathrm{Y}}_{1}=321.03$ equivalent to the temperature $\hat{\mathrm{Y}}_{1}=22.94^{\circ}$ and during july a minimum of $\hat{\mathrm{Y}}_{6}=$ 181.40, equivalent to the temperature $\overrightarrow{\mathrm{Y}}_{6}=16.83^{\circ}$. 


\section{INTRODUCÃO}

Todos sabemos que a temperatura é de suma importância no controle do crescimento das plantas, bem como de sua distribuição sobre o planeta.

Muitos fenōmenos fisiolögicos ocorrem entre 0 a $40^{\circ} \mathrm{C}$, portanto, existe uma ampla faixa de temperaturas que cada espécie requer para o seu desenvolvimento. Estudos e pesquisas sobre melhoramento genético têm proporcionado boa ampliação desta faixa nas ültimas décadas.

Em quase todas as partes do globo ocorrem tem peraturas médias de períodos longos de variaça anual e diurna, possibilitando assim atender às necessidades em temperat ras requeridas por uma certa cultura. Existem recursos tecno lógicos que possibilitiam variar a temperatura conveniente, tais como, casa de vegetação, coberturas plásticas, etc., mas 
esses recursos só podem ser aplicados quando o retorno de capital for compensador, pois tais instalações normalmente exigem grandes investimentos.

A importāncia desse trabalho prende-se ao fato de que não se tem conhecimento de estudos de análise harmô nica aplicados aos dados de temperatura,- o que se considera de importância relevante para a agricultura,- bem como tem a finalidade de informar aos agricultores sobre esse fenómeno, para que este possa se orientar em relação às atividades agri colas, e para que possa melhor planejar a época e local do plantio, visando assim a um maior rendimento económico.

0 presente trabalho tem como objetivo estudar as temperaturas médias de Campinas, SP, em seus componentes harmónicos e sintetizar aqueles componentes que se mostrarem significativos, após testar a estabilidade dos componentes harmónicos pelo método da análise de variação para selecionar as ondas mais importantes para o modelo.

Devemos salientar que a anālise harmônica é aplicada a dados provenientes de fenómenos periódicos ou quase periódicos. Entende-se por fenómeno periódico aquele que se repete em intervalos de tempos iguais, como por exemplo, a altura do sol acima do horizonte ao meio dia em uma dada lati tude e a hora do nascer e do pôr do sol, também em uma dada latitude. 
Segundo AMARAL (1968), muitos fenómenos meteo rológicos, astrusomicos e geofísicos, tais como fenómeno de marés, o número de manchas solares, o curso diurno e anual de elementos climáticos da temperatura, por exemplo, são fenômenos quase periódicos.

$$
\text { Por fenômenos quase periódicos entendem-se, }
$$
com BROOKS e CARRUTHERS (1953), aqueles em que o valor do ele mento estudado não se reproduz exatamente em certos intervalos de tempo, como se a um processo estritamente periódico se superpusessem influências modificadoras de carāter aleatório. 


\section{REVISÃo DE LITERATURA}

CONRAD e POLLAK (1950) descreveram o método de anālise harmōnica no estudo de fenómenos climatológicos que apresentam tendēncias periódicas. Exemplificaram o método pe 1 a análise harmónica de 12 valores equidistantes, que geralmente representam o curso anual de um elemento, e pela análise de 24 valores equidistantes, que representam o curso diário de um elemento, apresentando assim a sintese das ondas que compõem aquele fenōmeno.

BLISS (1958) utilizou a regressão periódica no estudo de fenömenos biológicos e climatológicos que apresentam tendencias ciclicas, concluiu que, se os dados observados mudam simetricamente durante o ciclo, a curva do seno representa bem o fenōmeno, porém, se a curva não é simétrica, poderão ser adicionados mais termos à equação, até que o ajus te desejado seja encontrado. 
GODOY et alii (1959) estudaram as temperatu ras médias de Campinas, SP, no periodo de 67 anos ( 1890 1956) e aplicaram o método dos polinōmios ortogonais às tempe raturas médias de janeiro, abril, julho, outubro e médias anuais. Concluiram que, em quase todos os casos estudados, hou ve regressão significativa de primeiro ou segundo grau, demonstrando assim tendência secular de modificação das tempera turas médias.

AMARAL (1968) apresentou um trabalho sobre anảlise harmónica, exemplificando sua aplicação com dados de precipitações pluviométricas mensais de Pelotas, RS, para um periodo de 52 anos (1900 a 1951). Testou a estabilidade dos componentes harmōnicos pelo método da análise de variância e concluiu serem significativas as ondas anual, semestral e qua drimestral. 0 teste de completicidade indicou que $91,2 \%$ da variação das precipitações médias mensais corre por conta des sas três ondas.

Em outro exemplo, utilizando dados das precipitaçoes pluviométricas mensais de Morro Velho, MG, no período de 1855 a 1951, o autor submeteu os dados à transformação $z=x^{0,351}$ e concluiu ser a onda anual responsável por $99,3 \%$ da variação entre médias mensais.

ANDERSON ( 1971 ) apresentou toda teoria sobre funções com tendência cíclica. Descreveu um estudo matricial 
detalhado da anälise harmónica, para calcular os componentes da regressão e coeficientes de correlação para os componentes harmōnicos.

DECICO e CRUZ (19.74) apresentaram um traba1ho sobre as vantagens e facilidades do emprego da série de Fourier no estudo e interpretação dos fenômenos periödicos. Exem plificaram com as precipitações mensais da região de Piracica ba, SP, no período de 1917 a 1970, e determinaram um valor mi nimo de seleção de amplitudes.

DUARTE (1974) aplicou a anālise harmōnica para determinar a curva epidemiológica da ferrugem alaranjada do cafeeiro da Zona da Mata, MG, utilizando duas transformações nos dados originais; a primeira indicada por BLISS (1958) : $Y=\log (F P+1)$, onde FP é porcentagem de infecção; a segunda recomendada por VAN DER PLANK: $Y=\log \frac{X}{1-X}$, onde $X=\frac{F P}{100}$.

Concluiu que em ambas as transformações a cur va do seno representa bem o fenómeno, sendo que o máximo de infeç̧ão se verifica em junho e o mínimo se verifica em dezem bro.

Para a primeira transformação obteve-se a seguinte equação de regressão: $\bar{Y}_{i}=1,1917+0,2893 U_{1 i}+0,3678 V_{1 i}$, onde $U_{1 i}=\cos (c \cdot i)$, $v_{1 i}=\operatorname{sen}(c . i), c=\frac{2 I}{i}, i=0,1, \ldots 11$ (meses), com coeficiente de variação de $18,63 \%$ e coeficiente de determinação de $94,11 \%$; com a segunda obteve-se $\overrightarrow{\mathrm{Y}}_{i}=-0,7267+0,4137 \mathrm{U}_{1 i}-0,5371 \mathrm{~V}_{1 i}$, com coeficiente de varia- 
ção de $11,81 \%$ e coeficiente de determinação de $95,77 \%$.

PIMENTEL GOMES e NOGUEIRA (1975), utilizaram as temperaturas médias anuais de 67 anos de observação, relativas à cidade de Campinas, SP, no periodo de 1890 a 1956, aplicando a regressão polinomial nos primeiros 22 anos, obteve-se uma equação de regressão de 1 ọ grau e concluiram que a equação relativa aos primeiros 22 anos não continua para $X>$ 22 e os valores observados se afastam cada vez mais dos calcu lados. No mesmo trabalho fizeram também um estudo dos dados no periodo de $X=23$ a $X=44$ (1912 a 1933) obteve-se : uma equação de regressão do 39 grau e concluíram que é excelente a concordancia das temperaturas observadas com as calculadas, mas que para $X<23$ e para $X>44$ as discrepancias são enormes; concluindo assim que a usada equação de regressão para extrapolação é extremamente perigosa e pode levar a resultados completamente fora da realidade.

Amaral et ali $i$ (1975), citado por BAPTISTA DA SILVA (1979), publicaram em 1975, no Boletim Técnico nọ 9 do Departamento Nacional de Meteorologia, tabelas de probabilida des de temperatura minima em Pelotas, RS.

As tabelas de probabi 1 idade da temperatura mí nima (média das minimas e minima absoluta em cada uma das .73 pêntadas do ano), calculadas com as observações feitas na cidade de Pelotas, no periodo de 1900-1051 (Posto Meteorológico da Faculdade de Agronomia Eliseu Maciel) são precedidas, no 
trabalho, de instruções para o uso de testes. Os referidos testes foram efetuados com as observações na Estação Meteoro -Agräria do Instituto de Pesquisas e Experimentação Agrope cuāria do Sul (IPEAS), a cerca de 15 quilómetros da cidade de Pelotas, no período de setembro de 1950 a agosto de 1971 ( 21 anos).

$$
\text { o mëtodo adotado na elaboração das tabelas }
$$
consistiu na transformaça dos dados com vistas a homogeneizar as variāncias e a normalizar a distribuição. As transformações adotadas foram:

$$
z=(1+x / 273)^{13,355}
$$

para a mèdia das mínimas, e

$$
W=(1+x / 273)^{6,553}
$$

para a minima absoluta da pēntada.

Os testes a que foram submetidas as tabelas de probabilidades indicaram que a concordāncia entre os valo res observados e os calculados com o auxilio das tabelas foi bastante satisfatória, donde os autores concluiram que as sé ries de observações na cidade de Pelotas, de 1900 a 1951, e no IPEAS, de 1950 a 1971 , são homogêneas, permitindo, portan to, o uso das tabelas para toda uma região em torno de Pelotas. 
THIEBAUT (1976) estudou, através da análise harmōnica, as precipitações mensais de Viçosa, MG, no periodo de 1924 a 1973. Obteve a equação de regressão para os se guintes periodos: periodo chuvoso (outubro a março); periodo seco (abril a setembro) e periodo anual (janeiro a dezembro). Concluiu que existem dois periodos bem definidos: periodo se co, sendo o mês de julho o mais seco e periodo chuvoso, sendo o mês de dezembro o mais chuvoso. Da variação total devi do a meses, a onda semestra1 é responsável por $91,96 \%$ no período chuvoso e $82,58 \%$ no periodo seco, enquanto que, para o periodo anua1, a onda anual foi responsável por 95,02\% da va riação total devido a meses.

BAPTISTA DA SILVA (1977) estimou as precipitą ções pluviométricas pentadais de Pelotas, RS, através da aná 1ise harmōnica no periodo de 1900 a 1951. Utilizou a transformação $Z=\sqrt[3]{\mathrm{X}}$ aos dados a fim de hómogeneizá-los e submeteu os contrastes 1 ineares $\mathrm{p}_{j}$ e $\mathrm{q}_{j}$ das ondas senoidais a um teste de estabilidade, verificando que as ondas semestral, quadrimestral e a 35ạ harmōnica são significativas. Daíafir mou que aproximadamente $40,9 \%$ da variaça entre as precipita ções pluviais pentadais é explicada pelo modelo.

A alta variabilidade das precipitações pentadais em Pelotas parece ser a principal responsável pela baixa representatividade do modelo. 
PEREIRA (1978) aplicou a anälise harmōnica a dados pluviométricos mensais do município de Grajaú, MA, num periodo de 45 anos (1914 a 1958). Ajustou os dados originais para meses de 30 dias e empregou a transformação $Z=\log (x+35)$, visando à uniformização das variâncias. Submeteu os contrastes 1 ineares $p_{k}$ e $q_{k}$ a um teste de estabilidade e verificou que as ondas anual, semestral e quadrimestral re velaram-se significativas, com predominância da onda anual.

A equação de regressão obtida foi:

$$
\begin{aligned}
\hat{\mathrm{Y}}_{\mathrm{t}}=2,0367 & +0,4336 \cos (30 \mathrm{t}-47,9165)^{\circ}+ \\
& +0,0868 \cos (60 \mathrm{t}-226,0739)^{\circ}+ \\
& +0,0402 \cos (90 \mathrm{t}-300,1334)^{\circ}
\end{aligned}
$$

Concluiu ainda que aproximadamente $99,75 \%$ da variação das precipitações mensais de chuva é explicada pelo modelo, com um máximo de chuvas em março e um minimo em ju1 ho .

DUARTE (1980) aplicou a regressão periódica a dados de porcentagem de infecção de ferrugem no cafeeiro, na região de Jaú, SP (1973/74). Utilizou a transformação $Y=\log \frac{X}{1-} \bar{X}+3$ e determinou a seguinte equação de regressão:

$$
\hat{\mathrm{Y}}_{t}=2,4336+1,0591 \cos (0,5236 t-5,7634)
$$

e estimou que o máximo de infeccão ocorre no mês de junho e o minimo ocorre em dezembro. 
Aplicou também a esses mesmos dados o método da regressão polinomial e obteve a equação de regressão:

$$
\bar{Y}_{i}=3,3389-0,6628 x_{i}+0,0650 x_{i}^{2}, \quad \text { onde }
$$

$x_{i}=$ tempo (meses), estimando um mínimo de infecção também em dezembro.

Salientou ainda sobre as desvantagens deste segundo método, pois este não indica, geralmente, o mês de máxima infecção e, em casos de extrapolação, esta técnica se ria muito perigosa.

FELTRIN (1980) estudou as precipitações pluviais referentes ao município de Bandeirantes, $P R$, através da anälise harmōnica, num periodo de 48 anos (1930 a 1977). Ajustou os dados a meses de trinta dias e submeteu os dados originais à transformação $\mathrm{Y}=\sqrt{ } \overline{\mathrm{X}}$.

Determinou os componentes harmōnicos para três casos distintos: periodo anual (janeiro a dezembro), pe riodo seco (abril a setembro) e período chuvoso (outubro a março). Concluiu que, da variação total devida a meses, a equação estimada exp1icou $99,54 \%$ para o período seco, com um mínimo de chuvas para o mês de agosto; $100 \%$ para o período chuvoso, com um máximo de chuvas durante o més de janeiro; $98,02 \%$ para o periodo anua1, com um máximo de chuvas durante o mês de janeiro e um minimo durante o mês de agosto.

COELHO (1980) aplicou a regressão períodica a 
dados de produção de citrus das variedades Valência e Hanlim num periodo de 9 anos (1970 a 1978). Utilizou a transformação $W=\sqrt{X}$ aos dados a fim de satisfazer as exigēncias do modelo matemático.

Pela anälise da variāncia verificou-se a variação de cada componente harmônico dos contrastes 1 ineares $\overrightarrow{\mathrm{p}}_{\mathrm{k}}$ e $\hat{\mathrm{q}}_{\mathrm{k}}$ e concluiu que as ondas de 2,25 anos e de 3,0 anos são as de maior importāncia, não só por serem significativas na maioria das variedades de porta-enxertos estudadas, mas por serem as maiores responsáveis pela variação total. A on da de 4,5 anos contribuiu com maior parte para a variação to tal que a onda de 9 anos.

DUARTE (1981) empregou a anālise harmōnica no estudo da incidência da ferrugem alaranjada do cafeeiro (Hemileia vastatrix Berk et Br) no Estado de Minas Gerais.

Utilizou dados de porcentagem de infecção de experimentos realizados em nove localidades do Estado de Minas Gerais: Ponte Nova, Alfenas, Jacutinga, São Gotardo, San to Antonio do Amparo, Três Pontas, São Sebastião do Paraíso, Machado e Nepomuceno, durante 3 anos, e nas três primeiras localidades os estudos se prolongaram por mais 3 anos.

Aplicou-se a análise harmônica para cada 1ocal e se verificou que, em seis localidades, o primeiro componente harmônico (onda anual) foi significativo; em duas ou 
tras localidades, o terceiro componente harmōnico (onda quadrimestral) foi significativa e no restante, o segundo compo nente harmónico (onda semestral) foi significativo.

Para os locais onde se prolongaram as observa ções por mais 3 anos, verificou-se que apenas o primeiro com ponente harmōnico foi significativo.

Realizou-se ainda a añ lise conjunta para 1ocais estudados durante 3 anos e se verificou que os três pri meiros componentes harmonicos foram significativos, sendo a equação:

$$
\begin{aligned}
\nabla_{j}=18,4646 & +1,8853 \cos (30 j)-13,6027 \operatorname{sen}(30 j)- \\
& -0,0899 \cos (60 j)+0,7681 \operatorname{sen}(60 j)+ \\
& +2,0922 \cos (90 j)+1,4086 \operatorname{sen}(90 j) \\
& \text { onde } j=0,1,2, \ldots, 11 \text { meses. }
\end{aligned}
$$

Porém, na anälise conjunta para locais onde as observações se prolongaram por mais 3 anos, apenas o primeiro componente harmōnico foi significativo, sendo a equa ção :

$$
\hat{Y}_{\ddot{j}}=11,7232-0,5821 \cos \left(30_{j}\right)-11,2523 \operatorname{sen}\left(30_{j}\right)
$$

Verificou-se ainda que o primeiro componente harmônico (onda anual) è o principal responsável pela varia ção na incidēncia de ferrugem do cafeeiro e tambēm que o mâximo desta incidēncia ocorre nos meses de maio e junho e o minimo em novembro e dezembro. 


\section{Material}

Os dados de temperaturas foram fornecidos pe10 Posto Meteorológico do Instituto Agronómico de Campinas, referentes à cidade de Campinas, SP.

De 1390 a 1956 as observações foram feitas no mesmo local do Instituto Agronómico de Campinas - Sede. De 1957 até a presente data, as observações foram feitas no Ins tituto Agronômico de Campinas - Centro Experimental, cujas coordenadas geogrä́icas são:

- IAC - SEDE

- Latitude: $22^{\circ} 53^{\prime} \mathrm{S}$

- Longitude: $47^{\circ} 05^{\prime} \mathrm{W}$

- Altitude: $663 \mathrm{~m}$ 


\section{- IAC - CENTRO EXPERIMENTAIL}

- Latitude: $22^{\circ} 54^{\prime} \mathrm{S}$

- Longitude: $47^{\circ} 05^{\prime} \mathrm{W}$

- Altitude: $669 \mathrm{~m}$

As observações são tomadas em abrigo meteorológico padrão, segundo a Organização Meteorológica Mundial (OMM), com termômetros de mercürio (R. Fues) de fabricação alemã, com graduação de dois em dois décimos de graus centigrados localizados a 1,70 metros de altura do solo.

As temperaturas médias diärias, que deram or $\underline{i}$ gem às temperaturas médias mensais, foram obtidas através da seguinte equação:

$$
T_{M E D}=\frac{T_{7}+T_{14}+2 T_{21}}{4}, \quad \text { onde, }
$$

$\mathrm{T}_{7}, \mathrm{~T}_{14}$ e $\mathrm{T}_{21}$ representam respectivamente as temperaturas do ar obtidas às 7,14 e 21 horas locais, nas quais são conside radas as leituras principais. 


\section{MÉTODOS}

A metodologia usada na anālise harmōnica é ba seada nas funções trigonométricas periódicas seno e coseno.

\subsection{Desenvolvimento teōrico}

Uma função $f(t)$, onde $t$ è uma variävel independente, é dita periódica de periodo $T$, se, para todo $t$, ocorrer

$$
f(t \pm T)=f(t)
$$

onde $T$ é uma constante positiva.

As funções trigonométricas sen $t e \cos t$ são funções periódicas de periodo $T=2 \Pi$, isto é, 


$$
\begin{aligned}
& \operatorname{sen}(t+2 \pi)=\operatorname{sen} t \\
& \cos (t+2 \pi)=\cos t
\end{aligned}
$$

na seqüència tem-se:

$$
\begin{aligned}
& \operatorname{sen}(t+2 \Pi k)=\operatorname{sen} t \\
& \cos (t+2 \Pi k)=\cos t
\end{aligned}
$$

$\operatorname{para} k=0, \pm 1, \pm 2, \ldots$

A função representada pela série trigonométrị

ca de Fourier

$$
f(t)=a_{0}+\sum_{h=1}^{\infty} a_{h} \operatorname{sen}\left(h \phi t+A_{h}\right)
$$

é periódica, de período $T$, onde $\phi=\frac{2 \pi}{T}$, sendo $\phi$ chamado freqüência angular.

Os coeficientes $a_{h}$ e os àngulos $A_{h}$, sendo $\left(a_{h}>0\right)$ e $A_{h}\left(0<A_{h}<2 I I\right)$, são denominados, respectívamente, am plitude harmónica e àngulo-fase.

Desenvolvendo-se [1], tem-se:

$$
\begin{aligned}
f(t)= & a_{0}+a_{1} \operatorname{sen}\left(\phi t+A_{1}\right)+a_{2} \operatorname{sen}\left(2 \phi t+A_{2}\right)+ \\
& +\ldots+a_{h} \operatorname{sen}\left(h \phi t+A_{h}\right)+\ldots
\end{aligned}
$$

Desenvolvendo o seno dá soma purra cada um dos harmônicos em [2], aplicando-se a propriedade: $\operatorname{sen}(a+b)=\operatorname{sen} a \cos b+\operatorname{sen} b \cos a$, tem-se: 


$$
\begin{aligned}
f(t)= & a_{0}+a_{1}\left(\operatorname{sen} \phi t \cos A_{1}+\operatorname{sen} A_{1} \cos \phi t\right)+ \\
& +a_{2}\left(\operatorname{sen} 2 \phi t \cos A_{2}+\operatorname{sen} A_{2} \cos 2 \phi t\right)+\ldots+ \\
& +a_{h}\left(\operatorname{sen} h \phi t \cos A_{h}+\operatorname{sen} A_{h} \cos h \phi t\right)+\ldots[3]
\end{aligned}
$$

Fazendo

$$
\begin{aligned}
& \mathrm{p}_{1}=\mathrm{a}_{1} \operatorname{sen} \mathrm{A}_{1} \quad \mathrm{q}_{1}=\mathrm{a}_{1} \cos \mathrm{A}_{1} \\
& \mathrm{p}_{2}=\mathrm{a}_{2} \operatorname{sen} \mathrm{A}_{2} \quad \mathrm{q}_{2}=\mathrm{a}_{2} \cos \mathrm{A}_{2} \\
& p_{h}=a_{h} \operatorname{sen} A_{h} \cdot q_{h}=a_{h} \cos A_{h} \\
& \begin{array}{llll}
\ldots & \ldots & \ldots
\end{array}
\end{aligned}
$$

e substituindo em [3], tem-se

$$
\begin{aligned}
f(t)= & a_{0}+q_{1} \operatorname{sen} \phi t+p_{1} \cos \phi t+ \\
& +q_{2} \operatorname{sen} 2 \phi t+p_{2} \cos 2 \phi t+\ldots+ \\
& +q_{h} \operatorname{sen} h \phi t+p_{h} \cos h \phi t+\ldots
\end{aligned}
$$

Considerando o h-ésimo harmōnico, onde:

$$
p_{h}=a_{h} \text { sen } A_{h} \quad \text { e } \quad q_{h}=a_{h} \cos A_{h}
$$

tem-se,

$$
p_{h}^{2}+q_{h}^{2}=a_{h}^{2} \operatorname{sen}^{2} A_{h}+a_{h}^{2} \cos ^{2} A_{h}
$$

e, fazendo

$$
\begin{aligned}
& a_{h}^{2}=p_{h}^{2}+q_{h}^{2} \\
& a_{h}=\left|\sqrt{p_{h}^{2}+q_{h}^{2}}\right|
\end{aligned}
$$




$$
\begin{aligned}
& \frac{p_{h}}{q_{h}}=\frac{a_{h} \operatorname{sen} A_{h}}{a_{h} \cos A_{h}}=\operatorname{tg} A_{h} \\
& A_{h}=\operatorname{arctg}\left(\frac{p_{h}}{q_{h}}\right)
\end{aligned}
$$

Representação grä́ica dos parâmetros $p_{h}, q_{h}$, $a_{h}$ e $A_{h}$.

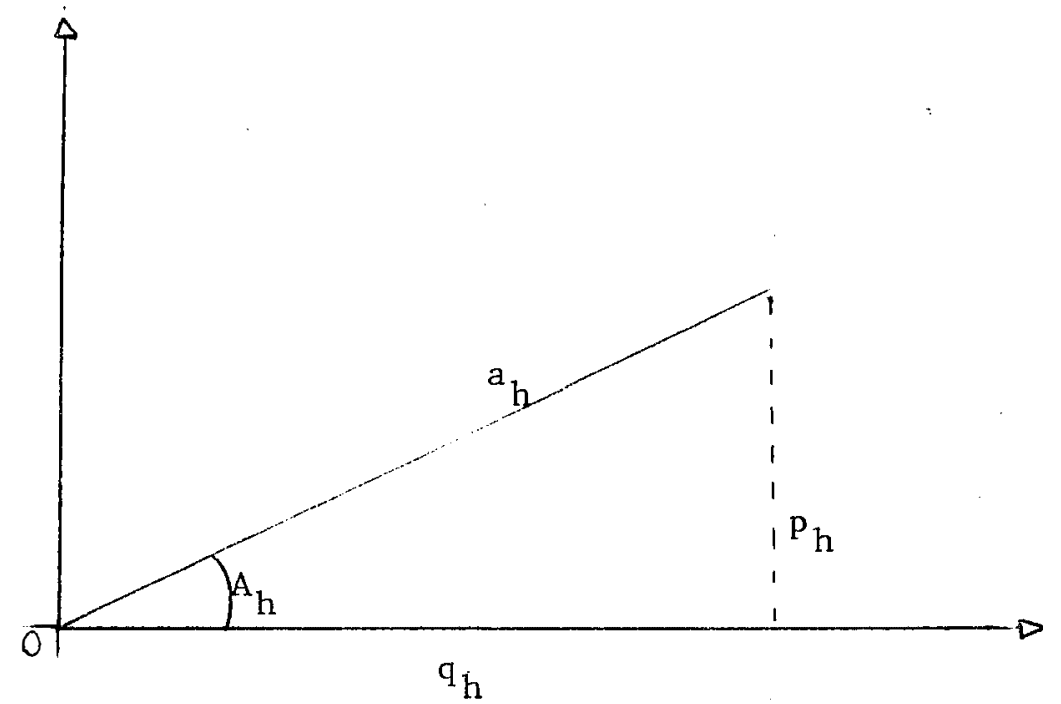

Segundo Conrad e Pollak (1950), o quadrante ao qual pertence o arco $A_{h}$ é determinado pelos sinais dos parämetros $p_{h}$ e $q_{h}$, aşsim tem-se: 


\begin{tabular}{cccc}
\hline $\begin{array}{c}\text { Sinal do } \\
\text { parämetro } \\
p_{h}\end{array}$ & $\begin{array}{c}\text { Sina1 do } \\
\text { parämetro } \\
q_{h}\end{array}$ & $\begin{array}{c}\text { Angulos } \\
\text { fases } \\
\left(A_{h}\right)\end{array}$ & $\begin{array}{c}\text { Quadrante a que } \\
\text { pertence o arco }\end{array}$ \\
+ & + & $A_{h}=A_{++}$ & 19 \\
+ & - & $A_{h}=180-A_{+-}$ & 29 \\
- & - & $A_{h}=180+A_{--}$ & 39 \\
\hline
\end{tabular}

\subsection{Modelo matemático}

Se $\mathrm{Y}_{t}$ é a temperatura média mensal observada para $t=0,1, \ldots(\mathrm{T}-1)$, onde $\mathrm{t}$ representa os meses $\mathrm{e} \mathrm{T}$ o comprimento do periodo a ser estudado, o modelo matémático serä:

$$
Y_{t}=a_{0}+\sum_{h=1}^{k} a_{h} \operatorname{sen}\left(h \phi t+A_{h}\right)+e_{t}
$$

onde

$\mathrm{Y}_{t}=$ valores observados, no caso, temperaturas médias mensais;

$a_{0}=$ média aritmética dos valores observados;

$a_{h}=$ amplitude do h-ésimo componente harmōnico;

$\mathrm{A}_{\mathrm{h}}=$ àngulo-fase do h-ēsimo componente harmōnico;

$e_{t}=$ efeito residual da t-ésima observação, onde $e_{t} \sim N\left(0, \sigma^{2}\right)$; 
$\mathrm{k}=$ maior inteiro que não supera $\left(\frac{\mathrm{T}}{2}\right)$ quando $\mathrm{T}$ é par e $\left(\frac{\mathrm{T}-1}{2}\right)$ quando $\mathrm{T}$ é impàr;

$\phi \quad=\frac{2 \pi}{T}$ é a freqüência angular.

Desenvolvendo o seno da soma em [5], obtēm-se $\begin{aligned} Y_{t}= & a_{0}+\sum_{h=1}^{k}\left(a_{h} \operatorname{sen} A_{h} \cos h \phi t+a_{h} \cos A_{h} \operatorname{sen} h \phi t\right)+ \\ & +e_{t}\end{aligned}$

Fazendo:

$$
\begin{aligned}
& \mathrm{p}_{\mathrm{o}}=\mathrm{a}_{0} \\
& \mathrm{p}_{\mathrm{h}}=\mathrm{a}_{\mathrm{h}} \operatorname{sen} \mathrm{A}_{\mathrm{h}} \\
& \mathrm{q}_{\mathrm{h}}=\mathrm{a}_{\mathrm{h}} \cos \cdot \mathrm{A}_{\mathrm{h}}
\end{aligned}
$$

temos o seguinte modelo matemático para o caso $\mathrm{T}$ par:

$$
\begin{aligned}
\mathrm{Y}_{\mathrm{t}}= & \mathrm{p}_{\mathrm{o}}+\mathrm{p}_{1} \cos \phi t+\mathrm{p}_{2} \cos 2 \phi t+\ldots+ \\
& +\mathrm{p}_{(\mathrm{k}-1)} \cos (\mathrm{k}-1) \phi \mathrm{t}+\mathrm{p}_{\mathrm{k}} \cos \mathrm{k} \phi \mathrm{t}+ \\
& +\mathrm{q}_{1} \operatorname{sen} \phi t+\mathrm{q}_{2} \operatorname{sen} 2 \phi t+\ldots+ \\
& +\mathrm{q}_{(\mathrm{k}-1)} \operatorname{sen}(\mathrm{k}-1) \phi \mathrm{t}+\mathrm{e}_{\mathrm{t}}
\end{aligned}
$$

$$
\text { O sistema de equações pode ser representado }
$$

matricialmente por:

$$
Y=X \beta+\varepsilon
$$

onde:

$$
\begin{aligned}
& Y=\text { vetor das observaçós } \\
& X=\text { matriz dos coeficientes } \\
& \beta=\text { vetor dos parämetros } p_{h} \text { e }{ }^{q_{h}}
\end{aligned}
$$




$$
\varepsilon=\text { vetor dos erros aleatórios, } \sim N\left(\phi, I \sigma^{2}\right)
$$

sendo

$$
Y=\left[\begin{array}{c}
Y_{0} \\
Y_{1} \\
Y_{2} \\
\cdot \\
\cdot \\
Y_{(T-1)}
\end{array}\right]
$$

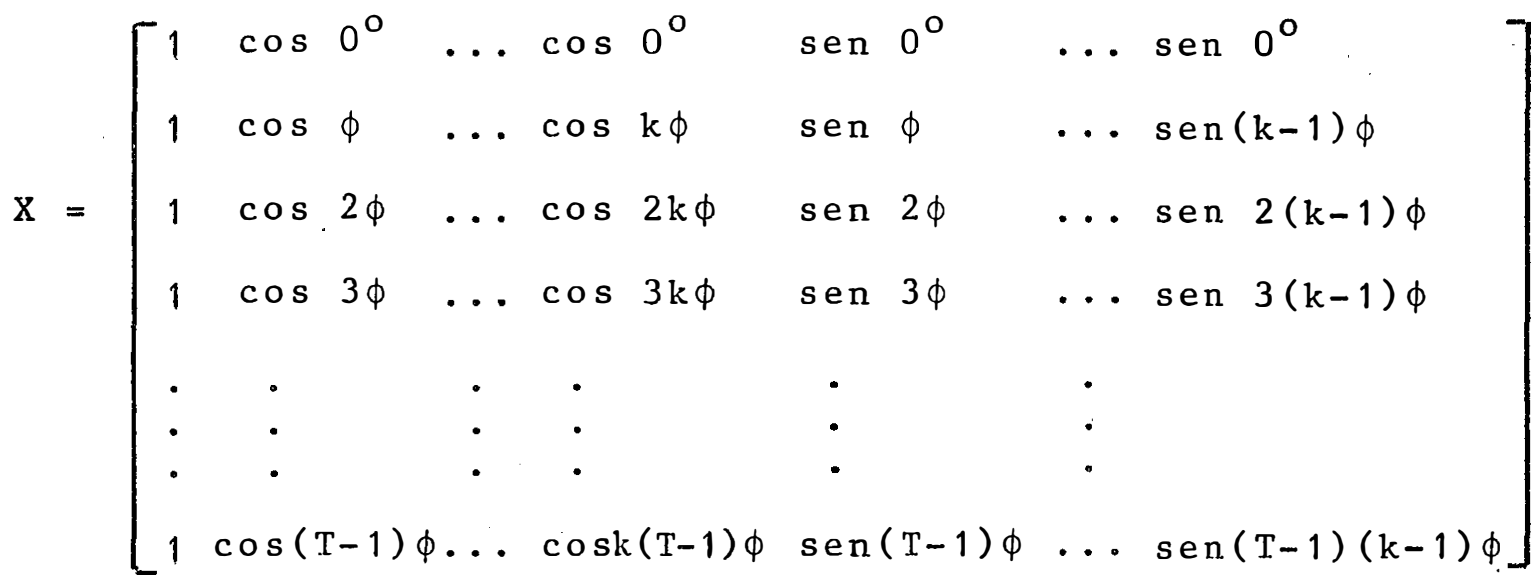

$$
\beta=\left[\begin{array}{l}
\mathrm{p}_{\mathrm{o}} \\
\mathrm{p}_{1} \\
\mathrm{p}_{2} \\
\dot{\cdot} \\
\mathrm{p}_{\mathrm{k}} \\
\mathrm{q}_{1} \\
\mathrm{q}_{2} \\
\dot{ }^{\prime} \\
\mathrm{q}_{(\mathrm{k}-1)}
\end{array}\right]
$$


$\varepsilon=\left[\begin{array}{l}e_{0} \\ e_{1} \\ e_{2} \\ \cdot \\ \cdot \\ e_{(T-1)}\end{array}\right]$

4.3. Estimativas dos parâmetros, suas variâncias e covariāncias

O modelo matemático pode ser representado matricialmente por:

$$
Y=X \beta+\varepsilon
$$

Através do método dos quadrados mínimos, obtém-se a solução do sistema de equações normais

$$
X^{\prime} X \vec{\beta}=X^{\prime} Y
$$

onde $S$ è uma matriz não singular.

$$
\begin{aligned}
& \text { Tem-se } \\
& \bar{\beta}=S^{-1} X^{\prime} Y
\end{aligned}
$$

onde 

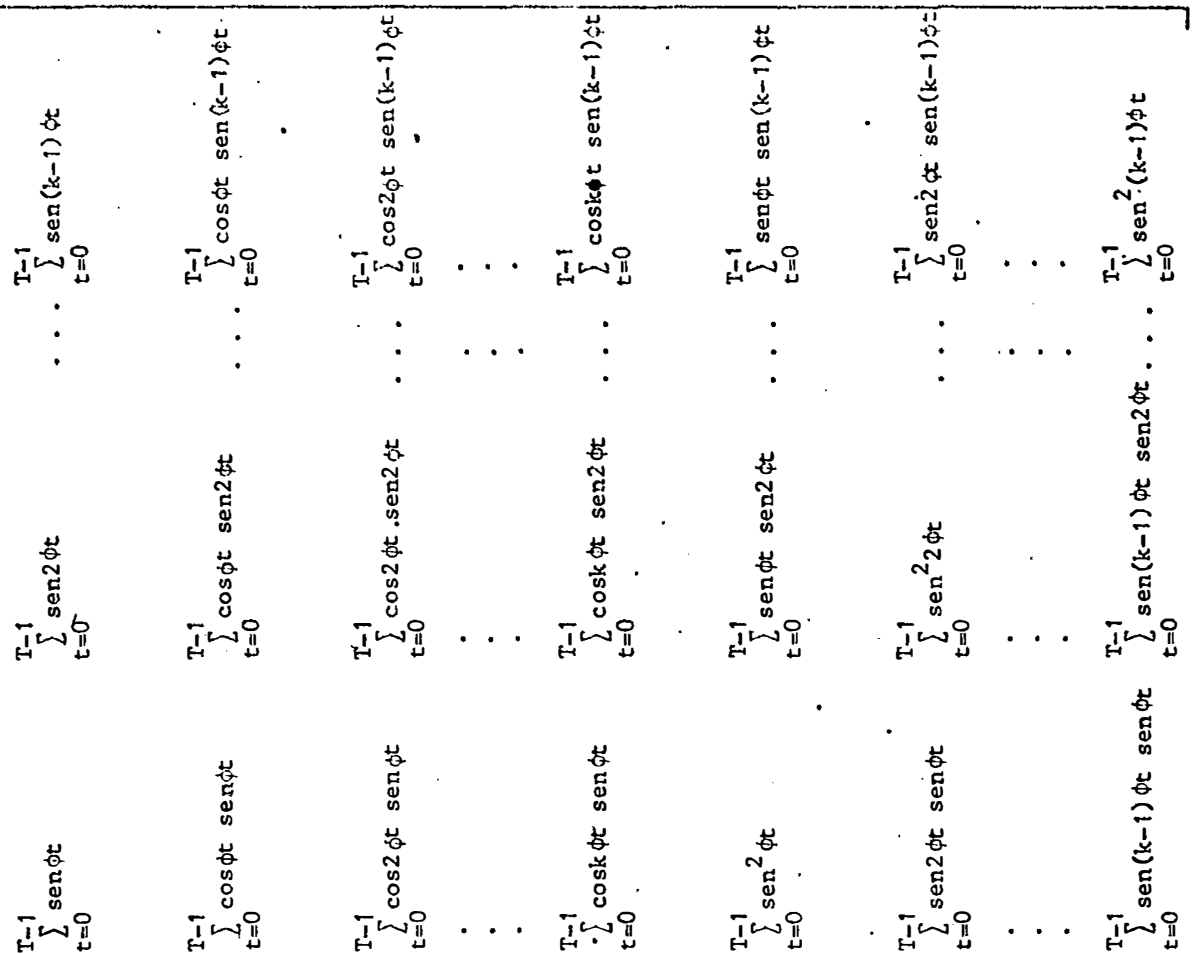

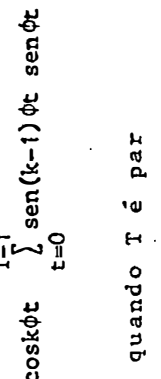

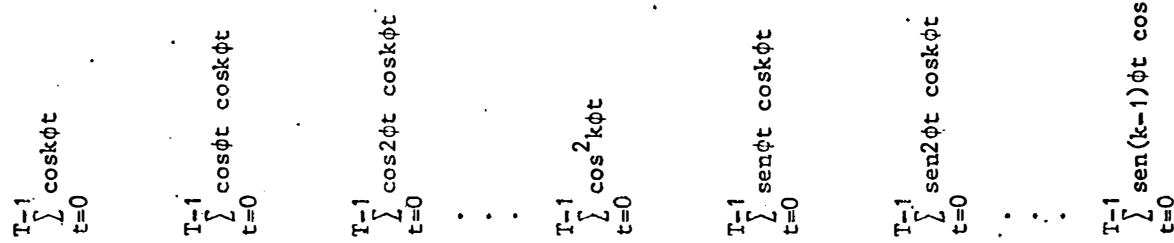

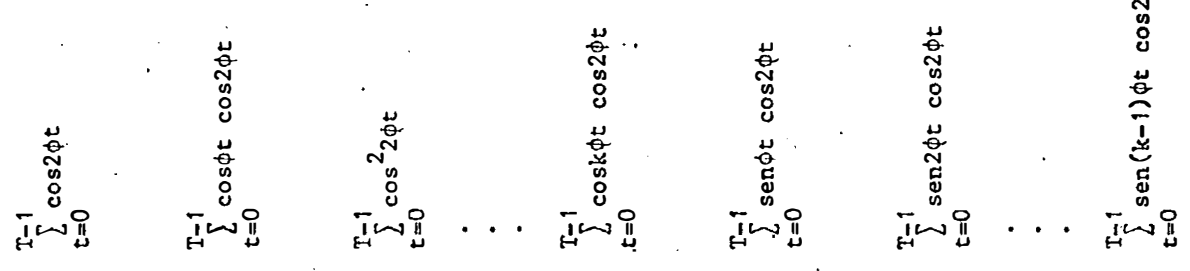

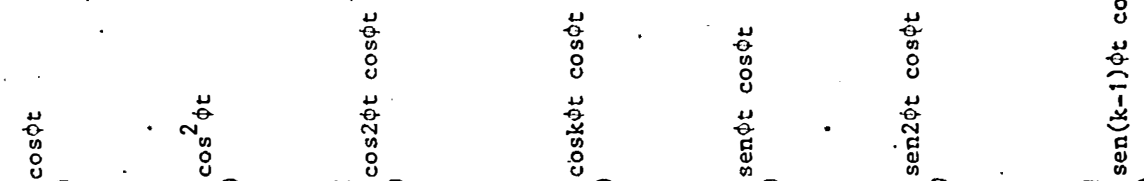

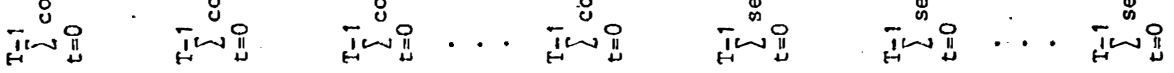
H $\quad$ iั

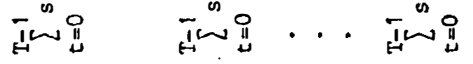

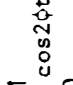

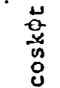

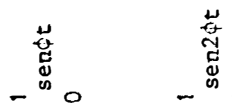

蒙 
Desta forma, tem-se:

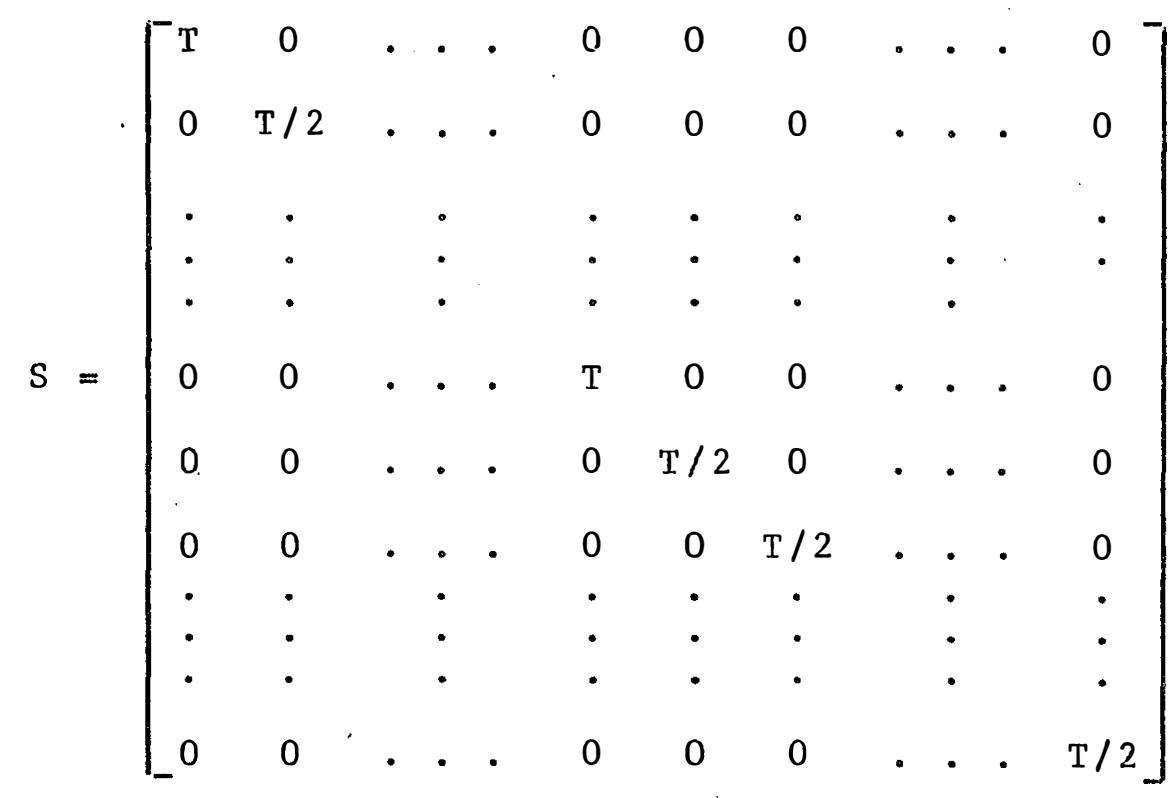

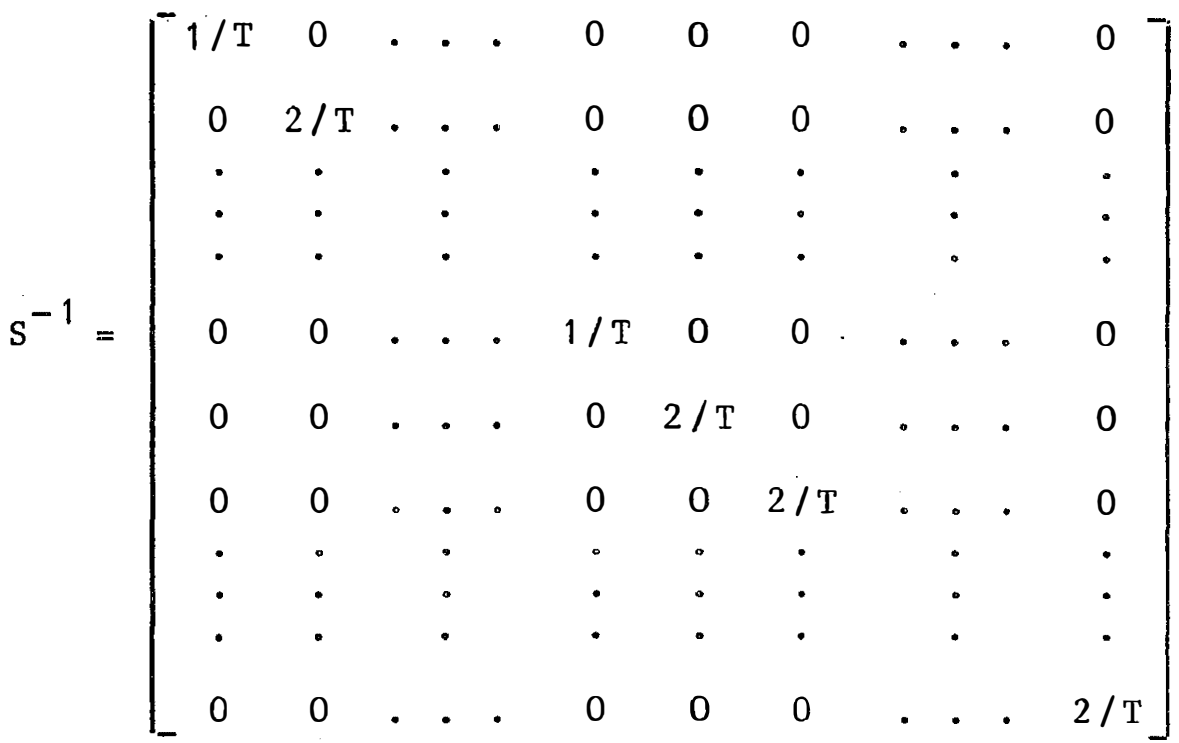


A matriz X'Y serà:

$X^{\prime} Y=\left[\begin{array}{cll}\sum_{t=0}^{T-1} & y_{t} \\ \sum_{t=0}^{T-1} & y_{t} \cos \phi t \\ t=0 & y_{t} \cos 2 \phi t \\ \sum_{t=0}^{T-1} & y_{t} \cos k \phi t \\ \sum_{t=0}^{T-1} & y_{t} \text { sen } \phi t \\ \sum_{t=0}^{T-1} & y_{t} \text { sen } 2 \phi t \\ \sum_{t=0}^{T-1} & y_{t} \text { sen }(k-1) \phi t\end{array}\right]$

Atravēs da matriz $\hat{\beta}$, têm-se a estimativa dos parâmetros $\mathrm{p}_{\mathrm{h}}$ e $\mathrm{q}_{\mathrm{h}}$.

$$
\begin{aligned}
& \overrightarrow{\mathrm{p}}_{0}=\frac{1}{\mathrm{~T}} \sum_{t=0}^{\mathrm{T}-1} \mathrm{y}_{t} \\
& \overrightarrow{\mathrm{p}}_{1}=\frac{2}{\mathrm{~T}} \sum_{t=0}^{\mathrm{T}-1} \mathrm{y}_{t} \cos \phi t
\end{aligned}
$$




$$
\begin{gathered}
\hat{\mathrm{p}}_{2}=\frac{2}{\mathrm{~T}} \sum_{\mathrm{t}=0}^{\mathrm{T}-1} \mathrm{y}_{\mathrm{t}} \cos 2 \phi \mathrm{t} \\
\overline{\mathrm{p}}_{\mathrm{k}}=\frac{1}{\mathrm{~T}} \sum_{\mathrm{t}=0}^{\mathrm{T}-1} \mathrm{y}_{\mathrm{t}} \cos \mathrm{k} \phi \mathrm{t} \\
\hat{\mathrm{q}}_{1}=\frac{2}{\mathrm{~T}} \sum_{\mathrm{t}=0}^{\mathrm{T}-1} \mathrm{y}_{\mathrm{t}} \operatorname{sen} \phi \mathrm{t} \\
\hat{\mathrm{q}}_{2}=\frac{2}{\mathrm{~T}} \sum_{\mathrm{t}=0}^{\mathrm{T}-1} \mathrm{y}_{\mathrm{t}} \operatorname{sen} 2 \phi \mathrm{t} \\
\mathrm{q}_{\mathrm{k}-1}=\frac{2}{\mathrm{~T}} \sum_{\mathrm{t}=0}^{\mathrm{T}-1} \mathrm{y}_{\mathrm{t}} \operatorname{sen}(\mathrm{k}-1) \phi \mathrm{t}
\end{gathered}
$$

Para o caso de $\mathrm{T}$ impar tem-se o seguinte mode

Io matemätico:

$$
\begin{aligned}
\mathrm{y}_{\mathrm{t}} & =\mathrm{p}_{\mathrm{o}}+\mathrm{p}_{1} \cos \phi \mathrm{t}+\mathrm{p}_{2} \cos 2 \phi \mathrm{t}+\ldots+\mathrm{p}_{\mathrm{k}} \cos \mathrm{k} \phi \mathrm{t}+ \\
& +\mathrm{q}_{1} \operatorname{sen} \phi \mathrm{t}+\mathrm{q}_{2} \operatorname{sen} 2 \phi \mathrm{t}+\cdots+\mathrm{q}_{\mathrm{k}} \operatorname{sen} \mathrm{k} \phi \mathrm{t}+\mathrm{e}_{\mathrm{t}}
\end{aligned}
$$

$$
\text { o sistema de equações pode ser representado }
$$

matricialmente por:

$$
\mathrm{Y}=\mathrm{X} \beta+\varepsilon
$$

onde 
.28 .

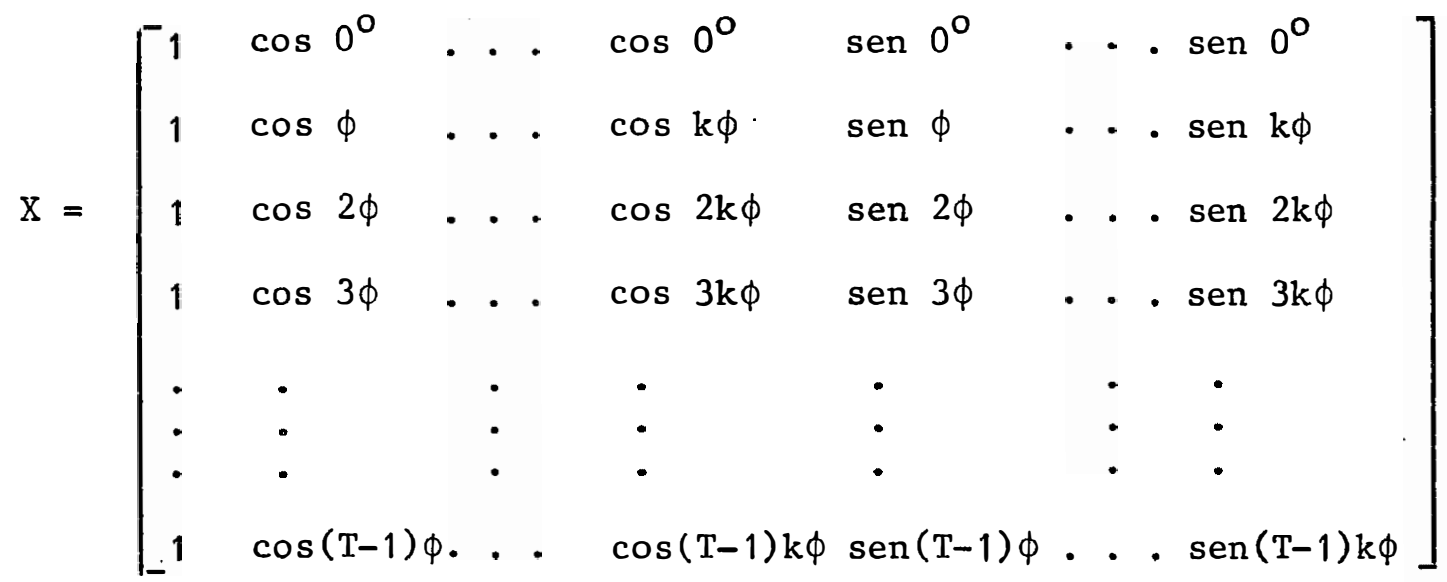

$B=\left[\begin{array}{c}p_{0} \\ p_{1} \\ p_{2} \\ \cdot \\ \cdot \\ p_{k} \\ q_{1} \\ q_{2} \\ \cdot \\ \cdot \\ q_{k}\end{array}\right]$

Através do métodos dos mínimos quadrados, obtém-se:

$$
\hat{\beta}=s^{-1} X^{\prime} Y
$$




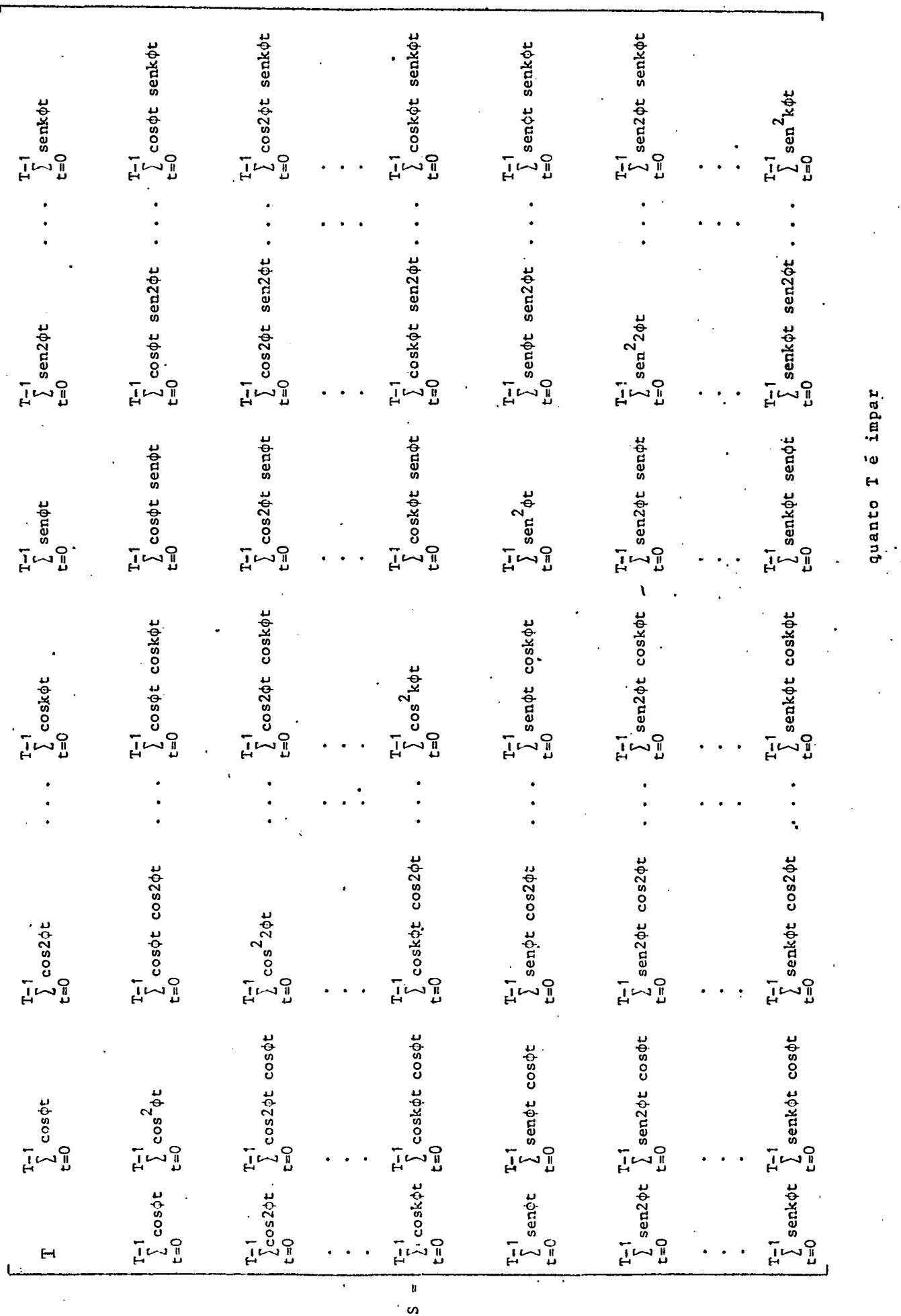


A matriz s pode ser escrita, da seguinte forma:

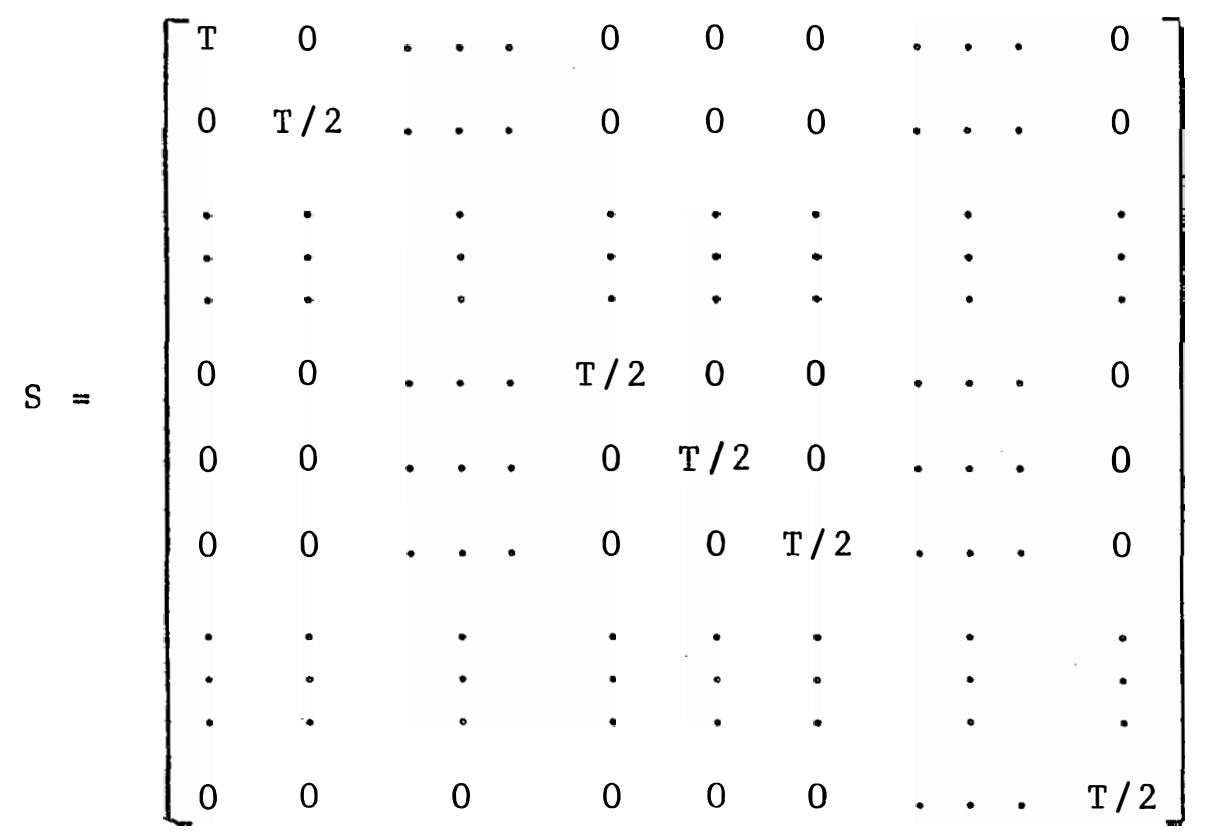

e consequentemente, tem-se a matriz. inversa

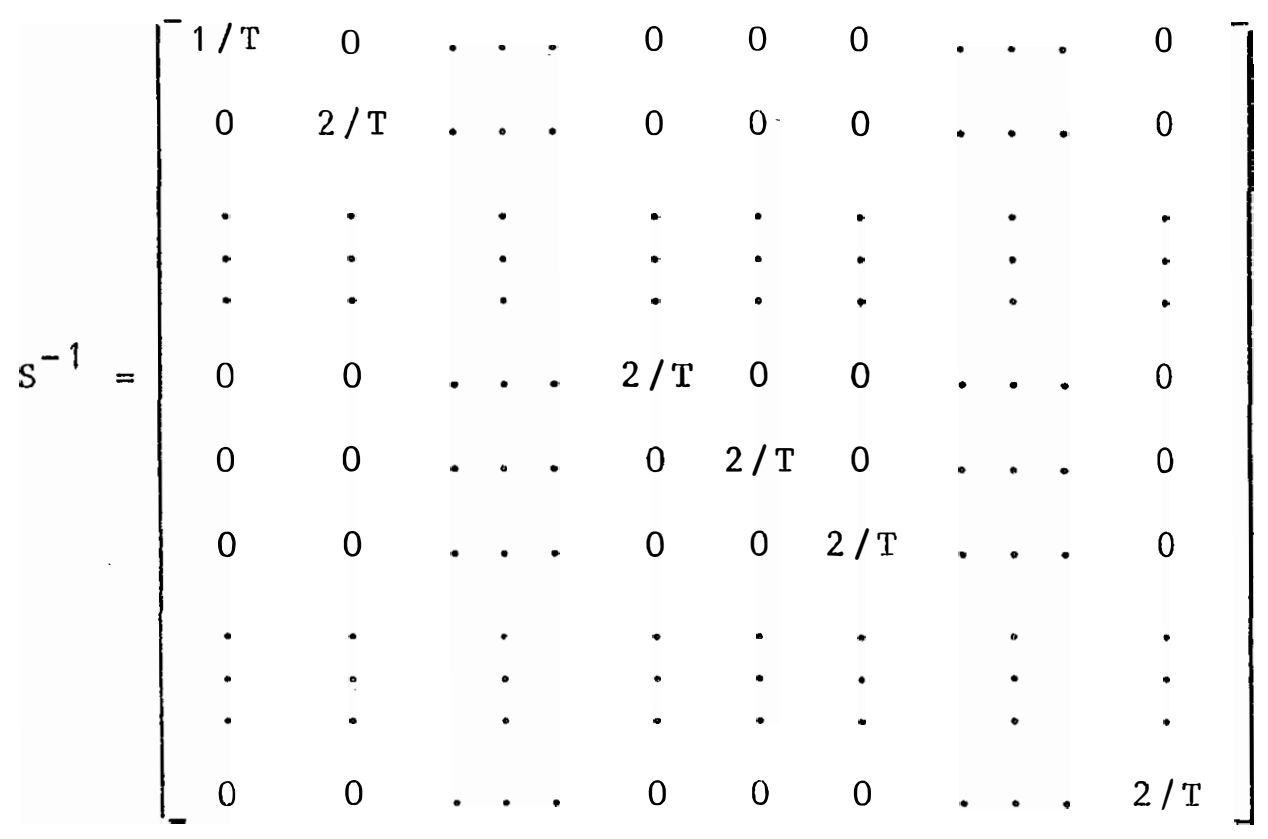


A matriz X'Y serä:

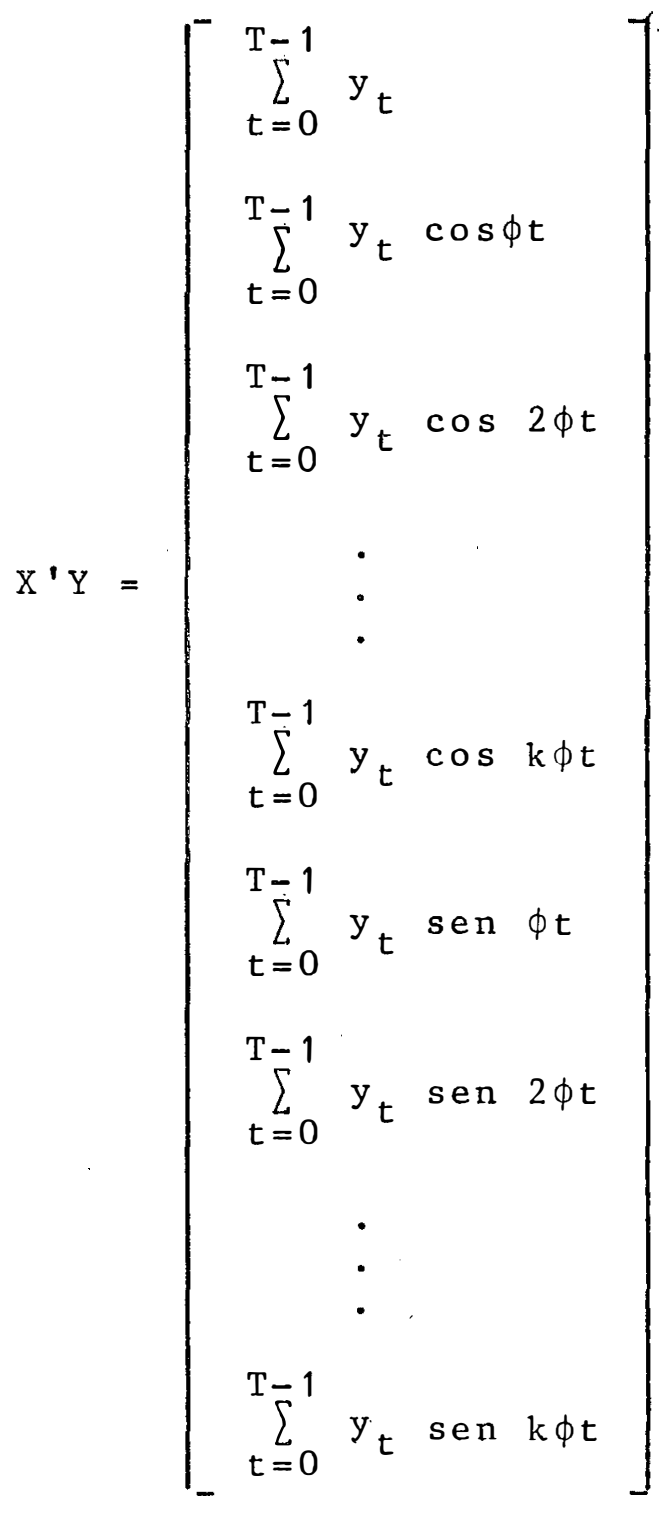

Atravès da matriz $\hat{\beta}$, tem-se as estimativas dos parāmetros $\mathrm{p}_{\mathrm{h}}$ e $\mathrm{q}_{\mathrm{h}}$ 
.32 .

$$
\begin{aligned}
& \overline{\mathrm{p}}_{\mathrm{o}}=\frac{1}{\mathrm{~T}} \sum_{\mathrm{t}=0}^{\mathrm{T}-1} \mathrm{y}_{\mathrm{t}} \\
& \hat{\mathrm{p}}_{1}=\frac{2}{\mathrm{~T}} \sum_{t=0}^{\mathrm{T}-1} \mathrm{y}_{t} \cos \phi t \\
& \hat{\mathrm{p}}_{2}=\frac{2}{\mathrm{~T}} \sum_{\mathrm{t}=0}^{\mathrm{T}-1} \mathrm{y}_{\mathrm{t}} \cos 2 \phi \mathrm{t} \\
& \overline{\mathrm{p}}_{\mathrm{k}}=\frac{2}{\mathrm{~T}} \sum_{\mathrm{t}=0}^{\mathrm{T}-1} \mathrm{y}_{\mathrm{t}} \cos \mathrm{k} \phi \mathrm{t} \\
& \bar{q}_{1}=\frac{2}{T} \sum_{t=0}^{T-1} y_{t} \text { sen } \phi t \\
& \overline{\mathrm{q}}_{2}=\frac{2}{\mathrm{~T}} \sum_{\mathrm{t}=0}^{\mathrm{T}-1} \mathrm{y}_{\mathrm{t}} \operatorname{sen} 2 \phi \mathrm{t} \\
& \hat{\mathrm{q}}_{k}=-\frac{2}{\mathrm{~T}} \sum_{t=0}^{\mathrm{T}-1} \mathrm{y}_{t} \text { sen } k \phi t
\end{aligned}
$$

ANDERSON (1971) através das förmulas de Euler

$$
\begin{aligned}
& \cos \phi=\frac{1}{2}\left(e^{i \phi}+e^{-i \phi}\right) \\
& \operatorname{sen} \phi=\frac{1}{2 i}\left(e^{i \phi}-e^{-i \phi}\right)
\end{aligned}
$$

e

$$
e^{i \phi}=\cos \phi+i \operatorname{sen} \phi
$$


comprova que:

$$
\begin{aligned}
& \sum_{t=0}^{T-1} \cos ^{2} h \phi t=\frac{T}{2} \quad \text { para } h=1,2, \ldots,(k-1) \\
& \sum_{t=0}^{T-1} \cos ^{2} k \phi t=T \quad \text { quando } T \text { é par } \\
& \sum_{t=0}^{T-1} \cos ^{2} k \phi t=\frac{T}{2} \quad \text { quando } T \text { é impar } \\
& \sum_{t=0}^{T-1} \operatorname{sen}^{2} h \phi t=-\frac{T}{2} \quad \text { para } h=1,2, \ldots, k \\
& \begin{aligned}
\sum_{t=0}^{T-1} \cos h \phi t \operatorname{sen} j \phi t \ldots 0 & \operatorname{para} \quad h=1, \ldots, k \\
& j=1, \ldots, k
\end{aligned}
\end{aligned}
$$$$
\sum_{t=0}^{T-1} \cos j \phi t \cos h \phi t=0 \quad \text { para } j \neq h
$$$$
\begin{aligned}
\mathrm{j} & =1, \ldots, \mathrm{k} \\
\mathrm{h} & =1, \ldots, \mathrm{k}
\end{aligned}
$$

$$
\begin{aligned}
\sum_{t=0}^{T-1} \text { sen } j \phi t \text { sen } h \phi t=0 \quad \text { para } j \neq h & \\
j & =1, \ldots, k \\
h & =1, \ldots, k
\end{aligned}
$$

No apêndice 2, apresenta-se esta demonstração.

$$
\text { As variāncias e covariāncias dos parāmetros }
$$

estimados são obtidos através da matriz de dispersão:

$$
D=s^{-1} \sigma^{2}
$$




$$
\begin{aligned}
& V\left(\hat{p}_{h}\right)=\frac{2 \sigma^{2}}{T} \text { para } h=1,2, \ldots,(k-1) \\
& V\left(\hat{p}_{k}\right)=\frac{2 \sigma^{2}}{T} \text { quando } T \text { é impar. } \\
& V\left(\hat{p}_{k}\right)=\frac{\sigma^{2}}{T} \text { quando } T . \dot{e} \text { par。 } \\
& V\left(\bar{q}_{h}\right)=\frac{2 \sigma^{2}}{T} \text { quando } h=1,2, \ldots, k .
\end{aligned}
$$

Como as covariâncias são todas nulas, conclui-se que os parâmetros estimados não são correlacionados.

\subsection{Intervalo de confiança}

Determinadas as estimativas dos parämetros $\hat{\mathrm{p}}_{\mathrm{h}}$ e $\bar{q}_{h}$ e sendo o quadrado médio residual, obtido pela anälise de variāncia para cada contraste, o intervalo de confiança é dado por:

$$
\begin{aligned}
& \hat{p}_{h}-t \cdot s\left(\hat{p}_{h}\right) \leqq p_{h} \leqq \hat{p}_{h}+t \cdot s\left(\hat{p}_{h}\right) \\
& \hat{q}_{h}-t \cdot s\left(\hat{q}_{h}\right) \leqq q_{h} \leqq \bar{q}_{h}+t \cdot s\left(\hat{q}_{h}\right)
\end{aligned}
$$

onde $t$ é obtido pela tabela de t, para o teste bilateral com N-1 graus de liberdade, a um determinado nivel de significân cia. 


\subsection{Transformação dos dados}

Para se realizar uma anālise de variāncia, é necessário verificar se as pressuposições básicas da análise são satisfeitas, caso contrário, deve-se recorrer ao estudo de transformações que visam à homogeneidade, à aditividade e à normalidade da distribuição o que tem sido feito, há mu to tempo, por diversos autores.

Segundo BAPTISTA DA SILVA (1977), BIiss (1958) salienta a necessidade de fazer preceder à anàlise harmônica uma transformação conveniente dos dados, de modo a obter adi tividade, homogeneidade das variāncias e normalidade da distribuição.

AMARAL (1968) recomenda uma transformação baseada na fórmula $\sigma_{x}=\beta x^{a}$, onde $\underline{a}$ e $\underline{\beta}$ podem ser determinados para cada grupo de observaçóes, sendo $x$ a média de precipitação mensal num periodo de $N$ anos e $\sigma_{x}$ o desvio padrão das ob servações utilizadas para o cálculo da média, determinado o valor de a aconselha-se a transformação $Y=x^{(1-a)}$.

Neste mesmo trabalho, foram ainda estudadas as precipitações mensais de Morro Velho (MG), extraidas. de uma publicação de J.M.P. Memória, onde obteve a transforma ção $Z=x^{1-0,649}$ ou seja $Z=x^{0,351}$ o que homogeneizou as variâncias, normalizando, possivelmente, a distribuição. 
AMARAL e MOTA (1956), analisando dados relati vos às precipitações mensais em Pelotas e Ponta Grossa, utilizaram a transformação $z=\log \left(x+\frac{b}{a}\right)$ onde a e b são coe ficientes da equação de regressão do desvio padrão em relação à média.

$$
\sigma_{x}=a x+b \text { para homogeneizar a variāncia. }
$$

AMARAL e BAPTISTA DA SILVA (1970) estudaram as precipitações pluviométricas pentadais em Pelotas, RS, e concluiram que a transformação $Z=x^{0,2395}$ homogeneizou a va riância.

o método utilizado na transformação dos dados no presente trabalho foi descrito por AMARAL et alii (1975), onde se cita que: "Se se dispõe de um conjunto de amostras, de cada uma das quais se possa calcular a média x, e o desvio padrão $s_{x}$, representa-se os pares de valores $\left(x, s_{x}\right)$ em um sistema cartesiano ortogonal. Se os pontos assim obtidos se dispuserem, aproximadamente, ao longo de uma reta paralela ao eixo das abcissas, pode-se admitir a independéncia do desvio padrão em relação à média. Se tal não for o caso, a relação de dependência entre o desvio padrão e a média poderá traduzir-se numa expressão analitica,

$$
s_{x}=f(x)
$$

Trata-se, então, de determinar uma função 


$$
Z=Z(x)
$$

cuja variāncia seja independente de $x$ e, portanto, de Z. Es pera-se que essa transformação, homogeneizando a variāncia, normalize também a distribuição.

$$
\text { De } Z=Z(x)
$$

tem-se

$$
\Delta \mathrm{Z} \simeq \mathrm{Z}^{\prime}(\mathrm{x}) \Delta \mathrm{x}
$$

elevando ao quadrado e determinando as expectāncias de ambos membros da equação, tem-se:

$$
\begin{aligned}
E\left[(\Delta Z)^{2}\right] & \cong\left[Z^{\prime}(x)\right]^{2} E\left[(\Delta x)^{2}\right] \\
\sigma_{Z}^{2} & =\left[Z^{\prime}(x)\right]^{2} \sigma_{x}^{2}, \\
\sigma_{Z} & =Z^{\prime}(x) \sigma_{x}
\end{aligned}
$$

Pretende-se determinar $Z=Z(x)$, de modo que $\sigma_{Z}$ seja constante, isto é,

$$
\begin{aligned}
& \sigma_{Z}=Z^{\prime}(x) \sigma_{x}=K \quad \text { (constante) } \\
& \text { Deve-se ter, portanto, } \\
& Z^{\prime}(x) \cong \frac{K}{\sigma_{x}}
\end{aligned}
$$


o que nos leva a

$$
Z(x) \cong \int \frac{K}{\sigma_{x}} d x
$$

admitida que a relação entre o desvio padrão e a média é da forma

$$
\sigma_{\mathrm{x}}=\mathrm{Bx} \mathrm{x}^{\mathrm{a}}
$$

onde $x$ e $\sigma_{x}$ säo respectivamente a média e o desvio padrão das temperaturas Mensais, deduz-se

$$
\log \sigma_{x}=\log B+a \log x
$$

ou

$$
Y=b+a X
$$

onde

e

$$
\begin{aligned}
& \mathrm{Y}=\log \sigma_{\mathrm{X}}, \quad \mathrm{b}=\log \mathrm{B} \\
& \mathrm{X}=\log \mathrm{x}
\end{aligned}
$$

Determinam-se a seguir os parāmetros a e b pe la regressão 1 inear.

$$
\begin{aligned}
& \text { Voltando em }[8] \text {, temos: } \\
& Z(x) \cong \int \frac{K}{\sigma_{x}} d x \text {, substituindo } \sigma_{x} \\
& Z(x)=\int \frac{K}{B x^{a}} d x \quad \text { e se }
\end{aligned}
$$

$a \neq 1$ 


$$
\begin{aligned}
& Z(x)=\frac{K}{B} \int x^{-a} d x \\
& Z(x)=\frac{K}{B} \cdot \frac{x^{1-a}}{1-a}+c
\end{aligned}
$$

e fazendo,

$$
c=0, k=\frac{k}{B(1-a)}
$$

obtém-se

$$
z(x)=k x^{1-a}
$$

$k$ é escolhido de modo a tornar os valores transformados da mesma grandeza dos valores originais, a transformação usada no presente trabalho foi $z=x^{1,84216}$ e utilizou-se $k=1$.

\subsection{Anāilise da variância}

A anảlise de variância foi usada com o objetí vo de testar a estabilidade dos componentes harmónicos, considerando observações mensais durante $\mathrm{N}$ anos.

De acordo com AMARAL (1968), para um conjunto de observações de $N$ anos, têm-se $N+1$ anảlises harmônicas,uma para cada ano e uma análise conjunta dos anos. Aplica-se. a análise de variāncia aos contrastes $p$ e q e se as variāncias residuais destes contrates forem homogêneas, podemos juntá- las em uma única análise da variāncia da amplitude da onda. 
4.6.1. Teste de homogeneidade de variāncias

Uma das pressuposições bäsicas para se efetuar uma anàise de variância é a homogeneidade de variância, o que se pode verificar por meio do teste de Bartlett.

Dadas $K$ estimativas de variāncias, desejamos testar a hipótese $H_{0}$ de que:

$$
\begin{aligned}
\mathrm{H}_{\mathrm{o}}: & \sigma_{1}^{2}=\sigma_{2}^{2}=\sigma_{3}^{2}=\cdot \cdot \cdot=\sigma_{\mathrm{K}}^{2} \\
\mathrm{H}_{\mathrm{a}} \text { : } & \text { pelo menos uma variância difere das ou- } \\
& \text { tras. }
\end{aligned}
$$

Segundo BARTLETT (1937), o método para testar se as estimativas de variāncia com (n-1) graus de 1 iberdade, de $K$ populaçóes distribuídas normalmente, é dado por:

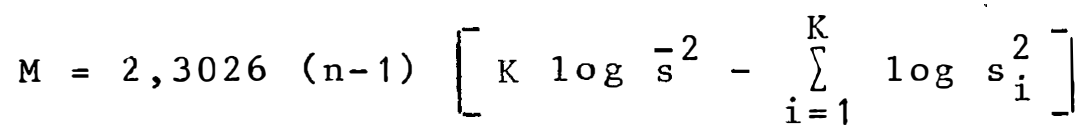

onde

$\mathrm{s}_{\mathrm{i}}^{2}=$ estimativa da variāncia para cada amostra $\bar{s}^{2}=$ estimativa da variância mèdia.

$$
\bar{s}^{2}=\frac{\sum_{i=1}^{k} s_{i}^{2}}{k}
$$

Sob a hipōtese de nulidade que cada $s_{i}^{2}$ é uma estimativa da mesma $\sigma^{2}$, a razão $\frac{M}{C}$ tem distribuição aproximada de $x^{2}$ com $(K-1)$ graus de 1 iberdade, onde 
C e um fator de correção, dado por:

$$
C=1+\frac{K+1}{3^{K}(n-1)}
$$

4.6.2. Teste de Normalidade

Para se verificar a normalidade dos dados foi utilizado o teste normalidade para grandes amostras, apresen tado por FISHER (1941), onde se comparam as medidas de assimetria $\left(g_{1}\right)$ e curtose $\left(g_{2}\right)$ dos contrastes, com as respect $\underline{i}$ vas medidas de assimetria $\left(g_{1}=0\right)$ e curtose $\left(g_{2}=0\right)$ da dis tribuicão normal, através do teste t.

As estatísticas $g_{1}$ e $g_{2}$ são estimadas através de :

$$
\bar{g}_{1}=\sqrt{\frac{\mathrm{K}_{3}^{2}}{\mathrm{~K}_{2}^{3}}}
$$

onde

$$
\begin{aligned}
K_{3} & =\frac{N \sum_{i=1}^{N}\left(\bar{p}_{1 i}-\bar{p}_{1}\right)^{3}}{(N-1)(N-2)} \\
K_{2} & =\frac{\sum_{i=1}^{N}\left(\bar{p}_{1 i}-\bar{p}_{1}\right)^{2}}{N-1}
\end{aligned}
$$

onde $\mathrm{N}$ é o número de anos de observação.

$$
\widehat{\mathrm{g}}_{2}=\frac{\mathrm{K}_{4}}{\mathrm{~K}_{2}^{2}}
$$


onde

$$
K_{4}=\frac{N}{(N-1)(N-2)(N-3)}\left\{(N+1) \sum_{i=1}^{N}\left(\hat{p}_{1 i}-\bar{p}_{1}\right)^{4}-\frac{3(N-1)}{N}\left[\sum_{i=1}^{N}\left(\hat{p}_{1 i}-\bar{p}_{1}\right)^{2}\right]^{2}\right\}
$$

Segundo FISHER (1941), se as amostras são grandes, $g_{1}$ e $g_{2}$ têm distribuição normal com médias zero e variāncias dadas por:

$$
\begin{aligned}
& \hat{V}\left(\hat{g}_{1}\right)=\frac{6 N(N-1)}{(N-2)(N+1)(N+3)} \\
& \hat{V} \quad\left(\bar{g}_{2}\right)=\frac{24 N(N-1)^{2}}{(N-3)(N-2)(N+3)(N+5)}
\end{aligned}
$$

Para testar $g_{1}$ e $g_{2}$ têm-se as seguintes hipötẹ se s

$$
\begin{array}{ll}
\mathrm{H}_{\mathrm{o}}: \mathrm{g}_{1}=0 & \mathrm{H}_{\mathrm{o}}: \mathrm{g}_{2}=0 \\
\mathrm{H}_{1}: \mathrm{g}_{1} \neq 0 & \mathrm{H}_{1}: \mathrm{g}_{2} \neq 0 \\
\mathrm{t}_{1}=\frac{\hat{\mathrm{g}}_{1}}{\sqrt{\hat{\mathrm{V}\left(\hat{g}_{1}\right)}}} & \\
\mathrm{t}_{2}=\frac{\hat{\mathrm{s}}_{2}}{\sqrt{\hat{\mathrm{V}\left(\hat{g}_{2}\right)}}}
\end{array}
$$

A distribuição de cada contraste será conside rada aproximadamente normal se ao nivel $\alpha$ de significância os valores de $t$ não superarem os da tabela com (N-1) graus de 1 iberdade. 
4.6.3. Teste de aditividade de rukey

Este teste è aplicado para saber se uma trans formação é necessária ou para sugerir uma transformação adequada ou para estudar se uma transformaça tem procedimento aditivo.

GROSH e SHARMA (1963) compararam o poder do teste de Tukey para não-aditividade com o poder do teste F não central e comprovaram que geralmente o teste de Tukèy é mais poderoso, sendo que o teste $F$ é ligeiramente e mais poderoso para valores pequenos de $\sum \frac{\alpha_{i}^{2}}{\sigma^{2}}=\sum \frac{\beta_{j}^{2}}{\sigma^{2}}$.

TUKEY (1949) mostra como isolar um grau de $1 \underline{i}$ berdade do residuo, quando os dados estão dispostos na forma de uma tabela de dupla entrada ( 1 inhas $x$ colunas).

o modelo matemático para o caso dos efeitos aditivos è dado por:

$$
x_{i j}=m+1_{i}+c_{j}+e_{i j}
$$

onde

$$
\begin{aligned}
& x_{i j} \text { é o valor relativo a linha } \underline{i} \text { e coluna } \underline{j} \\
& 1_{i}=\text { efeito da linha } \underline{i} \\
& c_{j}=\text { efeito da coluna } \underline{j} \\
& e_{i j}=\text { erro relativo ao valor } x_{i j} \text {. }
\end{aligned}
$$

Considerando o modelo matemático onde os efei tos não são aditivos, tem-se: 


$$
x_{i j}=m+L_{i}+c_{j}+\lambda 1_{i} c_{j}+e_{i j}
$$

O teste de aditividade verifica as hipóteses:

$$
\begin{aligned}
& \mathrm{H}_{\mathrm{o}}: \lambda=0 \text { (modelo aditivo) } \\
& \mathrm{H}_{\mathrm{a}}: \lambda \neq 0 \text { (modelo não-aditivo) }
\end{aligned}
$$

Na análise de variância a interação linhas $x$ colunas serā residuo se tivermos $\lambda=0$. Se $\lambda \neq 0$, essa inte ração não é a medida adequada da variação casual.

Se a soma de quadrados não-aditividade for significativo, indica que a diferença entre linhas não é cons tante para as diversas colunas, como deveria ser se os efeitos fossem aditivos.

A soma de quadrados não-aditividade é dado por:

$$
\text { S.Q. Não-aditiv. }=\frac{\left[\sum_{i, j} x_{i j}\left(\bar{x}_{i}-\bar{x}_{. .}\right)\left(\bar{x}_{. j}-\bar{x}_{.}\right)\right]^{2}}{\sum_{i, j}\left(\bar{x}_{i}-\bar{x}_{.} .\right)^{2}\left(\bar{x}_{. j}-\bar{x}_{. .}\right)^{2}}
$$

onde $\bar{x}_{i .}-\bar{x}_{.}=$estimativa do efeito da linha $i$
$\bar{x}_{\cdot j}-\bar{x}_{.}=$estimativa do efeito da coluna $j$ 
Anälise de variāncia

Causas de variação

GL

\begin{tabular}{lll}
\hline Linhas (L) & I-1 & SQ L \\
Colunas (C) & $\mathrm{J}-1$ & SQ C \\
[res. (inter LxC)] & {$[(\mathrm{I}-1)(\mathrm{J}-1)]$} & SQ res. \\
Não-aditividade & 1 & SQ Não-adit. \\
Novo residuo & $(\mathrm{I}-1)(\mathrm{J}-1)-1$ & SQ Novo res. \\
\hline Total & IJ-1 & SQ Total \\
\hline
\end{tabular}

Onde:

SQ Novo Residuo = SQ res. - SQ não-aditividade

$\mathrm{SQ}$ residuo $=\mathrm{SQ}$ Total $-\mathrm{SQ} \mathrm{L}-\mathrm{SQ} \mathrm{C}$

A não aditividade pode ser testada pelo teste

F.

$$
F=\frac{\text { QM Não-aditividade }}{\text { QM Novo residuo }}
$$

com 1 e (I,J - I - J) graus de 1 iberdade, ou

$$
t=\sqrt{\frac{Q M N a ̃ o-a d i t i v i d a d e}{Q M N o v o \text { residuo }}}
$$

com (IJ - I - J) graus de liberdade. 
Se a não-aditividade for significativa, reje ta-se a hipótese de nulidade a um nível $\alpha$ de probabilidade. o modelo apropriado não é aditivo. Se essa não-aditividade for devida à interação dos efeitos principais, deve-se fazer um estudo de transformação dos dados.

\subsection{Quadros de anālise de variância}

Segundo AMARAL (1968) temos o seguinte quadro de anālise de variāncia:

TABELA 1. Anälise de variância do contraste $\hat{\mathrm{p}}_{1}$.

Causa de variação

GI

SQ

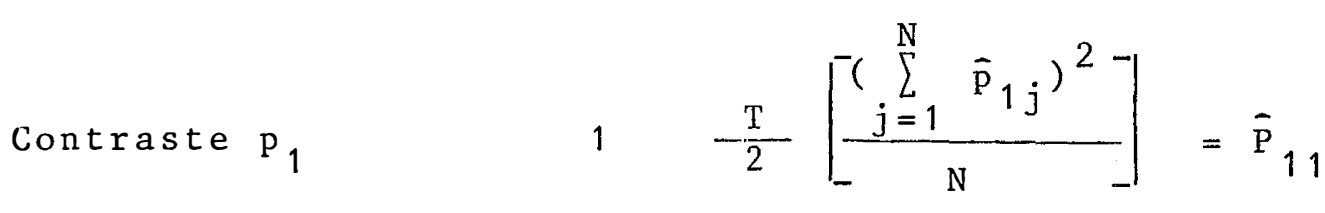

Variação do contraste
entre anos

Variação total $\quad N \quad \frac{T}{2}\left(\sum_{j=1}^{N} \hat{p}_{1 j}^{2}\right)$ 
TABELA 2. Anālise de variāncia do contraste $\hat{q}_{1}$.

Causa de variação

GL $\quad$ SQ

Contraste $q_{1} \quad 1 \quad \frac{T}{2}\left[\frac{\left(\sum_{j=1}^{N} \bar{q}_{1 j}\right)^{2}}{N}\right]=\bar{Q}_{11}$

Variação do con

traste entre años

$N-1 \quad \frac{T}{2}\left[\sum_{j=1}^{N} \hat{q}_{1 j}^{2}-\frac{\left(\sum \bar{q}_{1 j}\right)^{2}}{N}\right]=\hat{Q}_{12}$

Variação total

$N \quad \frac{T}{2}\left(\sum_{j=1}^{N} \bar{q}_{1 j}^{2}\right)$

TABELA 3. Anālise de variância da amplitude $\bar{a}_{1}$.

Causa de variação

GL

SQ

Amplitude $a_{1}$

$2 \quad \hat{\mathrm{P}}_{11}+\overline{\mathrm{Q}}_{11}$

Variação da amplitude

entre anos

$2(N-1)$

$\widehat{\mathrm{P}}_{12}+\widehat{\mathrm{Q}}_{12}$

Variação total

$2 \mathrm{~N}$

$\widehat{\mathrm{P}}_{11}+\widehat{\mathrm{P}}_{12}+\widehat{\mathrm{Q}}_{11}+\overline{\mathrm{Q}}_{12}$

De maneira anảloga para análise da variância 
dos contrastes $\bar{p}_{2}, \bar{p}_{3}, \ldots, \hat{q}_{2}, \widehat{q}_{3}, \ldots$

TABELA 4. Anālise de variāncia do contraste $\widehat{\mathrm{p}}_{k}$, para o caso $\mathrm{T}$ impar.

Causa de variação GL SQ

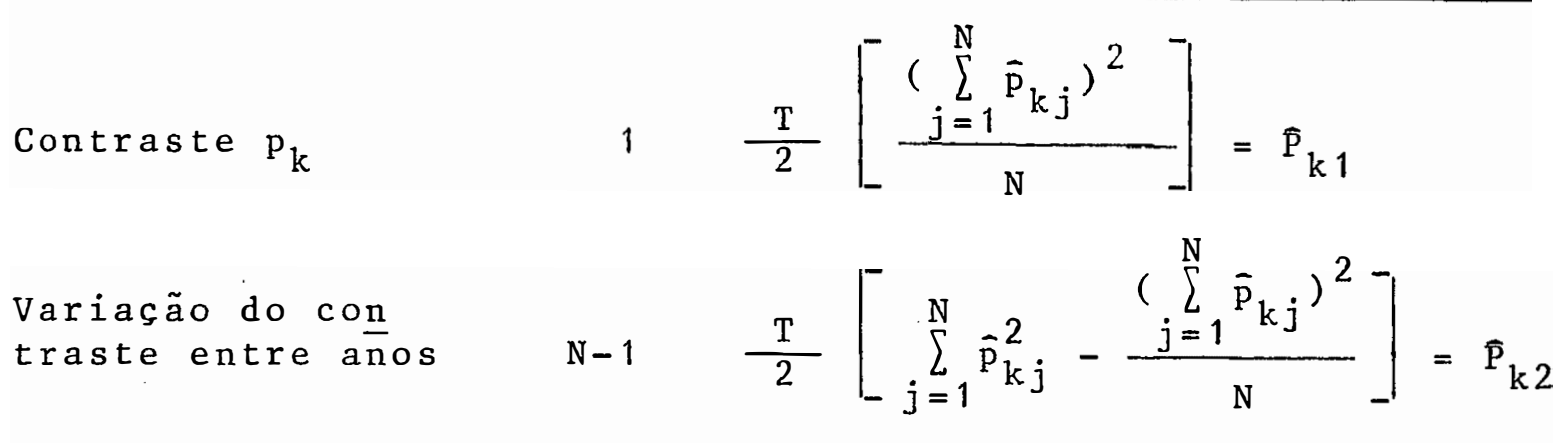

Variação total $\quad \mathrm{N} \quad \frac{\mathrm{T}}{2}\left(\sum_{j=1}^{N} \hat{\mathrm{p}}_{\mathrm{kj}}^{2}\right)$ 
TABELA 5. Anälise de variância do contraste $\widehat{q}_{k}$, para o caso T-ímpar.

Causa de variação

GL

SQ

Contraste $\mathrm{q}_{\mathrm{k}}$

$$
1 \frac{T}{2}\left[\frac{\left(\sum_{j=1}^{N} \bar{q}_{k j}\right)^{2}}{N}\right]=\widehat{Q}_{k 1}
$$

Variaça a do con traste entre años

$$
N-1 \frac{T}{2}\left[\sum_{j=1}^{N} \hat{q}_{k j}^{2}-\frac{\left(\sum_{j=1}^{N} \bar{q}_{k j}\right)^{2}}{N}\right]=\widehat{Q}_{k 2}
$$

Variação total $\quad N \quad \frac{T}{2}\left(\sum_{j=1}^{N} \hat{q}_{k j}^{2}\right)$

TABRL 6. Anālise de variāncia da amplitude $\hat{a}_{k}$ para o caso $\mathrm{T}$ impar.

Causa de variação

GL

SQ

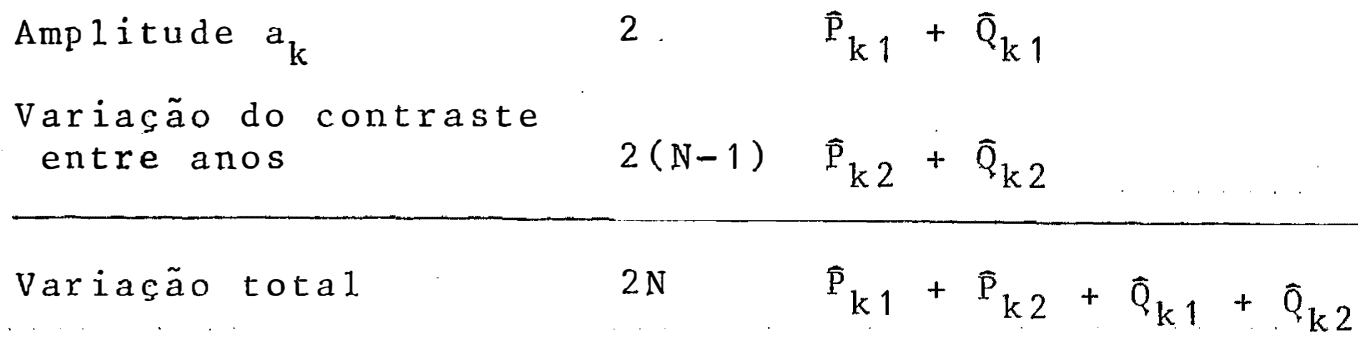


TABELA 7 . Anālise de variāncia do contraste $\hat{p}_{k}$, para o caso de $\mathrm{T}$ par.

Variação total $\quad N \quad T\left(\sum_{j=1}^{N} \dot{p}_{k j}^{2}\right)$

Determinados os componentes harmōnicos significativos, através da análise de variāncia, podemos estabele cer a equação de regressão. 


\section{Resultados e discussāo}

os dados originais das temperaturas médias mensais de Campinas, SP, num periodo de 91 anos (1890 a 1980), utilizados na anälise harmōnica, são encontrados no apêndice 1 .

\subsection{Transformacão dos dados}

Com a finalidade de atender às exigèncias do modelo matemático, foram realizados os testes de homogeneida de, aditividade e normalidade.

0 teste de homogeneidade de variäncia de Bartlett, aplicado aos dados originais (série de 91 anos), apre sentou um valor de qui-quadrado $\left(\chi^{2}=39.4064\right)$, significativo ao nível de $1 \%$ de probabilidade $\left(x_{0,01,11}^{2}=24.7000\right)$ o que 
indica heterogeneidade de variäncias, isto é, houve necessidade de transformação dos dados originais, conforme se verifica na Tabe 1 a 8 .

A transformação dos dados que melhor se ajustou foi $Y=X^{1,84216}$, sobre o qual o teste de Bartlett revelou um valor de $\left(\chi^{2}=22,7539\right)$, não significativo ao nivel de $1 \%$ de probabilidade $\left(\chi_{0,01,11}^{2}=24.700\right)$, o que indicou ho mogeneidade de variâncias. Os resultados são apresentados na Tabe 1 a 9 .

Nas Tabelas 10 e 11 apresenta-se o teste de aditividade de Tukey aplicado aos dados originais e transfor mados, em que se verificou para os dados originais um valor de $F=12,3976$, significativo ao nivel de $5 \%$ de probabilidade e, para os dados transformados $F=0,9752$, não significativo ao nivel de $5 \%$ de probabilidade.

Com relação à normalidade dos dados, realizamos o teste de normalidade apresentado por FISHER (1941), ba seado nas estatísticas $g_{1}$ e $g_{2}$, medidas de assimetria e curtose.

Através do teste t, foram testadas a significância dos desvios de normalidade de $g_{1}$ e $g_{2}$ ao nível de, 5\% de probabilidade, para os dados originais e para os, dados transformados. 
Os desvios da normalidade dos dados originais foram significativos nos meses de janeiro, novembro e dezembro. Para os dados transformados, o teste mostrou-se significativo nos meses de janeiro e dezembro, conforme se verifica nas Tabelas 12 e 13 .

Assim sendo, pode-se concluir que a transformação utilizada, alëm de homogeneizar as variāncias, conseguiu aditividade dos efeitos entre meses e anos e conseguiu normalizar parcialmente os dados.

\subsection{Anāiise hasmōnica}

A anảlise harmōnica permite decompor uma variação periódica de período $T$ em ondas senoidais de periodo $\mathrm{T}, \frac{\mathrm{T}}{2}, \frac{\mathrm{T}}{3}$, etc.

Considerando os dados de temperaturas médias mensais com período $\mathrm{T}=12$ meses, e cada mês como unidade de tempo, a variação anual pode decompor-se em seis ondas senoidais de periodo $12,6,4,3,2 \frac{2}{5}$ e 2 meses. 
TABHL 8. Médias de temperaturas $\left({ }^{\circ} \mathrm{C}\right)$, coeficiente de variacão, variância e $10 \mathrm{~g}$. das variāncias para o teste de homogeneidade de variāncia de Bartlett

\begin{tabular}{lcccc}
\hline Meses & Média & CV(\%) & variância & log da variância \\
\hline Janeiro & 22,758 & 4,075 & 0,860 & $-0,065$ \\
Fevereiro & 22,802 & 3,920 & 0,799 & $-0,097$ \\
Março & 22,426 & 3,709 & 0,692 & $-0,159$ \\
Abril & 20,514 & 5,082 & 1,087 & 0,036 \\
Maio & 18,172 & 6,499 & 1,395 & 0,145 \\
Junho & 16,908 & 6,800 & 1,322 & 0,121 \\
Julho & 16,720 & 6,993 & 1,367 & 0,136 \\
Agosto & 18,294 & 6,741 & 1,521 & 0,182 \\
Setembro & 19,695 & 6,759 & 1,772 & 0,249 \\
Outubro & 20,728 & 5,663 & 1,378 & 0,139 \\
Novembro & 21,501 & 4,478 & 0,927 & $-0,033$ \\
Dezembro & 22,290 & 5,121 & 1,303 & 0,115 \\
\hline Total & & & 14,423 & 0,769 \\
\hline
\end{tabular}

Média das variâncias $=1,202$.

Log. da média das variāncias $=0,080$

Qui-quadrado $(\operatorname{corrigido})=39,406 \%$

Valor qui-quadrado $(11 \mathrm{GL}, 1 \%)=24.700$

** significativo ao nivel de $1 \%$ de probabilidade. 
TABELA 9. Teste de homogeneidade de variancias de Bartlett aplicado aos dados transformados.

\begin{tabular}{lcc}
\hline Meses & variāncia & Log da variancia \\
\hline Janeiro & 575,967 & 2,760 \\
Fevereiro & 529,439 & 2,724 \\
Março & 443,564 & 2,647 \\
Abri1 & 607,517 & 2,784 \\
Maio & 615,566 & 2,789 \\
Junho & 516,389 & 2,713 \\
Julho & 531,816 & 2,726 \\
Agosto & 690,075 & 2,839 \\
Setembro & 928,652 & 2,968 \\
Outubro & 776,520 & 2,890 \\
Novembro & 542,891 & 2,735 \\
Dezembro & 778,541 & 2,891 \\
\hline Total & 7536,937 & 33,466 \\
\hline
\end{tabular}

Média das variāncias $=628,078$

Log da média das variâncias $=2,798$

Qui-quadrado (corrigido) $=22,754, \mathrm{~ns}$

Valor qui-quadrado $(11 \mathrm{GL}, 1 \%)=24,700$

ns = não significativo ao nivel de $1 \%$ de probabilidade. 
TABELA 10. Teste de aditividade de Tukey aplicado aos dados originais.

\begin{tabular}{lrrrl}
\hline Causa de variação & GL & SQ & QM & F \\
\hline Meses & 11 & 5114,2500 & 464,9318 & \\
Anos & 90 & 492,0000 & 5,4667 & \\
$\begin{array}{l}\text { Residuo (Interação } \\
\text { M x A) }\end{array}$ & 990 & 787,5000 & 0,7954 & \\
\hline $\begin{array}{l}\text { Não-aditividade } \\
\text { Novo-residuo }\end{array}$ & 1 & 9,7495 & 9,7495 & $12,40 *$ \\
Total & 989 & 777,7505 & 0,7864 & \\
\hline
\end{tabular}

* significativo ao nivel de $5 \%$ de probabilidade.

TABELA 11. Teste de aditividade de Tukey aplicado aos dados transformados.

\begin{tabular}{lrrrr}
\hline Causa de variação & GL & SQ & QM & F \\
\hline Meses & 11 & 2640304,00 & 240027,64 & \\
Anos & 90 & 243328,00 & 2703,64 & \\
$\begin{array}{l}\text { Residuo (Interação } \\
\text { M x A) }\end{array}$ & 990 & 428704,00 & 433,03 & \\
\hline Não-aditividade & 1 & 422,29 & 422,29 & 0,9752 ns \\
Novo-residuo & 989 & 428281,70 & 433,04 & \\
\hline Total & 1091 & 3741039,99 & & \\
\hline
\end{tabular}

$n s=$ não significativo 
TABela 12. Teste de normalidade de Fisher aplicado aos dados originais.

\begin{tabular}{lcccc}
\hline Meses & $\overline{\mathrm{g}}_{1}$ & $\overline{\mathrm{g}}_{2}$ & $\mathrm{t}_{1}$ & $\mathrm{t}_{2}$ \\
\hline Janeiro & 0,604 & 0,838 & $2,39 *$ & 1,67 \\
Fevereiro & 0,204 & $-0,716$ & 0,81 & 1,43 \\
Março & 0,044 & $-0,218$ & 0,18 & 0,44 \\
Abril & 0,335 & 0,825 & 1,32 & 1,65 \\
Maio & $-0,324$ & $-0,097$ & 1,28 & 0,19 \\
Junho & $-0,329$ & 0,065 & 1,30 & 0,13 \\
Julho & $-0,060$ & $-0,353$ & 0,24 & 0,70 \\
Agosto & $-0,028$ & $-0,073$ & 0,11 & 0,15 \\
Setembro & 0,325 & 0,820 & 1,28 & 1,64 \\
Outubro & 0,119 & $-0,248$ & 0,47 & 0,49 \\
Novembro & $-0,477$ & 1,110 & 1,89 & $2,22 *$ \\
Dezembro & $-1,419$ & 8,060 & $5,60 *$ & $16,09 *$ \\
\hline
\end{tabular}

$$
\begin{aligned}
& s\left(\bar{g}_{1}\right)=0,253 \\
& s\left(\bar{g}_{2}\right)=0,501
\end{aligned}
$$

* significativo ao nivel de $5 \%$ de probabilidade. 
TABELA 13. Teste de normalidade de Fisher aplicado aos dados transformados.

\begin{tabular}{lcccc}
\hline Meses & $\mathrm{g}_{1}$ & $\overline{\mathrm{g}}_{2}$ & $\mathrm{t}_{1}$ & $\mathrm{t}_{2}$ \\
Janeiro & 0,728 & 1,141 & $2,87 *$ & $2,28 *$ \\
Fevereiro & 0,265 & $-0,672$ & 1,05 & 1,34 \\
Marco & 0,126 & $-0,211$ & 0,50 & 0,42 \\
Abri1 & 0,501 & 0,857 & 1,98 & 1,71 \\
Maio & $-0,180$ & $-0,247$ & 0,71 & 0,49 \\
Junho & $-0,163$ & $-0,044$ & 0,64 & 0,09 \\
Julho & 0,083 & $-0,329$ & 0,33 & 0,66 \\
Agosto & 0,133 & $-0,052$ & 0,53 & 0,10 \\
Setembro & 0,548 & 1,025 & 2,16 & 2,05 \\
Outubro & 0,241 & $-0,161$ & 0,95 & 0,32 \\
Novembro & $-0,319$ & 0,843 & 1,26 & 1,68 \\
Dezembro & $-0,924$ & 5,469 & $3,65 *$ & $10,92 *$ \\
\hline
\end{tabular}

* significativo ao nivel de $5 \%$ de probabilidade. 
0 modelo matemätico para anälise serä:

$$
\begin{aligned}
Y_{t} & =p_{0}+p_{1} \cos \phi t+p_{2} \cos 2 \phi t+p_{3} \cos 3 \phi t+p_{4} \cos 4 \phi t+ \\
& +p_{5} \cos 5 \phi t+p_{6} \cos 6 \phi t+q_{1} \operatorname{sen} \phi t+q_{2} \operatorname{sen} 2 \phi t+ \\
& +q_{3} \operatorname{sen} 3 \phi t+q_{4} \operatorname{sen} 4 \phi t+q_{5} \operatorname{sen} 5 \phi t
\end{aligned}
$$

onde $\phi-\frac{360^{\circ}}{12}=30^{\circ}$

$$
t=0,1,2, \ldots, 11
$$

Nas labelas $1 \mathrm{~A}$ a $92 \mathrm{~A}$ apresenta-se a análise harmōnica, para cada ano e no total dos 91 anos, das tempera turas médias mensais transformadas $\left(Y=X^{1,84216}\right)$ no periodo de 1890 a 1980. Através da solução do sistema de equações, determinam-se as estimativas dos parämetros, os componentes harmōnicos $p_{j}$ e $q_{j}$ e conseqüentemente, a amplitude $a_{j} e$ o ân gulo-fase $A_{j}$ de cada onda senoidal. 
TABELA 1A. Anälise harmōnica das temperaturas médias mensais de Campinas, SP - 1890 .

\begin{tabular}{cccc}
\hline Coeficiente $P$ & Coeficiente $Q$ & Amplitude & Angulo-Fase \\
\hline 249,7001 & 0,0 & & \\
82,1329 & $-8,3782$ & 82,5591 & 95,8246 \\
$-2,9815$ & 20,1192 & 20,3389 & 351,5706 \\
$-2,8142$ & $-8,3808$ & 8,8406 & 198,5617 \\
$-4,2016$ & $-3,6436$ & 5,5614 & 229,0685 \\
$-6,5034$ & $-3,3950$ & 7,3362 & 242,4339 \\
7,1599 & 0,0 & 7,1599 & 90,0000 \\
\hline
\end{tabular}

TABELA 2A. Anälise harmónica das temperaturas mëdias mensais de Campinas, SP - 1891.

Coeficiente $P$ Coeficiente $Q \quad$ Amplitude Āngulo-Fase

$\begin{array}{rrrr}256,9780 & 0,0 & & \\ 72,4438 & -6,6642 & 72,7497 & 95,2561 \\ -10,3417 & 14,9900 & 18,2113 & 325,3977 \\ -1,1269 & 5,3678 & 5,4848 & 348,1438 \\ -0,9416 & -10,8665 & 10,9072 & 184,9522 \\ 0,8774 & -0,9935 & 1,3254 & 138,5516 \\ -0,5449 & 0,0 & 0,5449 & 270,0000\end{array}$


TABELA 3A. Análise harmônica das temperaturas médias mensais de Campinas, SP - 1892 .

\begin{tabular}{|c|c|c|c|}
\hline Coeficiente $P$ & Coeficiente Q & Amplitude & Ângulo-Fase \\
\hline 245,6106 & 0,0 & & \\
\hline 71,0025 & 7,5162 & 71,3992 & 83,9572 \\
\hline$-2,1116$ & 22,7739 & 22,8716 & 354,7026 \\
\hline$-1,7119$ & 0,8923 & 1,9305 & 297,5295 \\
\hline 7,5317 & 2,5765 & 7,9603 & 71,1145 \\
\hline 11,9150 & 3,9043 & 12,5383 & 71,8569 \\
\hline$-4,5599$ & 0,0 & 4,5599 & 270,0000 \\
\hline
\end{tabular}

TABELA 4A. Anālise harmōnica das temperaturas médias mensais de Campinas, SP - 1893 .

\begin{tabular}{rcrr}
\hline Coeficiente & Coeficiente & Amplitude & Ángulo-Fase \\
\hline 233,8901 & 0,0 & & \\
76,6073 & 4,0452 & 76,7140 & 86,9773 \\
9,7776 & 3,3513 & 10,3360 & 71,0809 \\
$-7,4985$ & $-6,8280$ & 10,1414 & 227,6794 \\
0,3151 & $-5,9501$ & 5,9584 & 176,9689 \\
1,1932 & $-8,6636$ & 8,7454 & 172,1585 \\
$-4,5891$ & 0,0 & 4,5891 & 270,0000
\end{tabular}


TABELA 5A. Anälise harmōnica das temperaturas médias mensais de Campinas, SP - 1894.

\begin{tabular}{cccc}
\hline Coeficiente $P$ & Coeficiente $Q$ & Amplitude & Ángulo-Fase \\
\hline 251,0364 & 0,0 & & \\
93,5116 & $-13,9679$ & 94,5490 & 98,4956 \\
$-8,3566$ & 20,8957 & 22,5047 & 338,2026 \\
5,5752 & 2,0740 & 5,9485 & 69,5944 \\
11,1915 & 7,6396 & 13,5504 & 55,6816 \\
5,9659 & $-6,4566$ & 8,7909 & 137,2624 \\
3,3726 & 0,0 & 3,3726 & 90,0000 \\
\hline
\end{tabular}

TABELA 6A. Anālise harmōnica das temperaturas médias mensais de Campinas, SP - 1895.

\begin{tabular}{|c|c|c|c|}
\hline Coeficiente P & Coeficiente $Q$ & Amp 1 i tude & Ângu $10-$ Fase \\
\hline 259,7449 & 0,0 & & \\
\hline 78,9797 & $-12,8763$ & 80,0224 & 99,2597 \\
\hline$-5,6879$ & 1,5936 & 5,9070 & 285,6516 \\
\hline$-10,2160$ & $-18,1703$ & 20,8453 & 209,3462 \\
\hline$-11,2866$ & $-7,4662$ & 13,5326 & 236,5151 \\
\hline$-0,0289$ & $-17,0151$ & 17,0151 & 180,0973 \\
\hline$-6,8607$ & 0,0 & 6,8607 & 270,0000 \\
\hline
\end{tabular}


TABEla 7A. Análise harmónica das temperaturas médias mensais de Campinas, SP - 1896.

\begin{tabular}{cccc}
\hline Coeficiente $P$ & Coeficiente $Q$ & Amplitude & Ángulo-Fase \\
\hline 264,8367 & 0,0 & & \\
76,4167 & $-20,6336$ & 79,1534 & 105,1104 \\
$-4,9316$ & 8,3812 & 9,7244 & 329,5266 \\
$-2,0306$ & $-6,0630$ & 6,3940 & 198,5168 \\
$-9,7810$ & $-6,2687$ & 11,6174 & 237,3436 \\
1,3508 & 2,8010 & 3,1097 & 25,7455 \\
$-3,3691$ & 0,0 & 3,3691 & 270,0000
\end{tabular}

TABELA 8A. Anālise harmônica das temperaturas médias mensais de Campinas, SP - 1897.

\begin{tabular}{cccc}
\hline Coeficiente $P$ & Coeficiente $Q$ & Amplitude & Angulo-Fase \\
\hline 260,6179 & 0,0 & & \\
77,6223 & 3,9475 & 77,7226 & 87,0886 \\
$-16,9692$ & $-5,6889$ & 17,8974 & 251,4662 \\
3,5017 & $-17,6843$ & 18,0276 & 168,7998 \\
$-0,2830$ & 2,3757 & 2,3925 & 353,2065 \\
0,5334 & $-6,9890$ & 7,0094 & 175,6356 \\
$-7,6781$ & 0,0 & 7,6781 & 270,0000 \\
\hline
\end{tabular}


TABELA 9A. Anälise harmônica das temperaturas médias mensais de Campinas, SP - 1898 .

\begin{tabular}{cccc}
\hline Coeficiente $P$ & Coeficiente $Q$ & Amplitude & Angulo-Fase \\
\hline 253,6018 & 0,0 & & \\
78,7728 & 9,7654 & 79,3757 & 82,9331 \\
5,7022 & 13,4656 & 14,6232 & 22,9511 \\
$-11,7099$ & $-9,9608$ & 15,3733 & 229,6145 \\
$-3,2796$ & $-7,1559$ & 7,8716 & 204,6221 \\
5,7524 & 4,4333 & 7,2625 & 52,3793 \\
$-6,3475$ & 0,0 & 6,3475 & 270,0000 \\
\hline
\end{tabular}

TABEla 10A. Anāi ise harmōnica das temperaturas médias mensais de Campinas, SP - 1899.

\begin{tabular}{|c|c|c|c|}
\hline Coeficiente $P$ & Coeficiente $Q$ & Amp 1 itude & Angulo-Fase \\
\hline 268,9421 & 0,0 & & \\
\hline 62,0057 & $-0,5435$ & 62,0081 & 90,5022 \\
\hline$-22,0555$ & 24,6946 & 33,1099 & 318,2310 \\
\hline$-11,0946$ & $-8,7065$ & 14,1030 & 231,8771 \\
\hline 1,4502 & 9,3671 & 9,4787 & 8,8003 \\
\hline$-4,8051$ & $-10,6122$ & 11,6494 & 204,3605 \\
\hline 5,1861 & 0,0 & 5,1861 & 90,0000 \\
\hline
\end{tabular}


TABELA 1 A. Anảlise harmōnica das temperaturas médias mensais de Campinas, SP - 1900

\begin{tabular}{|c|c|c|c|}
\hline Coeficiente $P$ & Coeficiente $Q$ & Amp 1 i tude & Ângu $10-\mathrm{Fase}$ \\
\hline 235,8427 & 0,0 & & \\
\hline 45,7135 & 2,8095 & 45,7998 & 86,4830 \\
\hline$-17,9828$ & 29,5432 & 34,5858 & 328,6711 \\
\hline$-5,5742$ & 22,2690 & 22,9561 & 345,9468 \\
\hline 7,5842 & 13,7002 & 15,6593 & 28,9683 \\
\hline 15,0294 & 5,7993 & 16,1095 & 68,9000 \\
\hline 16,5217 & 0,0 & 16,5217 & 90,0000 \\
\hline
\end{tabular}

TABELA 12A. Anālise harmōnica das temperaturas médias mensais de Campinas, SP - 1901.

\begin{tabular}{cccc}
\hline Coeficiente $P$ & Coeficiente $Q$ & Amplitude & Angulo-Fas \\
\hline 240,9885 & 0,0 & & \\
63,5764 & $-15,7499$ & 65,4982 & 103,9140 \\
$-12,7840$ & 15,5749 & 20,1497 & 320,6204 \\
$-6,5375$ & 3,5704 & 7,4489 & 298,6409 \\
9,6690 & 6,5709 & 11,6905 & 55,8007 \\
$-1,1100$ & $-5,3442$ & 5,4583 & 191,7334 \\
0,8500 & 0,0 & 0,8500 & 90,0000
\end{tabular}


TABELA 13A. Anälise harmōnica das temperaturas médias mensais de Campinas, SP - 1902 .

\begin{tabular}{cccc}
\hline Coeficiente $P$ & Coeficiente $Q$ & Amplitude & Ángulo-Fase \\
\hline 262,4011 & 0,0 & & \\
65,2886 & $-4,0100$ & 65,4117 & 93,5147 \\
$-7,1303$ & $-3,8209$ & 8,0895 & 241,8147 \\
$-5,3199$ & 0,8420 & 5,3861 & 278,9939 \\
$-2,6154$ & 0,4637 & 2,6562 & 280,0530 \\
$-7,5591$ & 10,7016 & 13,1021 & 324,7644 \\
7,1698 & 0,0 & 7,1698 & 90,0000 \\
\hline
\end{tabular}

TABELA 14A. Anālise harmōnica das temperaturas médias mensais de Campinas, SP - 1903.

\begin{tabular}{cccc}
\hline Coeficiente $P$ & Coeficiente $Q$ & Amplitude & Ángulo-Fase \\
\hline 248,9491 & 0,0 & & \\
65,6487 & 1,1620 & 65,6590 & 88,9859 \\
$-5,0930$ & 17,3159 & 18,0494 & 343,6101 \\
$-10,3621$ & $-0,2830$ & 10,3660 & 268,4353 \\
$-12,4959$ & $-8,7606$ & 15,2609 & 234,9666 \\
5,2938 & $-0,3133$ & 5,3031 & 93,3866 \\
0,2373 & 0,0 & 0,2373 & 90,0000 \\
\hline
\end{tabular}


TABEla 15A. Anälise harmōnica das temperaturas médias mensais de Campinas, SP - 1904.

\begin{tabular}{|c|c|c|c|}
\hline Coeficiente $P$ & Coeficiente $Q$ & Amplitude & Angulo-Fase \\
\hline 233,9950 & 0,0 & & \\
\hline 67,5862 & $-7,6786$ & 68,0209 & 96,4818 \\
\hline$-11,4286$ & 22,7120 & 25,4253 & 333,2883 \\
\hline$-13,1029$ & $-7,9061$ & 15,3034 & 238,8937 \\
\hline 1,1477 & $-9,0176$ & 9,0904 & 172,7470 \\
\hline 2,6689 & $-0,2269$ & 2,6785 & 94,8602 \\
\hline 6,3930 & 0,0 & 6,3930 & 90,0000 \\
\hline
\end{tabular}

TABEla 16A. Anālise harmōnica das temperaturas médias mensais de Campinas, SP - 1905.

\begin{tabular}{|c|c|c|c|}
\hline Coeficiente $P$ & Coeficiente $Q$ & Amp 1 itude & Angulo-Fase \\
\hline 247,5454 & 0,0 & & \\
\hline 68,4937 & $-10,8179$ & 69,3427 & 98,9752 \\
\hline$-9,0691$ & 7,9320 & 12,0485 & 311,1736 \\
\hline 7,3120 & 2,0410 & 7,5915 & 74,4037 \\
\hline 1,1901 & 2,4328 & 2,7083 & 26,0670 \\
\hline$-2,3205$ & $-1,1488$ & 2,5893 & 243,6616 \\
\hline$-0,9163$ & 0,0 & 0,9163 & 270,0000 \\
\hline
\end{tabular}


TABELA 17A. Anālise harmônica das temperaturas médias mensais de Campinas, SP - 1906.

\begin{tabular}{rccc}
\hline Coeficiente $P$ & Coeficiente $Q$ & Amplitude & . Angulo-Fase \\
\hline 251,5461 & 0,0 & & \\
43,9144 & $-10,3146$ & 45,1095 & 103,2181 \\
$-12,0417$ & 2,1701 & 12,2356 & 280,2158 \\
1,2597 & $-1,5327$ & 1,9839 & 140,5844 \\
$-1,9377$ & 2,2207 & 2,9472 & 318,8936 \\
0,1947 & $-8,9801$ & 8,9822 & 178,7582 \\
$-5,3984$ & 0,0 & 5,3984 & 270,0000 \\
\hline
\end{tabular}

TABELA 18A. Análise harmónica das temperaturas médias mensais de Campinas, SP - 1907.

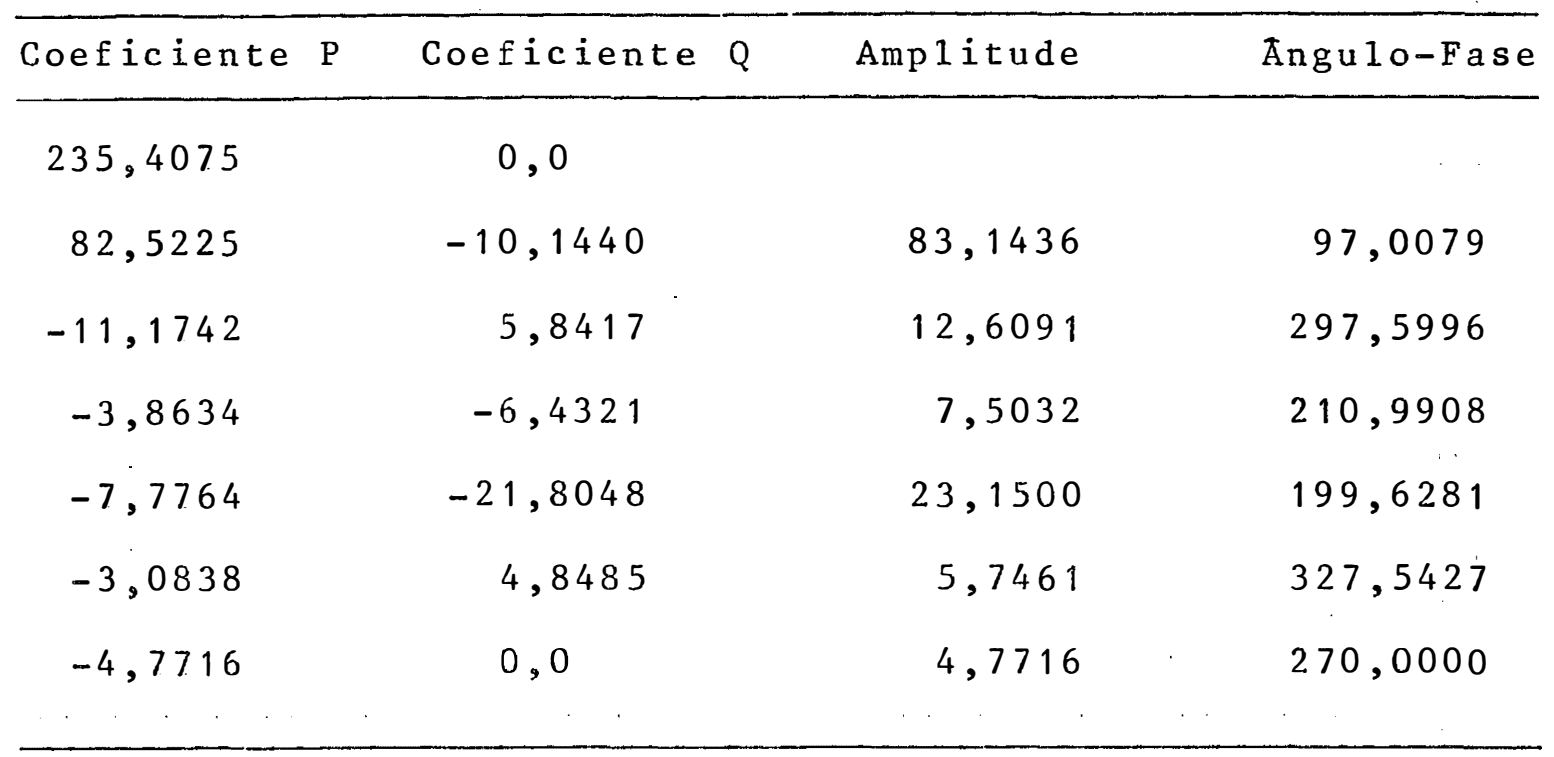


TABELA 19A. Anälise harmōnica das temperaturas mëdias mensais de Campinas, SP - 1908 .

\begin{tabular}{|c|c|c|c|c|c|}
\hline Coeficiente & $\mathrm{P}$ & Coeficiente & $Q$ & Amplitude & Angu $10-$ Fase \\
\hline 241,8013 & & 0,0 & & & \\
\hline 68,4026 & & $-4,0901$ & & 68,5248 & 93,4220 \\
\hline 0,8338 & & 5,2898 & & 5,3552 & 8,9572 \\
\hline$-6,4821$ & & $-7,6048$ & & 9,9926 & 220,4434 \\
\hline 2,8091 & & $-7,6847$ & & 8,1820 & 159,9202 \\
\hline$-4,2546$ & & 3,3163 & & 5,3944 & 307,9351 \\
\hline$-0,9794$ & & 0,0 & & 0,9794 & 270,0000 \\
\hline
\end{tabular}

TABELA 20A. Anảlise harmónica das temperaturas médias mensais de Campinas, SP - 1909.

\begin{tabular}{cccc}
\hline Coeficiente $P$ & Coeficiente $Q$ & Amplitude & Angulo-Fase \\
\hline 229,2733 & 0,0 & & \\
72,2827 & $-7,5926$ & 72,6803 & 95,9964 \\
6,8308 & 18,4299 & 19,6551 & 20,3364 \\
$-7,2579$ & 4,8887 & 8,7508 & 303,9629 \\
$-2,9865$ & 9,6805 & 10,1307 & 342,8545 \\
1,2038 & 13,5644 & 13,6177 & 5,0716 \\
0,2826 & 0,0 & 0,2826 & 90,0000 \\
\hline
\end{tabular}


TABELA 21A. Anālise harmônica das temperaturas médias mensais de Campinas, SP - 1910.

\begin{tabular}{cccc}
\hline Coeficiente $P$ & Coeficiente $Q$ & Amplitude & Angulo-Fase \\
\hline 237,3022 & 0,0 & & \\
77,8028 & 7,7247 & 78,1853 & 84,3299 \\
0,3513 & 22,3540 & 22,3567 & 0,9004 \\
$-0,8446$ & $-9,9274$ & 9,9633 & 184,8627 \\
1,2471 & $-4,3822$ & 4,5562 & 164,1149 \\
17,9520 & 10,7453 & 20,9222 & 59,0969 \\
$-6,1346$ & 0,0 & 6,1346 & 270,0000 \\
\hline
\end{tabular}

TABELA 22A. Anālise harmōnica das temperaturas médias mensais de Campinas, SP - 1911.

\begin{tabular}{cccr}
\hline Coeficiente & Coeficiente & Amplitude & Angulo-Fase \\
\hline 235,7388 & 0,0 & & \\
89,9675 & $-4,4276$ & 90,0764 & 92,8175 \\
$-6,4250$ & 8,6702 & 10,7913 & 323,4597 \\
$-0,1205$ & $-3,3210$ & 3,3232 & 182,0784 \\
$-7,3799$ & 6,4397 & 9,7945 & 311,1082 \\
$-0,5088$ & 7,7629 & 7,7796 & 356,2502 \\
3,5132 & 0,0 & 3.5132 & 90,0000
\end{tabular}


TABELA 23A. Anālise harmōnica das temperaturas médias mensais de Campinas, SP - 1912 .

\begin{tabular}{|c|c|c|c|}
\hline Coeficiente $P$ & Coeficiente $Q$ & Amplitude & Ângu $10-$ Fase \\
\hline 241,1112 & 0,0 & & \\
\hline 70,7833 & 12,5785 & 71,8923 & 79,9235 \\
\hline$-3,1259$ & $-2,6821$ & 4,1188 & 229,3697 \\
\hline$-7,5679$ & 0,2944 & 7,5736 & 272,2275 \\
\hline$-13,0482$ & 13,6590 & 18,8898 & 316,3101 \\
\hline 10,5034 & $-2,3224$ & 10,7571 & 102,4680 \\
\hline 0,9723 & 0,0 & 0,9723 & 90,0000 \\
\hline
\end{tabular}

TABLA 24A. Anàlise harmōnica das temperaturas médias mensais de Campinas, SP - 1913.

\begin{tabular}{cccc}
\hline Coeficiente $P$ & Coeficiente & Amplitude & Ángulo-Fas \\
\hline 240,8944 & 0,0 & & \\
65,9832 & $-0,2799$ & 65,9838 & 90,2432 \\
$-12,7593$ & 12,9294 & 18,1651 & 315,3794 \\
$-8,9703$ & $-2,2885$ & 9,2576 & 255,6880 \\
1,9367 & 0,2903 & 1,9583 & 81,4750 \\
$-5,2379$ & $-3,1680$ & 6,1214 & 238,8336 \\
0,5328 & 0,0 & 0,5328 & 90,0000
\end{tabular}


TABELA 25A. Anālise harmônica das temperaturas médias mensais de Campinas, SP - 1914.

\begin{tabular}{cccc}
\hline Coeficiente $P$ & Coeficiente & Amplitude & Angulo-Fase \\
\hline 260,5825 & 0,0 & & \\
59,4352 & $-12,7568$ & 60,7888 & 102,1139 \\
$-8,2474$ & 4,9457 & 9,6167 & 300,9497 \\
$-5,3186$ & 12,5704 & 13,6493 & 337,0662 \\
13,6357 & $-14,8626$ & 20,1700 & 137,4651 \\
9,4177 & $-0,1437$ & 9,4188 & 90,8744 \\
0,7772 & 0,0 & 0,7772 & 90,0000
\end{tabular}

TABELA 26A. Análise harmônica das temperaturas médias mensais de Campinas, SP - 1915 .

\begin{tabular}{|c|c|c|c|}
\hline Coeficiente $P$ & Coeficiente $Q$ & Amplitude & Angulo-Fase \\
\hline 258,7561 & 0,0 & & \\
\hline 76,3077 & 14,6345 & 77,6983 & 79,1434 \\
\hline$-0,5594$ & 16,2976 & 16,3072 & 358,0339 \\
\hline 16,7908 & $-7,3781$ & 18,3403 & 113,7215 \\
\hline 6,6886 & 5,2082 & 8,4772 & 52,0928 \\
\hline$-10,1487$ & $-2,8726$ & 10,5474 & 254,1955 \\
\hline$-7,0307$ & 0,0 & 7,0307 & 270,0000 \\
\hline
\end{tabular}


TABELA 27A. Anālise harmônica das temperaturas médias mensais de Campinas, SP - 1916.

\begin{tabular}{cccc}
\hline Coeficiente $P$ & Coeficiente $Q$ & Amplitude & Ángulo-Fase \\
\hline 242,4485 & 0,0 & & \\
48,4749 & $-6,0595$ & 48,8521 & $97 ; 1253$ \\
$-3,7421$ & 15,9810 & 16,4133 & 346,8210 \\
10,2891 & $-6,8871$ & 12,3813 & 123,7970 \\
$-6,9100$ & $-3,6498$ & 7,8146 & 242,1571 \\
6,1057 & 8,0471 & 10,1013 & 37,1894 \\
7,9760 & 0,0 & 7,9759 & 90,0000 \\
\hline
\end{tabular}

TABELA 28A. Anāi ise harmōnica das temperaturas médias mensais de Campinas, SP - 1917.

Coeficiente $P$ Coeficiente $Q$ Amplitude Āngulo-Fase

$\begin{array}{cccc}218,6522 & 0,0 & \\ 69,8537 & -7,7051 & 70,2774 & 96,2945 \\ -8,2223 & 25,5211 & 26,8129 & 342,1421 \\ -2,2619 & -1,2928 & 2,6053 & 240,2497 \\ 6,8774 & -8,3020 & 10,7806 & 140,3614 \\ -0,3664 & 1,9565 & 1,9906 & 349,3926 \\ 0,2821 & 0,0 & 0,2821 & 90,0000\end{array}$


TABELA 29A. Anälise harmōnica das temperaturas médias mensais de Campinas, SP - 1918 .

\begin{tabular}{cccc}
\hline Coeficiente $P$ & Coeficiente $Q$ & Amplitude & Angulo-Fase \\
\hline 234,4126 & 0,0 & & \\
69,8897 & 8,9847 & 70,4648 & 82,6745 \\
$-11,5727$ & 13,5574 & 17,8250 & 319,5156 \\
15,4191 & 7,5663 & 17,1755 & 63,8622 \\
8,6900 & $-6,2442$ & 10,7007 & 125,6990 \\
$-6,9089$ & $-9,5721$ & 11,8050 & 215,8209 \\
$-2,7652$ & 0,0 & 2,7652 & 270,0000 \\
\hline
\end{tabular}

TABELA 30A. Anālise harmōnica das temperaturas médias mensais de Campinas, SP - 1919.

\begin{tabular}{|c|c|c|c|}
\hline Coeficiente $P$ & Coeficiente $Q$ & Amp 1 itude & Ângulo-Fase \\
\hline 239,5643 & 0,0 & & \\
\hline 58,5855 & $-3,5051$ & 58,6902 & 93,4240 \\
\hline 0,6702 & 7,8665 & 7,8950 & 4,8697 \\
\hline 9,1558 & 17,8467 & 20,0582 & 27,1589 \\
\hline$-3,9490$ & $-17,2563$ & 17,7024 & 192,8897 \\
\hline$-16,5075$ & $-20,9754$ & 26,6920 & 218,2024 \\
\hline$-0,2593$ & 0,0 & 0,2593 & 270,0000 \\
\hline
\end{tabular}


TABELA 31A. Anälise harmônica das temperaturas mèdias mensais de Campinas, $\$ P-1920$.

\begin{tabular}{cccc}
\hline Coeficiente $P$ & Coeficiente $Q$ & Amplitude & Ângulo-Fase \\
\hline 242,8811 & 0,0 & & \\
71,4092 & 3,0377 & 71,4737 & 87,5640 \\
$-5,7043$ & 1,4815 & 5,8936 & 284,5593 \\
$-4,5397$ & 6,4695 & 7,9033 & 324,9424 \\
12,9346 & $-5,4488$ & 14,0355 & 112,8438 \\
$-2,6055$ & 5,7673 & 6,3285 & 335,6882 \\
2,9680 & 0,0 & 2,9680 & 90,0000 \\
\hline
\end{tabular}

TABELA 32A. Anảlise harmōnica das temperaturas médias mensais de Campinas, SP - 1921.

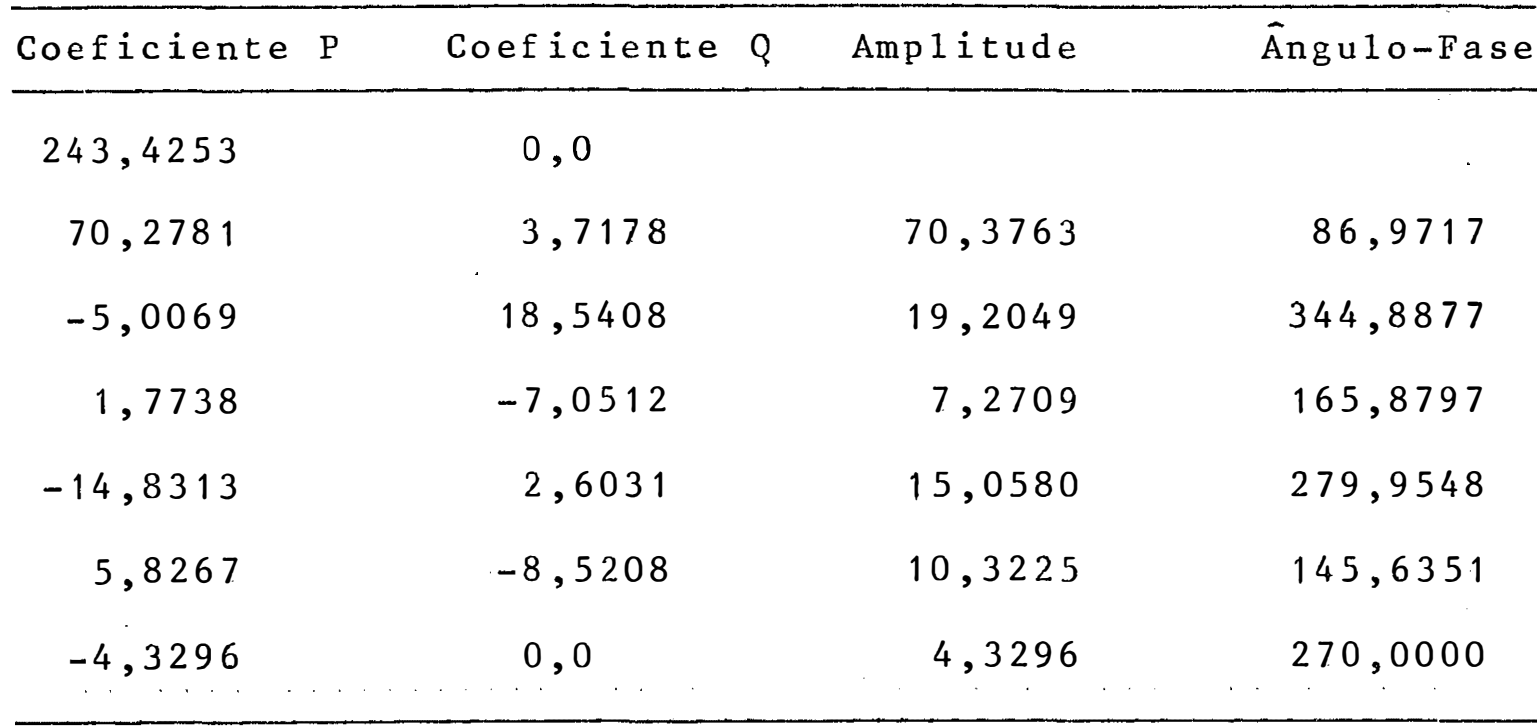


TABBLA 33A. Anālise harmōnica das temperaturas médias mensais de Campinas, SP - 1922 .

\begin{tabular}{rcrr}
\hline Coeficiente $P$ & Coeficiente $Q$ & Amplitude & Ángulo-Fase \\
\hline 245,3374 & 0,0 & & \\
59,5012 & 10,3754 & 60,3990 & 80,1085 \\
$-13,5462$ & 9,9167 & 16,7881 & 306,2065 \\
9,8645 & $-14,5478$ & 17,5769 & 145,8597 \\
0,0173 & $-2,8770$ & 2,8770 & 179,6564 \\
5,3494 & 6,5286 & 8,4403 & 39,3301 \\
0,6405 & 0,0 & 0,6405 & 90,0000 \\
\hline
\end{tabular}

TABELA 34A. Anālise harmónica das temperaturas, médias mensais de Campinas, SP - 1923.

\begin{tabular}{rcrr}
\hline Coeficiente $P$ & Coeficiente $Q$ & Amplitude & Ángulo-Fase \\
\hline 241,1141 & 0,0 & & \\
66,3847 & $-3,7862$ & 66,4925 & 93,2644 \\
$-8,4920$ & $-7,1152$ & 11,0788 & 230,0411 \\
0,7673 & $-16,4671$ & 16,4849 & 177,3322 \\
$-8,1798$ & $-6,8622$ & 10,6771 & 230,0059 \\
2,1350 & 0,0811 & 2,1366 & 87,8253 \\
$-13,7750$ & 0,0 & 13,7750 & 270,0000 \\
\hline
\end{tabular}


TABELA 35A. Anālise harmônica das temperaturas médias mensais de Campinas, SP - 1924.

\begin{tabular}{|c|c|c|c|}
\hline Coeficiente & Coeficiente & Amplitude & Ângulo-Fase \\
\hline 237,1011 & 0,0 & & \\
\hline 57,6299 & 22,3446 & 61,8101 & 68,8074 \\
\hline$-14,0637$ & 11,4902 & 18,1607 & 309,2490 \\
\hline$-3,0955$ & $-6,0553$ & 6,8006 & 207,0768 \\
\hline$-8,3490$ & $-10,1032$ & 13,1065 & 219,5695 \\
\hline$-4,1370$ & 2,0070 & 4,5981 & 295,8796 \\
\hline 2,8806 & 0,0 & 2,8806 & 90,0000 \\
\hline
\end{tabular}

TABELA 36A. Anālise harmônica das temperaturas médias mensais de Campinas, SP - 1925 .

\begin{tabular}{cccc}
\hline Coeficiente $P$ & Coeficiente $Q$ & Amp1itude & Angu1o-Fase \\
\hline 251,2635 & 0,0 & & \\
81,5850 & $-3,7677$ & 81,6719 & 92,6442 \\
$-21,2740$ & 17,2789 & 27,4070 & 309,0837 \\
4,6206 & $-21,3499$ & 21,8442 & 167,7881 \\
$-6,5300$ & 6,3846 & 9,1326 & 314,3552 \\
$-4,3453$ & 2,8761 & 5,2109 & 303,5000 \\
$-10,6668$ & 0,0 & 10,6668 & 270,0000 \\
\hline
\end{tabular}


TABELA 37A. Anālise harmōnica das temperaturas médias mensais de Campinas, SP - 1926.

\begin{tabular}{|c|c|c|c|}
\hline Coeficiente & Coeficiente & Amplitude & Ângulo-Fase \\
\hline 267,0601 & 0,0 & & \\
\hline 64,0146 & $-12,8308$ & 65,2878 & 101,3339 \\
\hline$-12,3612$ & 14,8210 & 19,2993 & 320,1707 \\
\hline 4,7437 & 7,1143 & 8,5508 & 33,6944 \\
\hline$-10,3850$ & $-14,2789$ & 17,6561 & 216,0282 \\
\hline 10,8042 & 10,4143 & 15,0063 & 46,0525 \\
\hline$-1,3834$ & 0,0 & 1,3834 & 270,0000 \\
\hline
\end{tabular}

TABELA 38A. Anālise harmônica das temperaturas médias mensais de Campinas, SP - 1927.

\begin{tabular}{rcrr}
\hline Coeficiente $P$ & Coeficiente $Q$ & Amplitude & Ángulo-Fase \\
\hline 258,3660 & 0,0 & & \\
67,8374 & 2,3290 & 67,8774 & 88,0336 \\
$-20,9775$ & 1,0689 & 21,0047 & 272,9167 \\
$-2,3896$ & $-14,9831$ & 15,1725 & 189,0617 \\
0,5527 & $-5,6846$ & 5,7114 & 174,4472 \\
8,0375 & 3,2275 & 8,6613 & 68,1214 \\
0,8093 & 0,0 & 0,8093 & 90,0000 \\
\hline
\end{tabular}


TABELA 39A. Análise harmônica das temperaturas médias mensais de Campinas, SP - 1928 .

\begin{tabular}{|c|c|c|c|}
\hline Coeficiente $P$ & Coeficiente $Q$ & Amplitude & Āngu $10-$ Fase \\
\hline 283,8884 & 0,0 & & \\
\hline 77,2046 & 2,2543 & 77,2374 & 88,3274 \\
\hline$-22,6761$ & 10,0160 & 24,7897 & 293,8311 \\
\hline$-2,9575$ & $-3,9308$ & 4,9191 & 216,9578 \\
\hline 7,2321 & $-4,3957$ & 8,4632 & 121,2915 \\
\hline$-6,0102$ & 9,1425 & 10,9411 & 326,6794 \\
\hline$-1,1561$ & 0,0 & 1,1561 & 270,0000 \\
\hline
\end{tabular}

TABela 40A. Anāi ise harmōnica das temperaturas médias mensais de Campinas, SP - 1929.

\begin{tabular}{|c|c|c|c|}
\hline Coeficiente & Coeficiente $Q$ & Amplitude & Āngulo-Fase \\
\hline 253,7212 & 0,0 & & \\
\hline 73,8377 & $-6,9046$ & 74,1598 & 95,3423 \\
\hline 2,4580 & 23,3432 & 23,4722 & 6,0110 \\
\hline$-0,6257$ & 1,4083 & 1,5410 & 336,0432 \\
\hline$-0,8723$ & $-14,8124$ & 14,8381 & 183,3701 \\
\hline$-2,0698$ & $-5,5208$ & 5,8961 & 200,5512 \\
\hline$-1,3694$ & 0,0 & 1,3694 & 270,0000 \\
\hline
\end{tabular}


TABela 41A. Anāi ise harmōnica das temperaturas médias mensais de Campinas, SP - 1930.

\begin{tabular}{rrrr}
\hline Coeficiente $P$ & Coeficiente $Q$ & Amplitude & Ángulo-Fase \\
\hline 259,6204 & 0,0 & & \\
44,4851 & 6,5657 & 44,9670 & 81,6040 \\
$-7,1100$ & 2,2257 & 7,4502 & 287,3823 \\
$-0,0061$ & $-2,4792$ & 2,4792 & 180,1401 \\
$-5,1942$ & $-6,2934$ & 8,1600 & 219,5344 \\
11,9359 & $-1,9531$ & 12,0946 & 99,2934 \\
$-4,1022$ & 0,0 & 4,1022 & 270,0000
\end{tabular}

TABELA 42A. Anàlise harmônica das temperaturas médias mensais de Campinas, SP - 1931.

\begin{tabular}{cccc}
\hline Coeficiente $P$ & Coeficiente & Amplitude & Angulo-Fase \\
\hline 256,4048 & 0,0 & & \\
72,0227 & $-9,9686$ & 72,7093 & 97,8803 \\
$-0,7021$ & 5,5290 & 5,5734 & 352,7625 \\
$-8,9125$ & $-11,4719$ & 14,5271 & 217,8437 \\
12,4488 & 0,8494 & 12,4777 & 86,0967 \\
5,1264 & $-11,0338$ & 12,1666 & 155,0800 \\
$-0,8626$ & 0,0 & 0,8626 & 270,0000 \\
\hline
\end{tabular}


TABELA 43A. Anảlise harmōnica das temperaturas médias mensais de Campinas, SP - 1932 .

\begin{tabular}{rccc}
\hline Coeficiente $P$ & Coeficiente $Q$ & Amplitude & Angulo-Fase \\
\hline 263,6567 & 0,0 & & \\
63,6260 & $-2,4094$ & 63,6716 & 92,1687 \\
$-25,2814$ & 16,1765 & 30,0138 & 302,6135 \\
$-10,7027$ & 1,7860 & 10,8507 & 279,4739 \\
5,0288 & $-3,4863$ & 6,1191 & 124,7326 \\
$-16,8100$ & 12,8874 & 21,1816 & 307,4756 \\
$-1,9809$ & 0,0 & 1,9809 & 270,0000
\end{tabular}

TABELA 44A. Anāi ise harmônica das temperaturas médias ménsais de Campinas, SP - 1933.

\begin{tabular}{cccc}
\hline Coeficiente $P$ & Coeficiente $Q$ & Amplitude & Ángulo-Fase \\
\hline 247,6083 & 0,0 & & \\
72,9548 & $-4,2712$ & 73,0797 & 93,3507 \\
$-6,8150$ & 21,9580 & 22,9913 & 342,7573 \\
5,7638 & 1,5419 & 5,9665 & 75,0235 \\
$-2,4832$ & 2,3046 & 3,3878 & 312,8647 \\
$-6,5035$ & 0,0372 & 6,5036 & 270,3279 \\
$-0,8304$ & 0,0 & 0,8304 & 270,0000 \\
\hline
\end{tabular}


TABELA 45A. Anālise harmônica das temperaturas médias mensais de Campinas, SP - 1934.

\begin{tabular}{rcrr}
\hline Coeficiente $P$ & Coeficiente & Amplitude & Angulo-Fase \\
\hline 260,1550 & 0,0 & & \\
65,6439 & 3,6591 & 65,7458 & 86,8094 \\
$-12,5556$ & 10,2423 & 16,2033 & 309,2058 \\
$-6,0740$ & 0,2748 & 6,0802 & 272,5903 \\
$-7,9458$ & 3,7001 & 8,7650 & 294,9700 \\
5,0178 & 7,2743 & 8,8370 & 34,5977 \\
$-2,1107$ & 0,0 & 2,1107 & 270,0000 \\
\hline
\end{tabular}

TABELA 46A. Anāi ise harmōnica das temperaturas médias mensais de Campinas, SP - 1935 .

\begin{tabular}{|c|c|c|c|}
\hline Coeficiente $P$ & Coeficiente Q & Amp1itude & Ângulo-Fase \\
\hline 256,3032 & 0,0 & & \\
\hline 72,2437 & $-7,6665$ & 72,6493 & 96,0577 \\
\hline 6,4661 & 6,1643 & 8,9336 & 46,3688 \\
\hline$-14,2813$ & $-2,4574$ & 14,4912 & 260,2363 \\
\hline$-3,1661$ & $-14,3809$ & 14,7253 & 192,4162 \\
\hline 0,1460 & $-1,6495$ & 1,6560 & 174,9420 \\
\hline$-0,3668$ & 0,0 & 0,3668 & 270,0000 \\
\hline
\end{tabular}


TABEL 47A. Anälise harmônica das temperaturas médias mensais de Campinas, SP - 1936 .

\begin{tabular}{cccc}
\hline Coeficiente $P$ & Coeficiente $Q$ & Amp1itude & Ángu1o-Fase \\
\hline 263,4812 & 0,0 & & \\
64,6760 & 10,1924 & 65,4741 & 81,0442 \\
$-4,3095$ & $-15,4477$ & 16,0376 & 195,5877 \\
11,1347 & 8,1550 & 13,8017 & 53,7813 \\
6,5319 & $-2,4648$ & 6,9815 & 110,6736 \\
1,8276 & $-5,6183$ & 5,9081 & 161,9812 \\
2,7779 & 0,0 & 2,7779 & 90,0000 \\
\hline
\end{tabular}

TABELA 48A. Anālise harmōnica das temperaturas médias mensais de Campinas, SP - 1937.

\begin{tabular}{cccc}
\hline Coeficiente $P$ & Coeficiente $Q$ & Amplitude & Angulo-Fase \\
\hline 249,3254 & 0,0 & & \\
56,6535 & 0,4036 & 56,6549 & 89,5918 \\
$-3,6905$ & 27,7055 & 27,9502 & 352,4124 \\
$-12,1518$ & 1,0218 & 12,1947 & 274,8064 \\
$-5,8647$ & $-0,4628$ & 5,8830 & 265,4878 \\
0,2477 & 2,9149 & 2,9254 & 4,8577 \\
$-2,1397$ & 0,0 & 2,1397 & 270,0000 \\
\hline
\end{tabular}


TABEL 49A. Anälise harmōnica das temperaturas médias mensais de Campinas; SP - 1938 .

\begin{tabular}{cccc}
\hline Coeficiente $P$ & Coeficiente & Amplitude & Ángulo-Fase \\
\hline 280,0083 & 0,0 & & \\
76,0040 & 9,6598 & 76,6153 & 82,7567 \\
$-2,1158$ & 18,2862 & 18,4082 & 353,3999 \\
$-3,9609$ & 0,6781 & 4,0185 & 279,7144 \\
1,7354 & $-3,9846$ & 4,3461 & 156.4656 \\
12,9838 & 3,0289 & 13,3324 & 76,8687 \\
8,6128 & 0,0 & 8,6128 & 90,0000 \\
\hline
\end{tabular}

TABELA 50A. Anālise harmōnica das temperaturas médias ménsais de Campinas, SP - 1939.

\begin{tabular}{rccc}
\hline Coeficiente $P$ & Coeficiente $Q$ & Amplitude & Ángulo-Fase \\
266,0757 & 0,0 & & \\
72,9205 & 1,8435 & 72,9438 & 88,5517 \\
$-23,1027$ & 17,4906 & 28,9768 & 307,1284 \\
0,5664 & 2,7294 & 2,7876 & 11,7234 \\
$-5,6432$ & 5,5790 & 7,9354 & 314,6719 \\
7,8100 & $-11,3627$ & 13,7879 & 145,4978 \\
$-3,8408$ & 0,0 & 3,8408 & 270,0000
\end{tabular}


TABELA 51A. Anal ise harmōnica das temperaturas médias mensais de Campinas, SP - 1940 .

\begin{tabular}{cccc}
\hline Coeficiente $P$ & Coeficiente $Q$ & Amplitude & Ángulo-Fase \\
\hline 281,1216 & 0,0 & & \\
58,7368 & 0,0888 & 58,7369 & 89,9133 \\
$-4,1511$ & 0,9020 & 4,2479 & 282,2588 \\
$-1,1271$ & $-24,3608$ & 24,3869 & 182,6489 \\
0,7716 & $-15,6078$ & 15,6269 & 177,1696 \\
$-3,6856$ & $-9,7499$ & 10,4233 & 200,7074 \\
$-1,3827$ & 0,0 & 1,3827 & 270,0000
\end{tabular}

TABELA 52A. Anālise harmōnica das temperaturas médias mensais de Campinas, SP - 1941 .

\begin{tabular}{|c|c|c|c|c|}
\hline Coeficiente $P$ & Coeficiente & Q & Amplitude & Angulo-Fase \\
\hline 267,5632 & 0,0 & & & \\
\hline 70,3189 & 26,8589 & & 75,2738 & 69,0951 \\
\hline$-3,3733$ & 10,9409 & & 11,4491 & 342,8645 \\
\hline$-0,9917$ & $-11,1942$ & & 11,2381 & 185,0628 \\
\hline 6,5481 & 25,7997 & & 26,6178 & 14,2413 \\
\hline$\uparrow 4,3181$ & $-3,89 \uparrow 0$ & & 14,8374 & 105,2033 \\
\hline$-8,2633$ & 0,0 & & 8,2633 & 270,0000 \\
\hline
\end{tabular}


TABELA 53A. Anälise harmōnica das temperaturas médias mensais de Campinas, SP - 1942 .

\begin{tabular}{rccc}
\hline Coeficiente $P$ & Coeficiente $Q$ & Amplitude & Angulo-Fase \\
\hline 255,2059 & 0,0 & & \\
74,7610 & $-3,1931$ & 74,8291 & 92,4457 \\
$-14,7362$ & 19,1476 & 24,1616 & 322,4177 \\
5,6639 & 3,7026 & 6,7667 & 56,8261 \\
$-2,9357$ & 6,8368 & 7,4404 & 336,7615 \\
17,0969 & 3,3289 & 17,4180 & 78,9819 \\
$-2,1565$ & 0,0 & 2,1565 & 270,0000 \\
\hline
\end{tabular}

TABELA 54A. Anālise harmōnica das temperaturas médias mensais de Campinas, SP - 1943.

\begin{tabular}{rccc}
\hline Coeficiente & Coeficiente & Amplitude & Ângulo-Fase \\
\hline 249,4976 & 0,0 & & \\
60,9346 & 6,9829 & 61,3334 & 83,4625 \\
$-6,1995$ & 5,4360 & 8,2452 & 311,2458 \\
$-8,7240$ & 12,3716 & 15,1382 & 324,8098 \\
$-3,3217$ & 1,1592 & 3,5182 & 289,2378 \\
2,1822 & $-6,0428$ & 6,4248 & 160,1442 \\
5,2596 & 0,0 & 5,2596 & 90,0000 \\
\hline
\end{tabular}


TABELA 55A. Anālise harmōnica das temperaturas médias mensais de Campinas, SP - 1944.

\begin{tabular}{rccc}
\hline Coeficiente $P$ & Coeficiente $Q$ & Amplitude & Angulo-Fase \\
\hline 265,8762 & 0,0 & & \\
66,7509 & $-21,2350$ & 70,0472 & 107,6471 \\
$-17,3724$ & 23,8985 & 29,5456 & 323,9856 \\
11,4494 & 6,1979 & 13,0193 & 61,5720 \\
5,1394 & $-13,4313$ & 14,3810 & 159,0609 \\
6,5653 & $-19,4695$ & 20,5466 & 161,3654 \\
$-5,5084$ & 0,0 & 5,5084 & 270,0000 \\
\hline
\end{tabular}

TABELA 56A. Anälise harmónica das temperaturas médias mensais de Campinas, SP - 1945 .

\begin{tabular}{cccc}
\hline Coeficiente $P$ & Coeficiente $Q$ & Amplitude & Ángulo-Fase \\
\hline 253,2485 & 0,0 & & \\
63,8553 & $-13,5000$ & 65,2667 & 101,9375 \\
$-8,4730$ & 30,5285 & 31,6825 & 344,4883 \\
$-5,9300$ & $-4,8584$ & 7,6661 & 230,6721 \\
3,1870 & 11,6513 & 12,0793 & 15,2979 \\
7,9180 & $-4,5426$ & 9,1285 & 119,8430 \\
$-9,1629$ & 0,0 & 9,1629 & 270,0000 \\
\hline
\end{tabular}


TABELA 57A. Anālise harmōnica das temperaturas médias mensais de Campinas, SP - 1946.

\begin{tabular}{rccc}
\hline Coeficiente $P$ & Coeficiente $Q$ & Amplitude & Ángulo-Fase \\
\hline 265,9631 & 0,0 & & \\
69,4874 & $-15,9907$ & 71,3035 & 102,9596 \\
$-11,4864$ & 15,5204 & 19,3085 & 323,4954 \\
9,7495 & 3,7008 & 10,4283 & 69,2138 \\
$-12,1958$ & 10,3947 & 16,0246 & 310,4414 \\
$-1,9126$ & $-5,0742$ & 5,4227 & 200,6530 \\
0,3086 & 0,0 & 0,3086 & 90,0000
\end{tabular}

TABELA 58A. Anālise harmōnica das temperaturas médias mensais de Campinas, SP - 1947.

\begin{tabular}{|c|c|c|c|c|}
\hline Coeficiente $P$ & Coeficiente & $Q$ & Amp 1 itude & Ângu $10-F$ ase \\
\hline 249,5901 & 0,0 & & & \\
\hline 62,7647 & 14,6614 & & 64,4543 & 76,8517 \\
\hline$-1,7285$ & 10,1000 & & 10,2468 & 350,2886 \\
\hline 11,8632 & 5,4244 & & 13,0445 & 65,4277 \\
\hline$-12,7735$ & 2,6328 & & 13,0420 & 281,6465 \\
\hline$-3,0461$ & 11,0795 & & 11,4906 & 344,6274 \\
\hline$-2,0270$ & 0,0 & & 2,0270 & 270,0000 \\
\hline
\end{tabular}


TABELA 59A. Anảlise harmōnica das temperaturas mëdias mensais de Campinas, SP - 1948 .

\begin{tabular}{rccc}
\hline Coeficiente $P$ & Coeficiente $Q$ & Amplitude & Angulo-Fase \\
\hline 264,8586 & 0,0 & & \\
65,0903 & $-4,1138$ & 65,2202 & 93,6164 \\
$-0,6245$ & 6,6494 & 6,6787 & 354,6348 \\
4,6170 & 0,6720 & 4,6656 & 81,7183 \\
5,9301 & $-1,7624$ & 6,1864 & 106,5521 \\
$-7,5243$ & 7,1501 & 10,3798 & 313,5393 \\
5,8124 & 0,0 & 5,8124 & 90,0000 \\
\hline
\end{tabular}

TABELA 60A. Anả 1 ise harmōnica das temperaturas médias mensais de Campinas, SP - 1949.

\begin{tabular}{|c|c|c|c|}
\hline Coeficiente $P$ & Coeficiente $Q$ & Amplitude & Āngulo-Fase \\
\hline 261,1567 & 0,0 & & \\
\hline 66,5731 & $-6,4566$ & 66,8855 & 95,5396 \\
\hline$-2,8232$ & 17,8724 & 18,0940 & 351,0234 \\
\hline$-9,9551$ & $-1,8874$ & 10,1324 & 259,2646 \\
\hline$-8,0977$ & $-17,1154$ & 18,9343 & 205,3199 \\
\hline 10,2197 & $-1,1825$ & 10,2879 & 96,6005 \\
\hline $5,417.5$ & 0,0 & 5,4175 & 90,0000 \\
\hline
\end{tabular}


TABela 61A. Anālise harmōnica das temperaturas médias mensais de Campinas, SP - 1950 .

\begin{tabular}{rrrr}
\hline Coeficiente $P$ & Coeficiente $Q$ & Amplitude & Angulo-Fase \\
\hline 267,1938 & 0,0 & & \\
51,1034 & $-1,3815$ & 51,1221 & 91,5486 \\
$-5,5962$ & 15,7419 & 16,7071 & 340,4297 \\
7,5153 & $-7,3016$ & 10,4782 & 134,1739 \\
$-5,4350$ & $-0,8641$ & 5,5032 & 260,9663 \\
6,9298 & $-4,7304$ & 8,3904 & 124,3183 \\
$-1,7974$ & 0,0 & 1,7974 & 270,0000 \\
\hline
\end{tabular}

TABELA 62A. Anālise harmōnica das temperaturas médias mensais de Campinas, SP - 1951.

\begin{tabular}{rrrr}
\hline Coeficiente $P$ & Coeficiente $Q$ & Amplitude & Angulo-Fase \\
\hline 258,5493 & 0,0 & & \\
68,1664 & $-31,1895$ & 74,9629 & 114,5865 \\
$-21,8470$ & 17,4284 & 27,9471 & 308,5808 \\
0,4034 & 11,2661 & 11,2733 & 2,0509 \\
$-17,8496$ & $-0,4485$ & 17,8553 & 268,5603 \\
1,4239 & $-2,9684$ & 3,2923 & 154,3738 \\
3,3320 & 0,0 & 3,3320 & 90,0000 \\
\hline
\end{tabular}


TABELA 63A. Anālise harmōnica das temperaturas médias mensais de Campinas, SP - 1952 .

\begin{tabular}{rrrr}
\hline Coeficiente $P$ & Coeficiente $Q$ & Amplitude & Ángulo-Fase \\
\hline 286,8655 & 0,0 & & \\
65,5276 & $-14,0911$ & 67,0255 & 102,1362 \\
6,3206 & 5,9225 & 8,6618 & 46,8626 \\
0,5655 & $-10,1473$ & 10,1631 & 176,8104 \\
$-8,0614$ & 6,0055 & 10,0525 & 306,6848 \\
9,5223 & $-12,6681$ & 15,8478 & 143,0688 \\
4,2848 & 0,0 & 4,2848 & 90,0000 \\
\hline
\end{tabular}

TABELA 64A. Anälise harmōnica das temperaturas médias mensais de Campinas, SP - 1953.

\begin{tabular}{cccc}
\hline Coeficiente $P$ & Coeficiente $Q$ & Amplitude & Ângulo-Fase \\
\hline 290,6560 & 0,0 & & \\
71,5991 & $-10,8176$ & 72,4117 & 98,5916 \\
$-7,5491$ & 24,1305 & 25,2837 & 342,6279 \\
11,0818 & 2,7674 & 11,4221 & 75,9787 \\
$-8,8272$ & $-2,8920$ & 9,2888 & 251,8601 \\
7,4357 & $-4,8240$ & 8,8634 & 122,9740 \\
0,6278 & 0,0 & 0,6278 & 90,0000
\end{tabular}


TABELA 65A. Anāi ise harmōnica das temperaturas mëdias mensais de Campinas, SP - 1954.

\begin{tabular}{rccc}
\hline Coeficiente $P$ & Coeficiente $Q$ & Amp1itude & Ángu1o-Fase \\
\hline 278,5081 & 0,0 & & \\
67,3016 & $-10,3052$ & 68,0860 & 98,7056 \\
$-2,7032$ & 19,4164 & 19,6037 & 352,0740 \\
1,3864 & 4,9735 & 5,1631 & 15,5765 \\
$-2,7379$ & $-0,1703$ & 2,7432 & 266,4402 \\
6,7882 & 3,3174 & 7,5555 & 63,9555 \\
5,6236 & 0,0 & 5,6236 & 90,0000 \\
\hline
\end{tabular}

TABELA 66A. Anālise harmōnica das temperaturas mèdias mensais de Campinas, SP - 1955.

\begin{tabular}{cccc}
\hline Coeficiente & Coeficiente $Q$ & Amplitude & Ángulo-Fase \\
\hline 269,1584 & 0,0 & & \\
67,8596 & 0,4886 & 67,8614 & 89,5874 \\
$-1,2161$ & 25,7645 & 25,7932 & 357,2976 \\
2,1917 & $-2,8518$ & 3,5967 & 142,4571 \\
$-4,1671$ & $-8,8360$ & 9,7693 & 205,2487 \\
$-8,3311$ & 4,9834 & 9,7078 & 300,8865 \\
$-3,0033$ & 0,0 & 3,0033 & 270,0000
\end{tabular}


TABELA 67A. Anảlise harmōnica das temperaturas médias mensais de Campinas, SP - 1956.

\begin{tabular}{rccc}
\hline Coeficiente $P$ & Coeficiente $Q$ & Amplitude & Angulo-Fase \\
\hline 260,3101 & 0,0 & & \\
94,0243 & $-4,5702$ & 94,1353 & 92,7829 \\
2,1938 & 23,7163 & 23,8176 & 5,2848 \\
16,1336 & $-1,3306$ & 16,1884 & 94,7148 \\
18,9391 & $-13,9687$ & 23,5332 & 126,4110 \\
3,5158 & 3,2405 & 4,7814 & 47,3328 \\
9,0918 & 0,0 & 9,0918 & 90,0000 \\
\hline
\end{tabular}

TABELA 68A. Anālise harmōnica das temperaturas médias mensais de Campinas, $\mathrm{SP}-1957$.

\begin{tabular}{|c|c|c|c|}
\hline Coeficiente $P$ & Coeficiente $Q$ & Amplitude & Ângulo-Fase \\
\hline 257,4690 & 0,0 & & \\
\hline 69,6174 & $-16,0550$ & 71,4447 & 102,9864 \\
\hline$-12,0448$ & 5,6364 & 13,2983 & 295,0774 \\
\hline$-2,4827$ & $-0,9364$ & 2,6534 & 249,3342 \\
\hline 6,1728 & $-4,6510$ & 7,7288 & 126,9966 \\
\hline 8,6020 & $-11,5125$ & 14,3712 & 143,2334 \\
\hline$-4,8411$ & 0,0 & 4,8411 & 270,0000 \\
\hline
\end{tabular}


TABELA 69A. Anālise harmōnica das temperaturas médias mensais de Campinas, SP - 1958 .

\begin{tabular}{cccc}
\hline Coeficiente $P$ & Coeficiente $Q$ & Amplitude & Angulo-Fase \\
\hline 269,8855 & 0,0 & & \\
73,9567 & $-20,0649$ & 76,6302 & 105,1794 \\
10,4114 & 10,5286 & 14,8071 & 44,6793 \\
$-3,7564$ & $-7,1591$ & 8,0847 & 207,6862 \\
$-0,7808$ & 9,3315 & 9,3641 & 355,2168 \\
2,5890 & $-0,0139$ & 2,5891 & 90,3080 \\
$-3,5123$ & 0,0 & 3,5123 & 270,0000 \\
\hline
\end{tabular}

TABELA 70A. Anälise harmōnica das temperaturas mëdias mensais de Campinas, SP - 1959.

\begin{tabular}{rccc}
\hline Coeficiente $P$ & Coeficiente $Q$ & Amplitude & Angulo-Fase \\
\hline 278,8540 & 0,0 & & \\
62,3877 & $-4,3798$ & 62,5413 & 94,0158 \\
$-17,1143$ & 16,9453 & 24,0841 & 314,7158 \\
7,3020 & $-4,6966$ & 8,6820 & 122,7491 \\
14,6617 & 1,1518 & 14,7069 & 85,5079 \\
$-17,9546$ & 8,5417 & 19,8828 & 295,4421 \\
2,1464 & 0,0 & 2,1464 & 90,0000 \\
\hline
\end{tabular}


TABEla 71A. Anālise harmōnica das temperaturas médias mensais de Campinas, SP - 1960.

\begin{tabular}{rccc}
\hline Coeficiente $P$ & Coeficiente $Q$ & Amplitude & Angulo-Fase \\
\hline 255,6825 & 0,0 & & \\
60,6594 & $-25,9331$ & 65,9703 & 113,1477 \\
$-10,2902$ & 25,9801 & 27,9438 & 338,3923 \\
$-2,4518$ & $-0,4532$ & 2,4933 & 259,5261 \\
3,6511 & $-7,3116$ & 8,1725 & 153,4644 \\
6,5128 & $-5,4940$ & 8,5206 & 130,1501 \\
$-1,5287$ & 0,0 & 1,5287 & 270,0000 \\
\hline
\end{tabular}

TABELA 72A. Análise harmōnica das temperaturas médias mensais de Campinas, SP - 1961.

\begin{tabular}{rcrr}
\hline Coeficiente $P$ & Coeficiente $Q$ & Amplitude & Angulo-Fase \\
\hline 274,1770 & 0,0 & & \\
52,2708 & $-37,4502$ & 64,3020 & 125,6203 \\
$-26,4266$ & 20,6164 & 33,5172 & 307,9590 \\
8,0649 & 6,9579 & 10,6515 & 49,2146 \\
1,5484 & $-4,6045$ & 4,8579 & 161,4135 \\
4,9376 & 8,2662 & 9,6286 & 30,8511 \\
2,7726 & 0,0 & 2,7726 & 90,0000 \\
\hline
\end{tabular}


TABELA 73A. Anālise harmōnica das temperaturas médias mensais de Campinas, SP - 1962 .

\begin{tabular}{ccrr}
\hline Coeficiente $P$ & Coeficiente $Q$ & Amplitude & Angulo-Fase \\
\hline 247,7821 & 0,0 & & \\
75,4851 & $-5,3002$ & 75,6709 & 94,0165 \\
$-8,7056$ & 22,1661 & 23,8143 & 338,5579 \\
0,7911 & $-10,5098$ & 10,5395 & 175,6955 \\
$-7,6732$ & $-1,6590$ & 7,8505 & 257,7996 \\
3,1785 & 8,4515 & 9,0295 & 20,6105 \\
3,9272 & 0,0 & 3,9272 & 90,0000 \\
\hline
\end{tabular}

TABELA 74A. Análise harmônica das temperaturas médias mensais de Campinas, SP - 1963.

\begin{tabular}{cccc}
\hline Coeficiente $P$ & Coeficiente $Q$ & Amplitude & Angulo-Fase \\
\hline 288,1599 & 0,0 & & \\
64,4874 & $-31,3683$ & 71,7119 & 115,9395 \\
$-23,6711$ & 27,8430 & 36,5452 & 319,6299 \\
$-2,6333$ & $-3,9822$ & 4,7741 & 213,4753 \\
$-2,6746$ & $-11,7359$ & 12,0368 & 192,8382 \\
$-3,8442$ & 3,6158 & 5,2775 & 313,2458 \\
7,8522 & 0,0 & 7,8522 & 90,0000
\end{tabular}


TABELA 75A. Anālise harmônica das temperaturas mèdias mensais de Campinas, SP - 1964 .

\begin{tabular}{cccc}
\hline Coeficiente $P$ & Coeficiente $Q$ & Amplitude & Angulo-Fase \\
\hline 258,5667 & 0,0 & & \\
59,8856 & 0,1386 & 59,8857 & 89,8674 \\
$-18,1679$ & 27,0160 & 32,5567 & 326,0796 \\
8,9859 & $-17,2608$ & 19,4597 & 152,4987 \\
0,2632 & $-4,5450$ & 4,5526 & 176,6859 \\
10,3456 & 10,2779 & 14,5831 & 45,1883 \\
0,0346 & 0,0 & 0,0346 & 90,0000
\end{tabular}

TABELA 76A. Anāli ise harmōnica das temperaturas médias mensais de Campinas, SP - 1965 .

\begin{tabular}{cccc}
\hline Coeficiente $P$ & Coeficiente $Q$ & Amplitude & Angulo-Fase \\
\hline 265,3259 & 0,0 & & \\
43,8330 & $-23,3460$ & 49,6626 & 118,0404 \\
$-13,8466$ & 9,9007 & 17,0221 & 305,5659 \\
8,1215 & $-4,6140$ & 9,3407 & 119,6019 \\
$-6,6144$ & $-8,5198$ & 10,7860 & 217,8240 \\
$-5,7883$ & 17,5294 & 18,4603 & 341,7266 \\
$-3,7719$ & 0,0 & 3,7719 & 270,0000 \\
\hline
\end{tabular}


TABELA 77A. Anảlise harmōnica das temperaturas médias mensais de Campinas, SP - 1966.

\begin{tabular}{|c|c|c|c|c|}
\hline Coeficiente $P$ & Coeficiente & $Q$ & Amplitude & Ângulo-Fase \\
\hline 274,2544 & 0,0 & & & \\
\hline 65,8743 & 4,5085 & & 66,0284 & 86,0846 \\
\hline 4,9094 & 10,7335 & & 11,8029 & 24,5789 \\
\hline$-1,5623$ & 4,2739 & & 4,5505 & 339,9202 \\
\hline 5,8105 & 0,9145 & & 5,8821 & 81,0553 \\
\hline$-7,5416$ & $-1,4420$ & & 7,6782 & 259,1753 \\
\hline$-3,5855$ & 0,0 & & 3,5855 & 270,0000 \\
\hline
\end{tabular}

TABELA 7\$A. Anālise harmónica das temperaturas médias mensais de Campinas, SP - 1967.

\begin{tabular}{cccc}
\hline Coeficiente & Coeficiente $Q$ & Amplitude & Angulo-Fase \\
\hline 266,9204 & 0,0 & & \\
44,1824 & $-6,0164$ & 44,5902 & 97,7544 \\
$-19,1155$ & 25,5762 & 31,9303 & 323,2256 \\
6,1590 & 2,6586 & 6,7083 & 66,6520 \\
2,6489 & 9,6727 & 10,0289 & 15,3153 \\
7,5716 & $-8,6069$ & 11,4633 & 138,6615 \\
$-3,7244$ & 0,0 & 3,7244 & 270,0000 \\
\hline
\end{tabular}


TABELA 79A. Anälise harmōnica das temperaturas médias mensais de Campinas, SP - 1968.

\begin{tabular}{rrrr}
\hline Coeficiente $P$ & Coeficiente $Q$ & Amplitude & Angulo-Fase \\
\hline 252,0181 & 0,0 & & \\
75,5613 & $-28,0734$ & 80,6079 & 110,3817 \\
$-7,8923$ & 1,9253 & 8,1238 & 283,7092 \\
$-17,5346$ & $-1,5582$ & 17,6037 & 264,9216 \\
$-7,4679$ & $-11,0928$ & 13,3724 & 213,9493 \\
2,3732 & 1,2599 & 2,6869 & 62,0373 \\
2,5714 & 0,0 & 2,5714 & 90,0000
\end{tabular}

TABEI. 80A. Anālise harmōnica das temperaturas médias mensais de Campinas, SP - 1969.

\begin{tabular}{|c|c|c|c|c|}
\hline Coeficiente & Coeficiente & Q & Amplitude & Angulo-Fase \\
\hline 274,6575 & 0,0 & & & \\
\hline 60,8775 & 6,2760 & & 61,2001 & 84,1139 \\
\hline 1,1827 & 29,3782 & & 29,4020 & 2,3054 \\
\hline 7,5658 & 4,9977 & & 9,0674 & 56,5526 \\
\hline$-11,4020$ & $-0,8010$ & & 11,4301 & 256,9812 \\
\hline 4,0532 & 11,4305 & & 12,1279 & 19,5242 \\
\hline 9,1852 & 0,0 & & 9,1852 & 90,0000 \\
\hline
\end{tabular}


TABELA 81A. Anālise harmōnica das temperaturas médias mensais de Campinas, SP - 1970 .

\begin{tabular}{cccc}
\hline Coeficiente $P$ & Coeficiente $Q$ & Amplitude & Angulo-Fase \\
\hline 265,5769 & 0,0 & & \\
62,3066 & 12,9065 & 63,6293 & 78,2969 \\
$-4,6777$ & 0,0995 & 4,6787 & 271,2192 \\
2,2672 & $-3,9632$ & 4,5658 & 150,2279 \\
$-4,5789$ & $-14,6277$ & 15,3277 & 197,3817 \\
$-2,6029$ & $-10,9237$ & 11,2295 & 193,4026 \\
$-3,5051$ & 0,0 & 3,5051 & 270,0000 \\
\hline
\end{tabular}

TABELA 82A. Anālise harmōnica das temperaturas mèdias mensais de Campinas, SP - 1971.

\begin{tabular}{cccc}
\hline Coeficiente $P$ & Coeficiente $Q$ & Amplitude & Angulo-Fase \\
\hline 263,6489 & 0,0 & 75,8033 & 83,8569 \\
75,3681 & 8,1117 & 32,4771 & 10,3550 \\
5,8376 & 31,9482 & 4,4113 & 95,1504 \\
4,3935 & $-0,3960$ & 2,6113 & 130,5655 \\
1,9837 & $-1,6981$ & 4,2136 & 129,5315 \\
2,2498 & $-2,6820$ & 2,3841 & 90,0000 \\
\hline
\end{tabular}


TABELA 83A. Anālise harmônica das temperaturas médias mensais de Campinas, SP - 1972.

\begin{tabular}{rrrr}
\hline Coeficiente $P$ & Coeficiente $Q$ & Amp1itude & Angulo-Fase \\
\hline 264,4714 & 0,0 & & \\
59,8134 & $-5,8573$ & 60,0995 & 95,5930 \\
$-8,2064$ & 3,7698 & 9,0308 & 294,6726 \\
$-2,8344$ & 2,4475 & 3,7448 & 310,8103 \\
$-10,8482$ & $-9,7252$ & 14,5693 & 228,1243 \\
5,7392 & $-11,4983$ & 12,8510 & 153,4747 \\
4,1002 & 0,0 & 4,1002 & 90,0000 \\
\hline
\end{tabular}

TABELA 84A. Anālise harmōnica das temperaturas médias mensais de Campinas, SP - 1973 .

\begin{tabular}{rcrr}
\hline Coeficiente $P$ & Coeficiente $Q$ & Amplitude & Ángu1o-Fase \\
\hline 273,7935 & 0,0 & & \\
69,5429 & 21,1823 & 72,6974 & 73,0596 \\
$-1,3336$ & 13,6703 & 13,7352 & 354,4280 \\
1,8601 & $-1,7235$ & 2,5358 & 132,8158 \\
10,0811 & $-0,9139$ & 10,1224 & 95,1800 \\
$-1,2818$ & 12,9608 & 13,0240 & 354,3518 \\
$-9,2051$ & 0,0 & 9,2051 & 270,0000
\end{tabular}


TABELA 854. Anälise harmōnica das temperaturas médias mensais de Campinas, SP - 1974.

\begin{tabular}{cccc}
\hline Coeficiente $P$ & Coeficiente $Q$ & Amplitude $\therefore$ & Angulo-Fase \\
\hline 263,2961 & 0,0 & & \\
64,4275 & $-2,4276$ & 64,4731 & 92,1580 \\
$-6,2662$ & 30,2204 & 30,8632 & 348,2856 \\
$-4,2531$ & 6,7890 & 8,0112 & 327,9338 \\
$-5,2703$ & 3,9919 & 6,6114 & 307,1418 \\
$-7,9820$ & 9,2173 & 12,1931 & 319,1079 \\
5,7433 & 0,0 & 5,7433 & 90,0000 \\
\hline
\end{tabular}

TABELA 86A. Anālise harmônica das temperaturas médias mensais de Campinas, SP - 1975.

\begin{tabular}{|c|c|c|c|}
\hline Coeficiente $P$ & Coeficiente Q & Amplitude & Ângulo-Fase \\
\hline 267,6785 & 0,0 & & \\
\hline 59,6297 & $-14,1802$ & 61,2925 & 103,3768 \\
\hline$-8,0009$ & 32,4163 & 33,3890 & 346,1355 \\
\hline 3,3535 & $-10,2142$ & 10,7506 & 161,8240 \\
\hline$-21,1661$ & $-7,1212$ & 22,3319 & 251,4049 \\
\hline 8,2813 & $-6,6050$ & 10,5928 & 128,5752 \\
\hline$-7,6444$ & 0,0 & 7,6444 & 270,0000 \\
\hline
\end{tabular}


TABELA 87A. Anảlise harmônica das temperaturas médias mensais de Campinas, SP - 1976.

\begin{tabular}{|c|c|c|c|}
\hline Coeficiente $P$ & Coeficiente Q & Amplitude & Angulo-Fase \\
\hline 248,4448 & 0,0 & & \\
\hline 70,9901 & $-0,4010$ & 70,9912 & 90,3237 \\
\hline$-4,8914$ & 7,5680 & 9,0111 & 327,1243 \\
\hline$-5,1971$ & $-10,8716$ & 12,0499 & 205,5499 \\
\hline$-0,1348$ & $-0,5281$ & 0,5451 & 194,3237 \\
\hline 13,1602 & $-2,4168$ & 13,3803 & 100,4062 \\
\hline 2,7071 & 0,0 & 2,7071 & 90,0000 \\
\hline
\end{tabular}

TABELA 88A. Anālise harmōnica das temperaturas médias mensais de. Campinas, SP - 1977.

\begin{tabular}{rrrr}
\hline Coeficiente $P$ & Coeficiente $Q$ & Amplitude & Angulo-Fase \\
\hline 282,9104 & 0,0 & & \\
53,3775 & $-6,2046$ & 53,7370 & 96,6304 \\
$-3,1204$ & 30,3034 & 30,4637 & 354,1206 \\
$-13,1702$ & 17,3988 & 21,8213 & 322,8757 \\
2,8475 & 5,5676 & 6,2535 & 27,0869 \\
$-0,3417$ & $-2,2690$ & 2,2946 & 188,5645 \\
$-2,5897$ & 0,0 & 2,5897 & 270,0000 \\
\hline
\end{tabular}


TABELA 89A. Anālise harmōnica das temperaturas médias mensais de Campinas, SP - 1978 .

\begin{tabular}{cccc}
\hline Coeficiente $P$ & Coeficiente $Q$ & Amplitude & Angu1o-Fase \\
\hline 272,8850 & 0,0 & & \\
74,9756 & $-1,9846$ & 75,0018 & 91,5164 \\
$-3,9270$ & 19,7298 & 20,1168 & 348,7432 \\
$-5,5980$ & 9,0599 & 10,6498 & 328,2886 \\
12,8858 & $-4,6140$ & 13,6870 & 109,7007 \\
0,8088 & $-8,5533$ & 8,5914 & 174,5982 \\
2,1361 & 0,0 & 2,1361 & 90,0000
\end{tabular}

TABELA 90A. Anālise harmōnica das temperaturas médias mensais de Campinas, SP - 1979.

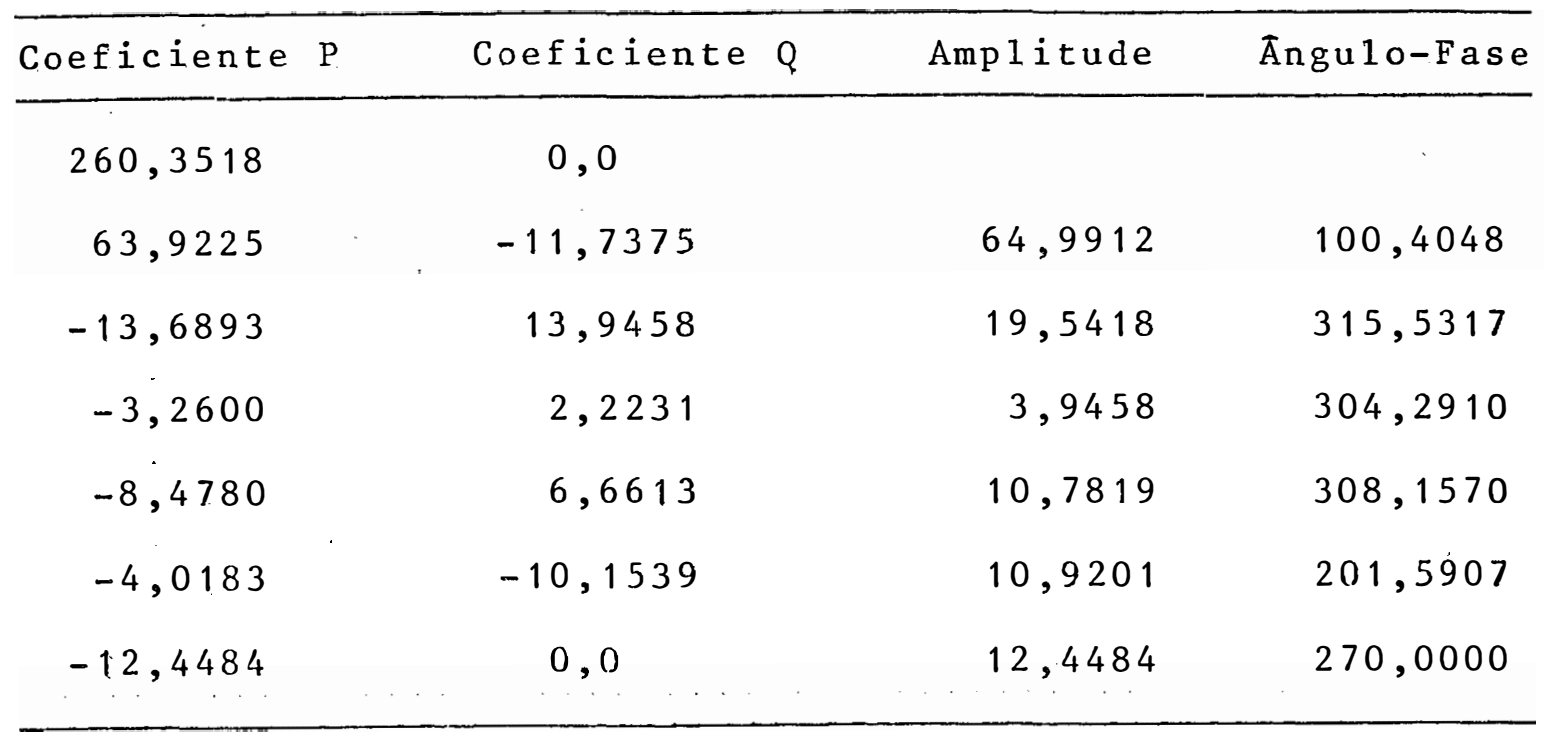


TABELA 91A. Anāi ise harmōnica das temperaturas médias mensais de Campinas, SP - 1980 .

\begin{tabular}{cccr}
\hline Coeficiente $P$ & Coeficiente $Q$ & Amplitude & Angulo-Fase \\
\hline 273,6597 & 0,0 & & \\
62,9226 & 5,2350 & 63,1400 & 85,2440 \\
$-12,9386$ & 10,7892 & 16,8468 & 309,8240 \\
$-15,4917$ & $-9,6424$ & 18,2474 & 238,1007 \\
0,1334 & 3,6363 & 3,6387 & 2,1014 \\
$-1,8188$ & $-16,0994$ & 16,2018 & 186,4454 \\
0,6978 & 0,0 & 0,6978 & 90,0000
\end{tabular}

TABEL 92A. Anāi ise harmōnica das temperaturas médias mensais de Campinas, SP - médias.

\begin{tabular}{|c|c|c|c|}
\hline Coeficiente $P$ & Coeficiente $Q$ & Amp1 itude & Angu $10-F$ ase \\
\hline 257,5209 & 0 & & \\
\hline 67,2764 & $-3,7408$ & 67,3803 & 93,1827 \\
\hline$-7,6356$ & 14,1099 & 16,0434 & 331,5798 \\
\hline$-0,6419$ & $-1,8029$ & 1,9138 & 199,5975 \\
\hline$-1,2105$ & $-2,1830$ & 2,4962 & 209,0092 \\
\hline 1,7476 & $-0,6546$ & 1,8661 & 110,5337 \\
\hline$-0,3827$ & & 0,3827 & 270,0000 \\
\hline
\end{tabular}




\subsection{Anālise de variancia}

Os resultados da anālise de variāncia dos con trastes $\mathrm{p}_{\mathrm{h}}$ e $\mathrm{q}_{\mathrm{h}}$ e da amplitude $\mathrm{A}_{\mathrm{h}}$ são apresentados nas Tabelas $93 \mathrm{~A}$ a $98 \mathrm{~A}$.

Segundo AMARAL (1968) a anālise de variāncia da amplitude das ondas senoidais é obtida pela soma das aná1 ises dos contrastes que a compõem, desde que as variāncias residuais destes contrastes se mostrem homogèneas.

Pelo teste $F$, verificou-se que as ondas semes tral, trimestral e anual foram significativas ao nivel de $5 \%$ de probabilidade; logo, o modelo final (equação de regressão) pode ser representado pelas ondas significativas, ajustado a um ano médio.

$$
\begin{aligned}
\widehat{Y}_{t}=257,5209 & +67,3803 \operatorname{sen}(30 t+93,1827)^{\circ}+ \\
& +16,0434 \operatorname{sen}(60 t+331,5798)^{\circ}+ \\
& +2,4962 \operatorname{sen}(120 t+209,0092)^{\circ}
\end{aligned}
$$

Verificou-se também que aproximadamente $99,8 \%$ da variação das temperaturas médias mensais transformadas é explicada pelo modelo. E, considerando somente a onda anual, esta é responsável por 94,5\% da variação total entre os 12 meses de 1 ano.

Na Tabela 99A apresentam-se os resultados das estimativas e componentes harmonicos dos valores transforma- 
dos das temperaturas médias mensais de Campinas, SP a 1980).

A partir dos dados da Tabela 99A, foram construidos os gráficos das ondas senoidais significativas. Näs Figuras 1, 2, 3, 4 são representadas as ondas anual, semestral e trimestral, sintese das trēs ondas. A Figura 5 repre senta a equação de regressão, obtida a partir dos valores es timados, e os pequenos circulos (•), representam os valores observados.

\footnotetext{
Por meio da transformação inversa $\hat{\mathrm{X}}_{\mathrm{t}}=10^{\frac{\log \mathrm{Y}_{\mathrm{t}}}{1,84216}}$, podemos voltar aos dados originais, a partir dos valores transformados.
} 
TABELA 93A. Anālise de variāncia dos contrastes $\bar{p}_{1}, \bar{q}_{1}$ e da amplitude $\bar{a}_{1}$ das temperaturas médias mensais de Campinas, SP, no periodo de 1890 a 1980 .

\begin{tabular}{lcccc}
\hline Causa de variação & GL & SQ & QM & F \\
\hline $\begin{array}{l}\text { Contraste }\left(p_{1}\right) \\
\begin{array}{l}\text { Variação do contraste } \\
\text { entre anos }\end{array}\end{array}$ & 1 & 411865,3125 & 411865,3125 & $4198,6016 * *$ \\
\hline Variação total & 90 & 8828,6250 & 98,0958 & \\
\hline
\end{tabular}

\begin{tabular}{lcccc}
\hline Causa de variação & GL & SQ & QM & F \\
\hline $\begin{array}{l}\text { Contraste }\left(q_{1}\right) \\
\begin{array}{l}\text { Variação do contraste } \\
\text { entre anos }\end{array}\end{array}$ & 1 & 1273,5583 & 1273,5583 & $9,2770 * *$ \\
\hline Variação total & 91 & 12355,3555 & 137,2817 & \\
\hline
\end{tabular}

\begin{tabular}{lcccc}
\hline Causa de variação & GL & SQ & QM & F \\
\hline $\begin{array}{l}\text { Amplitude }\left(a_{1}\right) \\
\begin{array}{l}\text { Variação } \\
\text { da amplitude }\end{array}\end{array}$ & 2 & 413138,8125 & 206569,3750 & $1755,2156 \% *$ \\
\hline Variação total & 180 & 21184,0000 & 117,6889 & \\
\hline
\end{tabular}


TABELL 94A. Anālise de variāncia dos contrastes $\overline{\mathrm{p}}_{2}, \overline{\mathrm{q}}_{2}$ e da amplitude $\bar{a}_{2}$ das temperaturas médias mensais de Campinas, SP, no periodo de 1890 a 1980.

\begin{tabular}{lcccc}
\hline Causa de variação & GL & SQ & QM & F \\
\hline $\begin{array}{l}\text { Contraste }\left(p_{2}\right) \\
\begin{array}{l}\text { Variação do contras } \\
\text { te entre anos }\end{array}\end{array}$ & 1 & 5305,3789 & 5305,3789 & $79,1429 * *$ \\
\hline \begin{tabular}{l} 
Variação total \\
\hline
\end{tabular}
\end{tabular}

\begin{tabular}{lcccc}
\hline Causa de variação & GL & SQ & QM & F \\
\hline $\begin{array}{l}\text { Contraste }\left(q_{2}\right) \\
\begin{array}{l}\text { Variaça do contras } \\
\text { te entre anos }\end{array}\end{array}$ & 1 & 18116,8984 & 18116,8984 & $181,9203 * *$ \\
\hline \begin{tabular}{l} 
Variação total \\
\hline
\end{tabular}
\end{tabular}

\begin{tabular}{|c|c|c|c|c|}
\hline Causa de variação & GL & SQ & $\mathrm{QM}$ & F \\
\hline Amplitude $\left(\mathrm{a}_{2}\right)$ & 2 & 23422,2773 & 11711,1367 & $140,5709 * *$ \\
\hline $\begin{array}{l}\text { Variação da } \\
\text { amplitude }\end{array}$ & 180 & 14996,0234 & 83,3112 & \\
\hline Variação total & 182 & 38418,3008 & & \\
\hline
\end{tabular}


TABELA 95A. Anälise de variância dos contrastes $\bar{p}_{3}, \bar{q}_{3}$ e da amplitude $\hat{a}_{3}$ das temperaturas médias mensais de Campinas, SP, no periodo de 1890 a 1980.

\begin{tabular}{lcccc}
\hline Causa de variação & GL & SQ & QM & F \\
\hline $\begin{array}{l}\text { Contraste }\left(p_{3}\right) \\
\begin{array}{l}\text { Variacão do contras } \\
\text { te entre anos }\end{array}\end{array}$ & 90 & 5146,9531 & 57,1884 & \\
\hline \begin{tabular}{l} 
Variação total \\
\hline
\end{tabular}
\end{tabular}

\begin{tabular}{lcccc}
\hline Causa de variação & GL & SQ & QM & $F$ \\
\hline $\begin{array}{l}\text { Contraste }\left(q_{3}\right) \\
\begin{array}{l}\text { Variação do contras } \\
\text { te entre anos }\end{array}\end{array}$ & 90 & 295,8098 & 295,8098 & $4,1180 \%$ \\
\hline \begin{tabular}{l} 
Variação total \\
\hline
\end{tabular}
\end{tabular}

\begin{tabular}{lcccc}
\hline Causa de variação & GL & SQ & QM & F \\
\hline $\begin{array}{l}\text { Amplitude }\left(a_{3}\right) \\
\begin{array}{l}\text { Variação da } \\
\text { amplitude }\end{array}\end{array}$ & 2 & 333,3054 & 166,6527 & $2,5833 \mathrm{~ns}$ \\
\hline $\begin{array}{l}\text { Variação tota } \\
\text { a }\end{array}$ & 180 & 11611,9961 & 64,5111 & \\
\hline
\end{tabular}




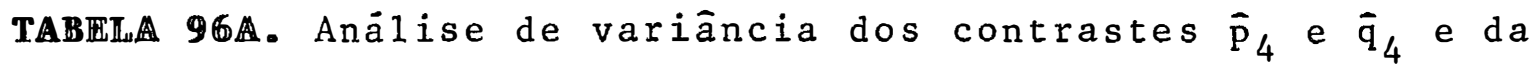
amplitude $\bar{a}_{4}$ das temperaturas médias mensais de Campinas, SP, no período de 1890 a 1980.

\begin{tabular}{lcccc}
\hline Causa de variação & GL & SQ & QM & F \\
\hline $\begin{array}{l}\text { Contraste }\left(\mathrm{P}_{4}\right) \\
\begin{array}{l}\text { Variação do contras } \\
\text { te entre anos }\end{array}\end{array}$ & 1 & 133,3525 & 133,3525 & $2,2091 \mathrm{~ns}$ \\
\hline \begin{tabular}{l} 
Variação total \\
\hline
\end{tabular} & 90 & 5432,8594 & 60,3651 & \\
\hline
\end{tabular}

\begin{tabular}{lcccc}
\hline Causa de variação & GL & SQ & QM & F \\
\hline $\begin{array}{l}\text { Contraste }\left(\varphi_{4}\right) \\
\begin{array}{l}\text { Variação do contras } \\
\text { te entre anos }\end{array}\end{array}$ & 1 & 433,6140 & 433,6140 & $6,3454 *$ \\
\hline \begin{tabular}{l} 
Variação total \\
\hline
\end{tabular} & 91 & 6150,1563 & 68,3351 & \\
\hline
\end{tabular}

\begin{tabular}{|c|c|c|c|c|}
\hline Causa de variação & GL & $\mathrm{SQ}$ & $Q \mathrm{M}$ & $\mathrm{F}$ \\
\hline Amplitude $\left(\mathrm{a}_{4}\right)$ & 2 & 566,9663 & 283,4832 & $4,4053 \%$ \\
\hline $\begin{array}{l}\text { Variação da } \\
\text { amplitude }\end{array}$ & 180 & 11583,0195 & 64,3501 & \\
\hline Variação total & 182 & 12149,9883 & & \\
\hline
\end{tabular}


TABEL 974. Anälise de variāncia dos contrastes $\bar{p}_{5}$ e $\bar{q}_{5}$ e da amplitude $\hat{a}_{5}$ das temperaturas médias mensais de Campinas, SP, no periodo de 1890 a $1980^{\circ}$

\begin{tabular}{lcccc}
\hline Causa de variação & GL & SQ & QM & F \\
\hline $\begin{array}{l}\text { Contraste }\left(p_{5}\right) \\
\begin{array}{l}\text { Variação do contras } \\
\text { te entre anos }\end{array}\end{array}$ & 1 & 277,8999 & 277,8999 & $5,3014 *$ \\
\hline \begin{tabular}{l} 
Variacaão total \\
\hline
\end{tabular}
\end{tabular}

\begin{tabular}{lcccc}
\hline Causa de variação & GL & SQ & QM & F \\
\hline $\begin{array}{l}\text { Contraste }\left(\mathrm{q}_{5}\right) \\
\begin{array}{l}\text { Variação do contras } \\
\text { te entre anos }\end{array}\end{array}$ & 90 & 38,9652 & 38,9652 & $0,6034 \mathrm{~ns}$ \\
\hline \begin{tabular}{l} 
Variação total \\
\hline
\end{tabular}
\end{tabular}

\begin{tabular}{|c|c|c|c|c|}
\hline Causa de variação & GL & SQ & $\mathrm{QM}$ & F \\
\hline Amplitude $\left(\mathrm{a}_{5}\right)$ & 2 & 316,8650 & 158,4325 & $2,7084 \mathrm{~ns}$ \\
\hline $\begin{array}{r}\text { Variação da } \\
\text { amplitude }\end{array}$ & 180 & 10529,4570 & $58,497.0$ & \\
\hline Variação total & 182 & $1.0846,3242$ & & \\
\hline
\end{tabular}


TABEL 98 Análise de variāncia do contraste $\overline{\mathrm{p}}_{6}$ das tempera turas médias mensais de Campinas, SP, no periodo de 1890 a 1980 .

Causa de variação

GL

SQ

QM

F

Contraste $\left(\mathrm{p}_{6}\right) \quad 1 \quad 13,3423 \quad 13,3423 \quad 0,4948 \mathrm{~ns}$

Variação do contras

te entre anos $\quad 90 \quad 2426,9792 \quad 26,9664$

Variação total $\quad 91 \quad 2440,3218$ 
TABEHA 99A. Estimativas e componentes harmōnicos das tempera turas médias mensais de Campinas, SP, no periodo de 1890 a 1980 .

\begin{tabular}{lccccccc}
\hline Meses & i & $\bar{Y}$ & A & B & C & D & Y \\
\hline Jan. & 0 & 257,5209 & 67,2764 & $-7,6356$ & $-1,2105$ & 58,4303 & 315,9512 \\
Fev. & 1 & 257,5209 & 56,3926 & 8,4017 & $-1,2853$ & 63,5090 & 321,0299 \\
Mar. & 2 & 257,5209 & 30,3984 & 16,0373 & 2,4958 & 48,9315 & 306,4524 \\
Abr. & 3 & 257,5209 & $-3,7409$ & 7,6356 & $-1,2105$ & 2,6842 & 260,2051 \\
Mai. & 4 & 257,5209 & $-36,8779$ & $-8,4017$ & $-1,2853$ & $-46,5649$ & 210,9560 \\
Jun. & 5 & 257,5209 & $-60,1335$ & $-16,0373$ & 2,4958 & $-73,6750$ & 183,8459 \\
Ju1. & 6 & 257,5209 & $-67,2763$ & $-7,6356$ & $-1,2105$ & $-76,1224$ & 181,3985 \\
Ago. & 7 & 257,5209 & $-56,3926$ & 8,4017 & $-1,2853$ & $-49,2762$ & 208,2447 \\
Set. & 8 & 257,5209 & $-30,3984$ & 16,0373 & 2,4958 & $-11,8653$ & 245,6556 \\
Out. & 9 & 257,5209 & 3,7409 & 7,6356 & $-1,2105$ & 10,1660 & 267,6869 \\
Nov. & 10 & 257,5209 & 36,8779 & $-8,4017$ & $-1,2853$ & 27,1909 & 284,7118 \\
Dez. & 11 & 257,5209 & 60,1335 & $-16,0373$ & 2,4958 & 46,5920 & 304,1129 \\
\hline
\end{tabular}

onde:

$$
\begin{aligned}
& \bar{Y}=\text { média geral } \\
& A=\text { componente harmônico anual } \\
& B=\text { componente harmônico semestral } \\
& C=\text { componente harmônico trimestral } \\
& D=\text { sintese das ondas } D=A+B+C \\
& \hat{Y}=\bar{Y}+D
\end{aligned}
$$




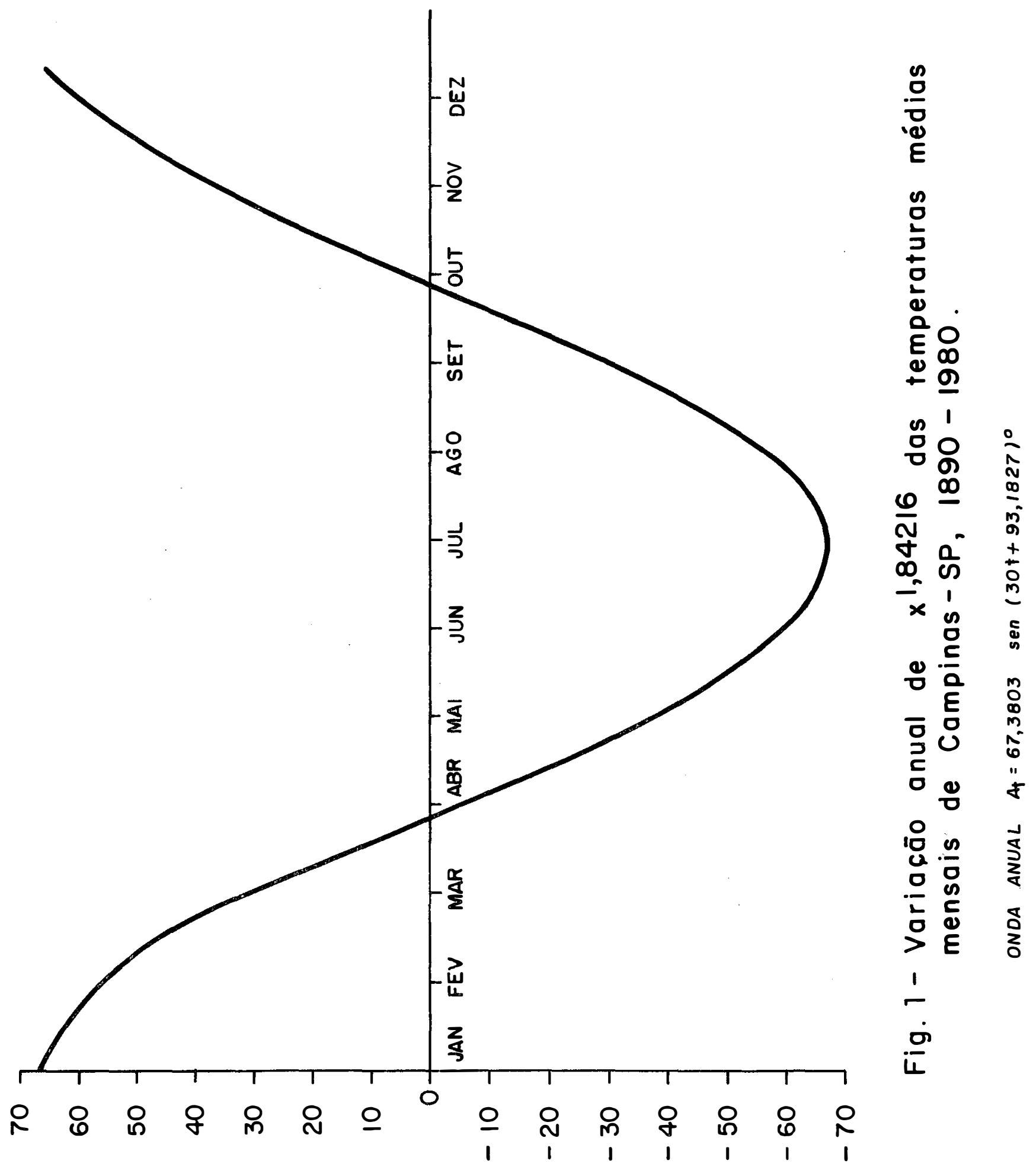




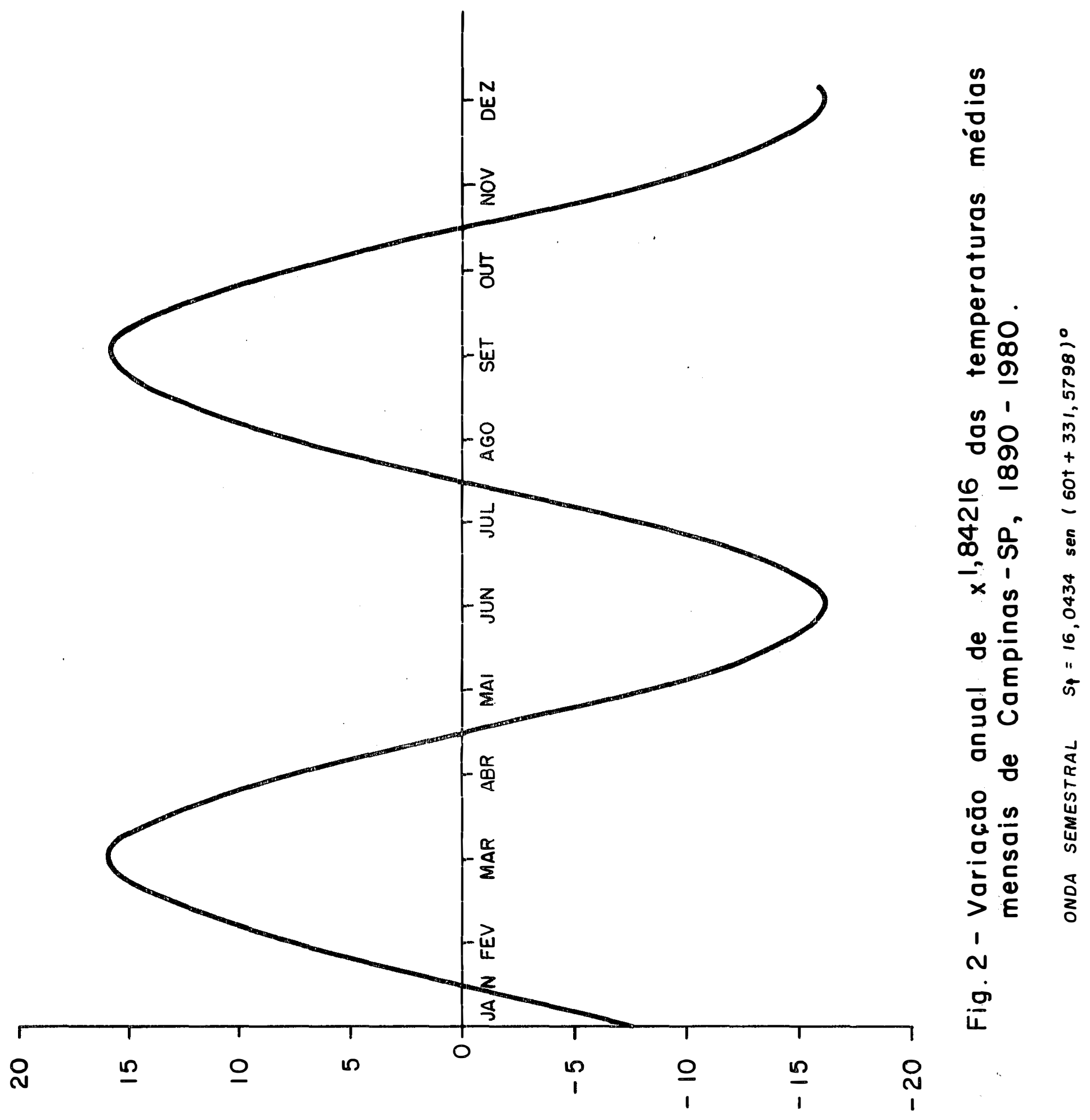


.117.

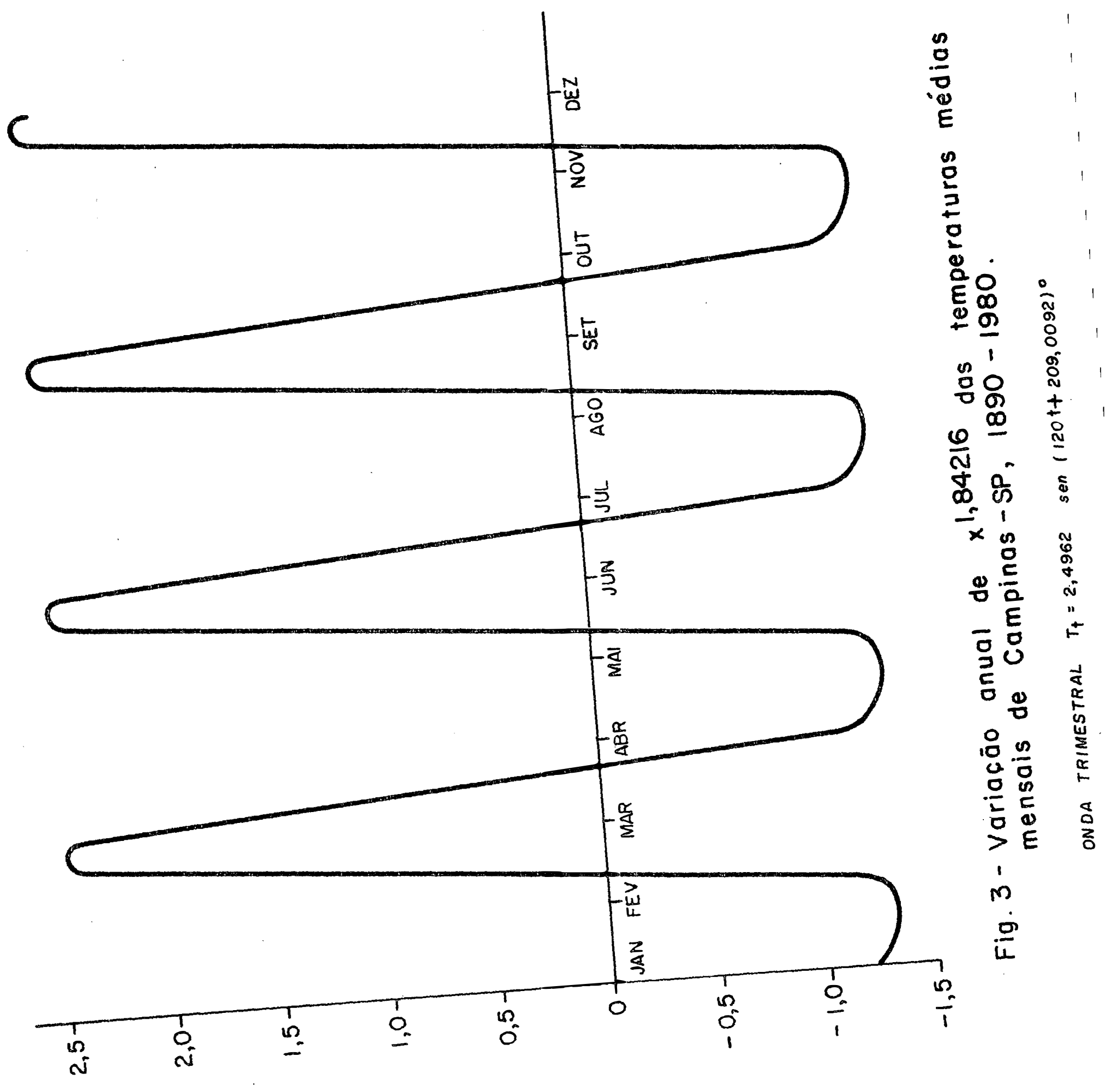




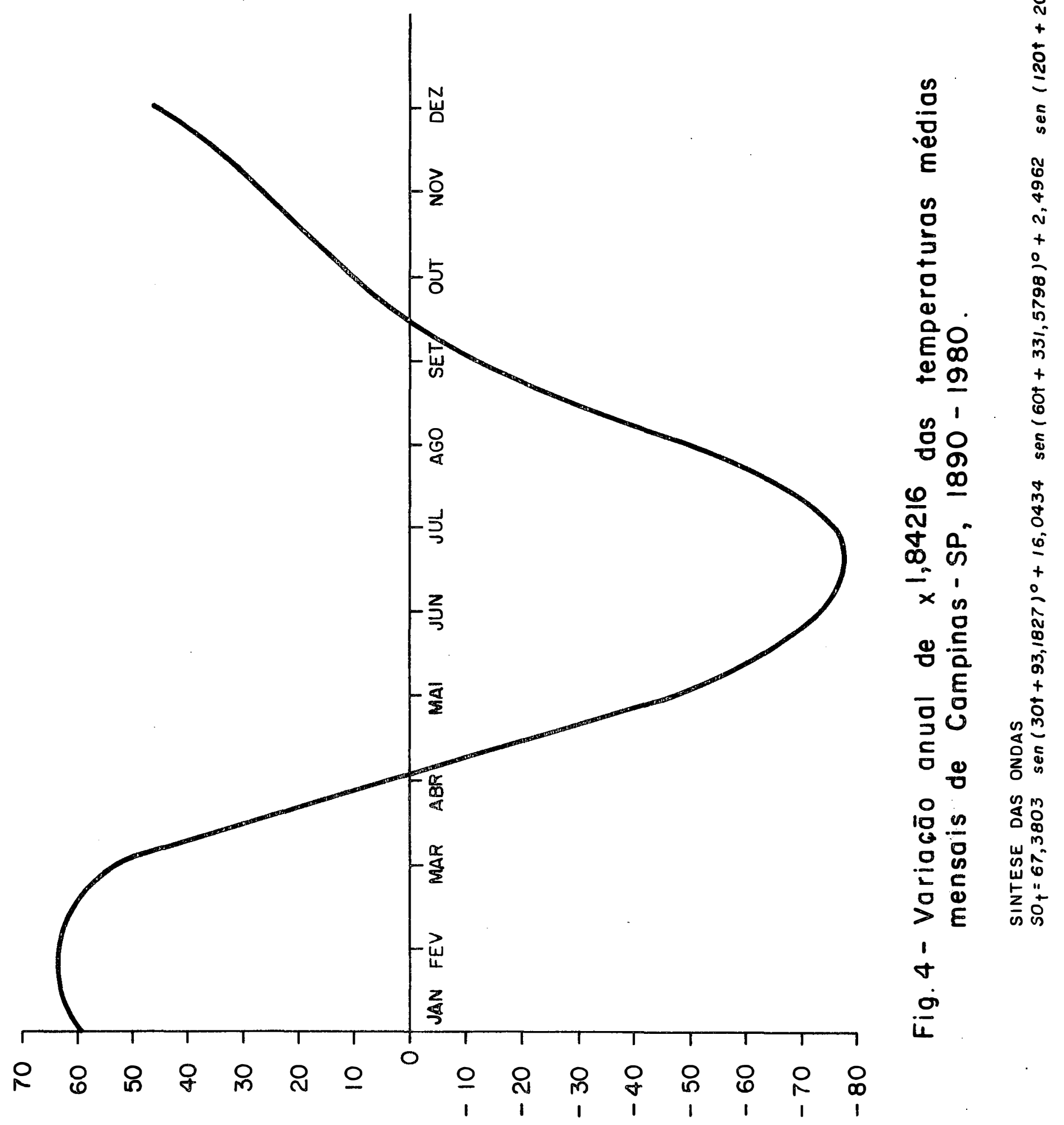


.119.

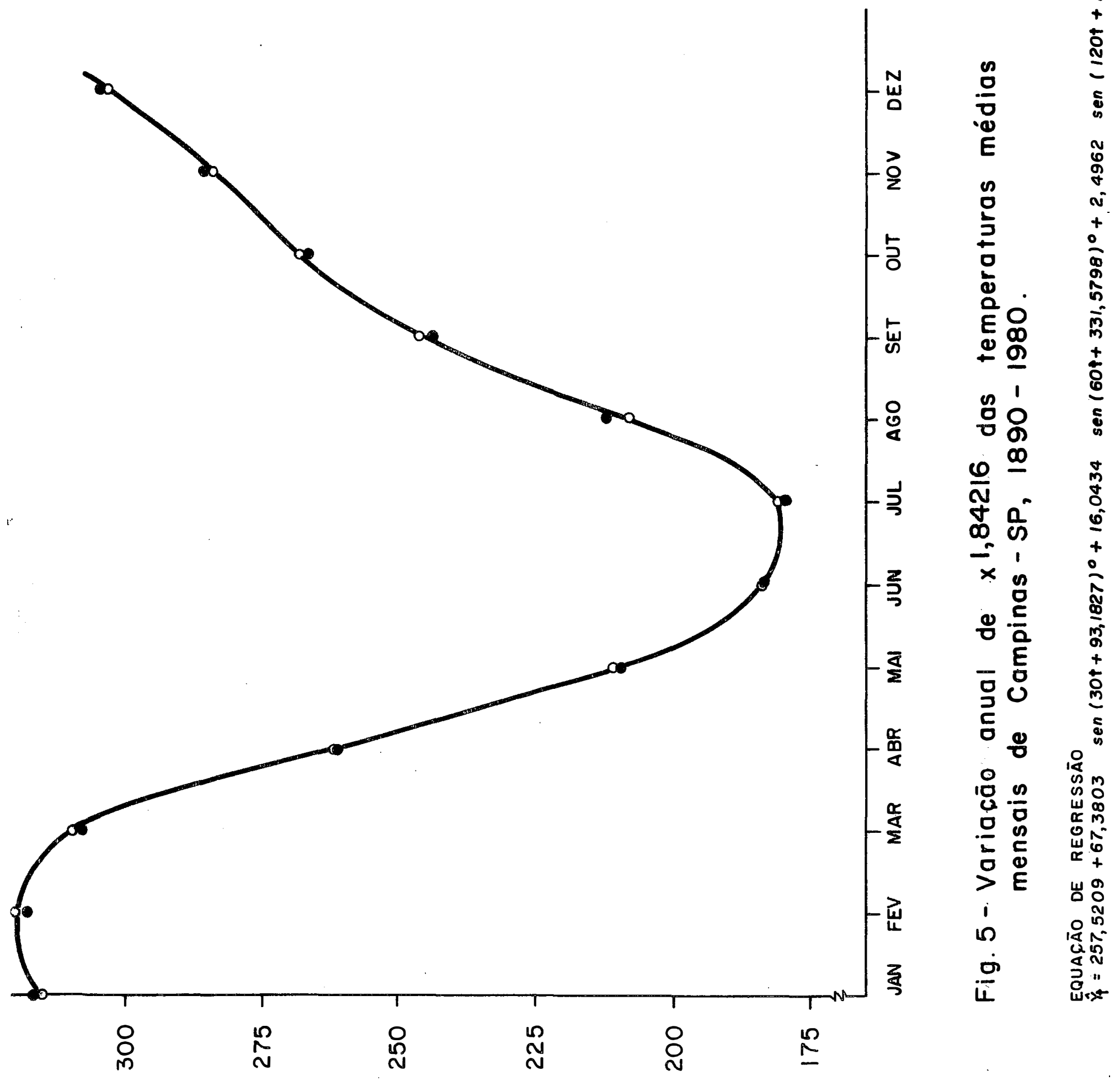




\subsection{Variāncias dos parâmetros estimados}

$$
\text { As estimativas da variāncia dos contrastes } \hat{\mathrm{p}}_{\mathrm{h}}
$$

e $\widehat{\mathrm{q}}_{\mathrm{h}}$, referentes aos componentes harmónicos são:

$$
\begin{array}{ll}
\mathrm{V}\left(\hat{\mathrm{p}}_{1}\right)=16,3493 & \mathrm{~V}\left(\overline{\mathrm{q}}_{1}\right)=22,8803 \\
\mathrm{~V}\left(\hat{\mathrm{p}}_{2}\right)=11,1726 & \mathrm{~V}\left(\overline{\mathrm{q}}_{2}\right)=16,5978 \\
\mathrm{~V}\left(\hat{\mathrm{p}}_{3}\right)=9,5314 & \mathrm{~V}\left(\overline{\mathrm{q}}_{3}\right)=11,9723 \\
\mathrm{~V}\left(\hat{\mathrm{p}}_{4}\right)=10,0608 & \mathrm{~V}\left(\overline{\mathrm{q}}_{4}\right)=11,3892 \\
\mathrm{~V}\left(\hat{\mathrm{p}}_{5}\right)=8,7367 & \mathrm{~V}\left(\overline{\mathrm{q}}_{5}\right)=10,7623 \\
\mathrm{~V}\left(\hat{\mathrm{p}}_{6}\right)=2,2472 &
\end{array}
$$

\subsection{Intervalo de confianca}

Obtidas as estimativas $\hat{\mathrm{p}}_{\mathrm{h}}$ e $\hat{\mathrm{q}}_{\mathrm{h}}$ e suas respectivas variancias, pode-se calcular o intervalo de confiança para $\alpha=0,05$ (média dos 91 anos).

$$
\begin{array}{r}
59,2462 \leqq \hat{\mathrm{p}}_{1} \leqq 75,3066 \\
-14,2739 \leqq \overline{\mathrm{p}}_{2} \leqq-0,9973 \\
-6,7733 \leqq \overline{\mathrm{p}}_{3} \leqq 5,4895 \\
-7,5098 \leqq \hat{\mathrm{p}}_{4} \leqq 5,0888 \\
-4,1226 \leqq \overline{\mathrm{p}}_{5} \leqq 7,6178 \\
-3,3598 \leqq \overline{\mathrm{p}}_{6} \leqq 2,5944 \\
-13,2405 \leqq \overline{\mathrm{q}}_{1} \leqq 5,7589 \\
6,0189 \leqq \overline{\mathrm{q}}_{2} \leqq 22,2009
\end{array}
$$


. 121.

$-8,6747 \leqq \overline{\mathrm{q}}_{3} \leqq 5,0689$
$-8,8853 \leqq \overline{\mathrm{q}}_{4} \leqq 4,5193$
$-7,1699 \leqq \overline{\mathrm{q}}_{5} \leqq 5,8607$




\section{Conclusões}

Das anālises realizadas, podemos concluir que:

1. Os dados originais das temperaturas médias mensais de Cam pinas, SP, num periodo de 91 anos (1890 a 1980) não apresentaram homogeneidade das variâncias, nem aditividade dos efeitos e nem normalidade da distribuição.

2. No estudo de uma transformação que homogeneizasse as variâncias obteve-se $Y=X^{1,84216}$, que além disso, apresentou aditividade dos efeitos e melhorou a normalidade.

3. Pelos resultados da análise harmōnica do total dos 91 anos, ajustados a um ano médio, obtivemos a seguinte equa ção de regressão: 


$$
\begin{aligned}
\vec{Y}_{t}=257,5209 & +67,3803 \operatorname{sen}(30 t+93,1827)^{\circ}+ \\
& +16,0434 \operatorname{sen}(60 t+331,5798)^{\circ}+ \\
& +2,4962 \operatorname{sen}(120 t+209,0092)
\end{aligned}
$$

onde $\mathrm{t}=0,1,2, \ldots, 11 ; \overline{\mathrm{Y}}_{\mathrm{t}}=$ a estimativa de $Y=X^{1,84216}$ valor transformado, da temperatura média referente ao mès t.

4. A equação de regressão estimada, composta pelas ondas anual, semestral e trimestral, explicou $99,8 \%$ das varia ções devidas a meses. Somente o componente anual é responsäve1 por $94,5 \%$ das variações devidas a meses.

5. Pela equação obtida estimou-se a ocorrēncia de um máximo durante o més de fevereiro $\left(\vec{Y}_{1}=321,03\right)$ equivalente à temperatura de $\overrightarrow{\mathrm{Y}}_{1}=22,94^{\circ}$ e um mínimo durante o mês de julho $\left(\vec{Y}_{6}=181,40\right)$ equivalente à temperatura de $\overline{\mathrm{Y}}_{6}=16,83^{\circ}$. 


\section{BIBLIOGRAFIA}

AMARAL, E. e F.S. MOTA, 1956. Normais e variabilidade relativa das precipitacões mensais. Pelotas, Boletim Técnico no 13, Instituto Agronómico do Su1, 19 p.

AMARAL, E., 1967. Transformação dos dados - Curso de Estatistica Experimenta1, fasciculo 12, IPEAS, Pelotas, RS.

AMARAL, E., 1968. Anālise harmōnica. Pesquisa Agropecuäria Brasileira, 3: 7-43.

. AMARAL, E. e J. BAPTISTA DA SILVA, 1970. Tabela de Probabili dades das precipitacões pluviométricas em Pelotas, RS. Pe lotas, Circular no 44, Instituto de Pesquisas e Experimentação Agropecuäria do Su1, 27 . 
AMARAL, E., 1975. Anālise harmônica e Previsão a longo prazo. Apresentado na Reunião Comemorativa do 20 e Aniversário da Região Brasileira da Sociedade Internacional de Biometria. Piracicaba, 34 p. Anais

AMARAL, E., J. BAPTISTA DA SILVA, e M. BASSOLS, 1975. Tabelas de probabizidades da temperatura minima em Pelotas, RS. (média das minimas e minima absoluta). Brasilia, Boletim Técnico nọ 9, Departamento Nacional de Meteorologia, $61 \mathrm{p}$.

ANDERSON, T.W., 1971. The Statistical Analysis of Time Series. Nova York, John Wiley and Sons, 704 p.

ARRUDA, H.V. e H.S. PINTO, 1977. An attempt to establish a new model for rainfall analysis. Campinas, Seminärio Internacional sobre Climatologia do hemisfério sul.

BAPTISTA DA SILVA, J., 1977. Anālise harmōnica das precipitações pluviométricas pentadais. Pelotas, RS, $1900 / 51$. 216 p. (Tese de Livre-docência).

BAPTISTA DA SILVA, J。, 1979. Tabela de probabilidade das precipitações pluviométricas máximas pentadais em Pelotas, RS. Pelotas, UFPe1. 144 p. (Tese de Professor Titular)。

BARTLETT, M.S., 1937. Properties of sufficiency and statistical test, Proc. Royal Soc., A160:268-282. 
BLISS, C.I., 1958. Periodic regression in biology and climatology. New Haven, Connecticut Agri Exp. Station, 55 p. (Bo1. 615).

BLOOMFIELD, P., 1946. Fourier analysis of time series: An introduction. 1ạ edição, Nova York, John Wiley and Sons, $258 \mathrm{p}$.

BROOKS, C.E.P. e N. CARRUTHERS, 1953. Handbook of statistical methods in meteorology. Her Majesty's Stationery Office London, $412 \mathrm{p}$.

COCHRAN, W.G. e G.M. COX, 1978. Diseños Experimentales. 1a edição, 5ạ reimpressão, México, Ed. Trillas, 661 p.

COElho, H., 1980. Emprego da anālise harmōnica a dados da produção de citros (Citrus sinensis L. Osbeck). Piracica ba, ESALQ/USP, $65 \mathrm{p}$. (Dissertação de Mestrado).

CONRAD, V. e L.W. POLLAK, 1950. Methods in Climatology. Mas sachusetts. Harvard University Press, 459 p.

- DECICO, A. e V.F. CRUZ, 1974. Estudo de fenómenos periódicos. IV Jornada Cientifica da Faculdade de Ciências Médi cas e Biológicas de Botucatu, 15 p. (Anexo 19).

DRAPPER, N.R. e H. SMITH, 1966. Applied Regression Analysis. Nova York, John Willey, 407 p. 
DUARTE, G.S., 1974. Curva epidemiológica da ferrugem alaran jada do cafeeiro na Zona da Mata - MG. Piracicaba, ESALQ/ USP, 65 p. (Dissertação de Mestrado).

DUARTE, G.S., 1980. Uso da regressão periódica na experimentação agronōmica. Piracicaba, ESALQ/USP. Seminärio apre sentado no curso de Estatística e Experimentação Agronômi ca, 11 p. (mimeog.).

DUARTE, G.S., 1981. O emprego da anālise harmōnica no estudo de incidência da ferrugem alaranjada do cafeeiro (Hem $\underline{i}$ leia vastatrix Berk et Br) no estado de Minas Gerais. Pi racicaba, ESALQ/USP, 72 p. (Tese de Doutoramento).

FELTRIN, M.A.V., 1980. A anälise harmônica no estudo das precipitações pluviais no municipio de Bandeirantes, PR. Piracicaba, ESALQ/USP, 92 p. (Dissertação de Mestrado).

FISHER, R.A., Sc.D.; F.R.S., 1941. Statistical Methods for Research Workers. 8ạ Edição, London, 01 iver and Boyd, $354 \mathrm{p}$.

GODOY, H., I.R. NOGUEIRA e F. PIMENTEL GOMES, 1959. Estudo sobre as temperaturas médias em Campinas. Anais E.S.A. "Luiz de Queiroz", Piracicaba, 16: 277-287.

GROSH, M.N. e D. SHARMA, 1963. Power of Tuke'y test for non-additivity. Journal of the Royal Statistical Society. Londres, 25: 213-219. 
.128 .

PEREIRA, N.S.C., 1978. Regressão periódica aplicada a dados pluviométricos mensais do municipio de Grajaú, MA. Pira cicaba, ESALQ/USP, 66 p. (Dissertação de Mestrado).

PIMENTEL GOMES, F. e I.R. NOGUEIRA, 1975. Extrapolação ou projeção: uma tënica difícil e perigosa. Anais da Reunião Internacional de Biometria. Piracicaba, p. 272-279.

PIMENTEL GOMES, F., 1978. Curso de Estatistica Experimental. 8a edição, Piracicaba, ESALQ, 430 p.

SNEDECOR, G.W. e W.G. COCHRAN, 1976. Statistical Methods. 6ạ edição, Iowa, The State University Press, 593 p.

SOUZA, B.B., 1977. Uso de transformações que visam a homoce dasticidade. Tese defendida na Universidade de Brasilia. $63 \mathrm{p}$.

SPIEGEL, M.R., 1976. Anälise de Fourier. São Paulo, McGraw Hil1 do Brasil, 249 p. Coleção Schawn.

TAYLOR, L.R., 1961. Agregation, variance and the mean. Nature, $189,732-735$.

THIEBAUT, J.T.L., 1976. O emprego da anälise harmōnica no estudo das precipitações mensais do municipio de Viçosa, MG. Piracicaba, ESALQ/USP, 92 p. (Dissertação de Mestra do ) 
TUKEY, J.W., 1949. One degrees of freedrom for non-additivity. Biometrics. Raleigh, 5:232-242.

WINER, B.Y., 1971. Statistical Principles in Experimental Design. 2a edição. Kogakusha, Ltda., 907 p. 
.130 .

APÊNDICE 
APENDCE 1. Dados originais das temperaturas médias mensais de Campinas, SP, no período de 1890 a 1980.

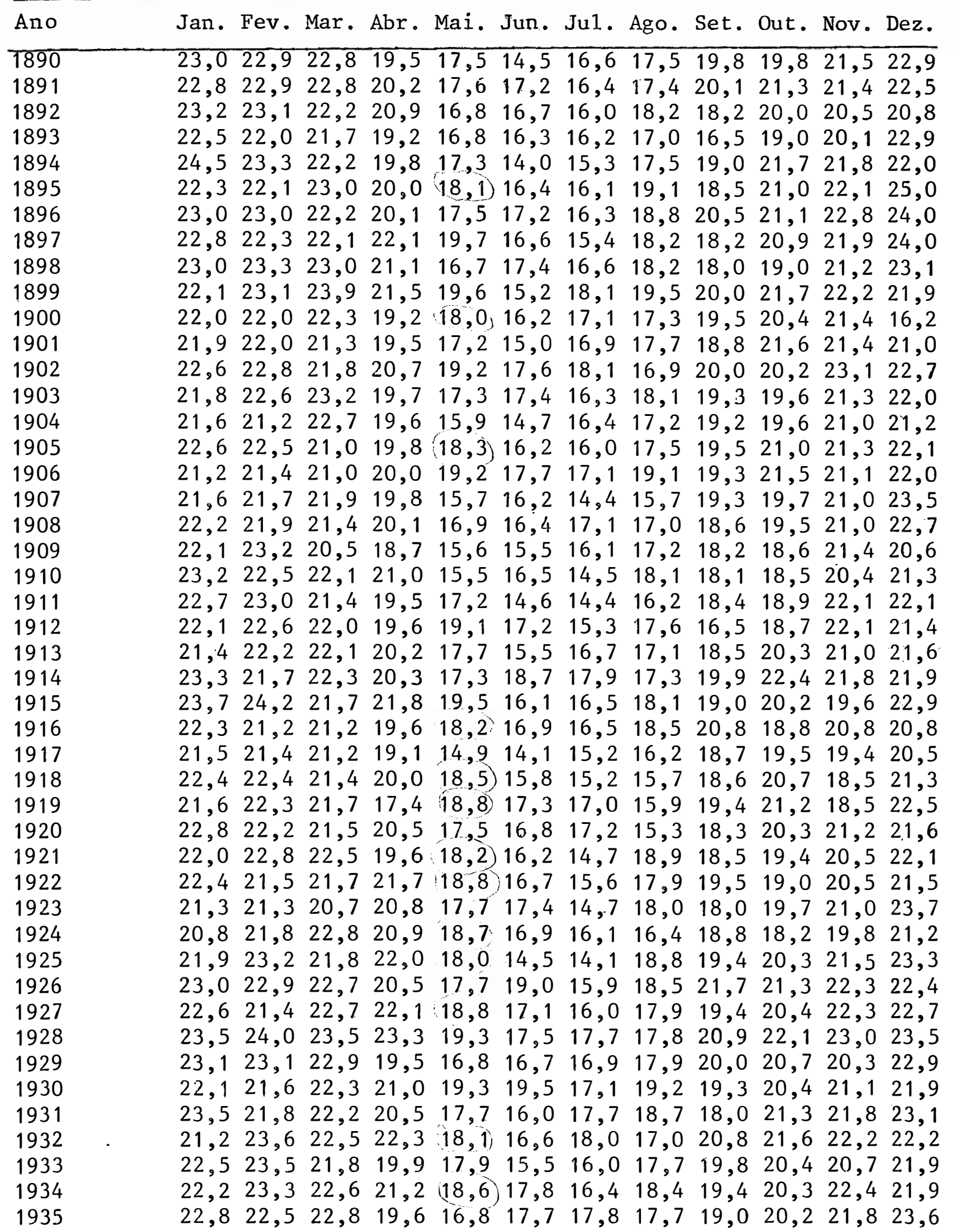


APENDICE 2. (cont inuação)

\begin{tabular}{|c|c|c|c|c|c|c|c|c|c|c|c|c|}
\hline Ano & an. & Fev. & r. & $r$. & Mai & Jun. & 11. & \%o. & et. & dt. & Nov. & $e z$ \\
\hline 1936 & 23,9 & 22,3 & 21,7 & 20,8 & 20,8 & 19,0 & 17,3 & 16,5 & 18,6 & 21,2 & 21,5 & 22,7 \\
\hline 1937 & 21,4 & 23,2 & 22,7 & 20,1 & 17,0 & 16,9 & 17,4 & 18,9 & 19,5 & 19,9 & 20,9 & 21,1 . \\
\hline 1938 & 24,9 & 23,8 & 24,5 & 21,6 & 19,0 & 18,2 & 17,9 & 18,7 & 20,2 & 20,6 & 22,6 & 22,3 \\
\hline 1939 & 22,7 & 23,5 & 23,6 & 21,1 & 19,5 & 16,9 & 15,3 & 19,0 & 19,4 & 22,1 & 21,9 & 22,1 \\
\hline 1940 & 23,3 & 21,8 & 23,4 & 22,2 & 19,9 & 18,2 & 18,8 & 19,7 & 20,4 & 21,0 & 21,6 & 25,0 \\
\hline 1941 & 23,9 & 24,1 & 22,7 & 22,9 & 20,2 & 17,3 & 16,7 & 20,2 & 16,5 & 20,1 & 21,6 & 21,6 \\
\hline 1942 & 23,4 & 23,2 & 22,4 & 20,7 & 18,0 & 16,9 & 14,5 & 18,7 & 19,5 & 21,0 & 22,0 & 21,1 \\
\hline 1943 & 22,1 & 22,6 & 22,7 & 19,4 & 19,0 & 17,7 & 17,3 & 17,0 & 18,3 & 20,4 & 21,5 & 21,1 \\
\hline 1944 & 23,4 & 22,4 & 23,0 & 19,9 & $18,1)$ & 17,0 & 15,9 & 19,2 & 21,1 & 23,7 & 20,5 & 22,8 \\
\hline 1945 & 22,3 & 23,2 & 22,0 & 20,5 & 16,8 & 15,6 & 16,4 & 20,4 & 19,1 & 21,6 & 21,3 & 21,4 \\
\hline 1946 & 22,9 & 23,8 & 22,0 & 19,6 & 19,6 & 16,5 & 16,0 & 19,3 & 20,8 & 21,7 & 22,4 & 22,6 \\
\hline 1947 & 22,3 & 23,8 & 21,4 & 20,5 & 19,3 & 18,1 & 15,8 & 17,4 & 19,6 & 18,7 & 20,6 & 21,5 \\
\hline 1948 & 23,6 & 23,1 & 21,7 & 20,8 & 19,0 & 17,3 & 18,4 & 17,5 & 20,5 & 20,6 & 21,9 & 22,6 \\
\hline 1949 & 23,0 & 22,2 & 23,9 & 19,8 & 17,2 & 17,9 & 17,2 & 18,5 & 20,4 & 20,3 & 21,9 & 22,6 \\
\hline 1950 & 22,9 & 22,5 & 22,5 & 20,9 & 19,5 & 18,1 & 17,2 & 20,2 & 20,5 & 20,8 & 21,1 & 22,3 \\
\hline 1951 & 21,8 & 22,9 & 22,4 & 18,4 & 18,1 & 16,5 & 15,3 & 18,5 & 21,6 & 22,3 & 23,1 & 22,2 \\
\hline 1952 & 24,6 & 23,1 & 23,2 & 20,1 & 20,2 & 18,1 & 18,4 & 21,1 & 20,3 & 21,5 & 23,3 & 24,1 \\
\hline 1953 & 24,6 & 24,4 & 23,9 & 20,9 & 19,7 & 18,3 & 17,0 & 20,4 & 22,1 & 22,4 & 22,5 & 23,4 \\
\hline 1954 & 24,2 & 23,8 & 23,2 & 20,5 & 18,8 & 18,0 & 17,9 & 19,4 & 21,3 & 21,5 & 22,8 & 22,4 \\
\hline 1955 & 23,0 & 24,2 & 23,0 & 21,2 & 18,1 & 17,4 & 17,7 & 18,8 & 21,1 & 20,5 & 20,9 & 23,1 \\
\hline 1956 & 26,0 & 23,2 & 22,8 & 20,8 & 17,1 & 15,4 & 16,6 & 16,5 & 20,7 & 20,8 & 20,7 & 22,7 \\
\hline 1957 & 23,0 & 21,8 & 22,2 & 20,2 & 17,8 & 17,0 & 16,3 & 18,5 & 19,0 & 22,4 & 21,8 & 22,9 \\
\hline 1958 & 24,0 & 23,7 & 21,6 & 20,0 & 17,8 & 16,9 & 17,9 & 20,1 & 19,5 & 21,1 & 22,9 & 23,7 \\
\hline 1959 & 23,3 & 23,8 & 22,1 & 22,8 & 19,7 & 16,4 & 19,0 & 18,2 & 21,8 & 22,1 & 21,9 & 22,8 \\
\hline 1960 & 22,6 & 22,0 & 22,3 & 19,6 & 16,5 & 16,3 & 16,9 & 19,4 & 20,8 & 22,2 & 21,4 & 22,0 \\
\hline 1961 & 22,8 & 22,3 & 21,8 & 20,6 & 18,1 & 17,5 & 17,1 & 19,5 & 23,3 & 23,5 & 23,2 & 21,8 \\
\hline 1962 & 22,7 & 22,7 & 22,4 & 20,4 & 17,2 & 15,4 & 15,5 & 18,1 & 20,2 & 19,2 & 21,7 & 22,0 \\
\hline 1963 & 23,2 & 23,1 & 23,9 & 21,2 & 18,3 & 16,7 & 18,3 & 19,7 & 23,7 & 23,1 & 23,6 & 23,4 \\
\hline 1964 & 22,9 & 22,1 & 22,6 & 22,3 & 18,0 & 16,5 & 15,8 & 19,5 & 21,2 & 20,0 & 21,1 & 21,5 \\
\hline 1965 & 21,6 & 22,2 & 20,6 & 21,1 & 18,2 & 18,4 & 17,5 & 19,2 & 22,6 & 21,2 & 22,2 & 22,7 \\
\hline 1966 & 23,6 & 24,3 & 22,5 & 21,2 & 19,2 & 18,2 & 18,9 & 18,6 & 19,5 & 21,3 & 21,4 & 23,1 \\
\hline 1967 & 22,3 & 22,8 & 22,4 & 21,1 & 19,6 & 17,4 & 17,2 & 20,6 & 20,6 & 22,5 & 21,1 & 20,7 \\
\hline 1968 & 22,1 & 21,7 & 22,3 & 18,9 & 16,2 & 16,7 & 16,7 & 17,4 & 19,7 & 21,1 & 23,4 & 23,5 \\
\hline 1969 & 23,9 & 24,4 & 23,5 & 20,7 & 19,3 & 18,3 & 17,8 & 19,3 & 21,9 & 19,6 & 21,8 & 21,4 \\
\hline 1970 & 22,7 & 22,5 & 23,2 & 21,1 & 19,9 & 18,8 & 17,3 & 17,9 & 19,2 & 20,6 & 20,5 & 23,7 \\
\hline 1971 & 24,3 & 24,2 & 23,5 & 20,6 & 18,1 & 16,6 & 17,3 & 18,9 & 19,9 & 20,1 & 20,4 & 22,0 \\
\hline 1972 & 22,6 & 22,0 & 23,3 & 19,5 & 19,4 & 18,4 & 17,1 & 18,5 & 20,0 & 21,2 & 22,0 & 22,9 \\
\hline 1973 & 23,8 & 24,6 & 22,6 & 23,3 & 18,8 & 18,7 & 17,9 & 18,3 & 19,3 & 20,4 & 21,0 & 22,6 \\
\hline 1974 & 22,5 & 24,4 & 22,9 & 20,4 & 18,2 & 16,5 & 18,0 & 18,4 & 21,1 & 20,4 & 21,9 & 21,3 \\
\hline 1975 & 22,2 & 23,2 & 23,4 & 20,1 & 17,9 & 17,5 & 15,7 & 21,3 & 21,5 & 21,0 & 21,2 & 23,1 \\
\hline 1976 & 23,1 & 21,6 & 22,5 & 20,4 & 17,8 & 16,5 & 16,1 & 18,3 & 18,3 & 19,7 & 21,8 & 22,1 \\
\hline 1977 & 22,9 & 24,9 & 23,6 & 20,7 & 18,5 & 18,6 & 19,6 & 20,2 & 20,7 & 22,8 & 22,2 & 21,5 \\
\hline 1978 & 24,2 & 23,8 & 23,7 & 20,8 & 18,3 & 17,2 & 18,4 & 18,1 & 19,7 & 22,4 & 21,6 & 22,5 \\
\hline 1979 & 21,4 & 23,6 & 22,0 & 20,2 & 18,6 & 17,0 & 16,2 & 19,5 & 19,3 & 22,2 & 21,6 & 22,9 \\
\hline 1980 & 22,4 & 22,9 & 24,1 & 21,5 & 19,9 & 16,9 & 18,5 & 19,5 & 18,8 & 21,6 & 22,2 & 23,1 \\
\hline
\end{tabular}


APENDICE 2. Demonstração para o caso de:

$$
\begin{aligned}
& S=\sum_{t=0}^{T-1} \cos ^{2} k \phi t=\frac{T}{2} \\
& S=1+\cos ^{2} k \phi+\cos ^{2} 2 k \phi+\ldots+\cos ^{2}(T-1) k \phi
\end{aligned}
$$

sabendo-se que $\cos (k \phi, t)=\frac{e^{i k \phi t}+e^{-i k \phi t}}{2}$

e aplicando no somatörio, tem-se:

$$
\begin{aligned}
& S=1+\left(\frac{\left.e^{i k \phi}+e^{-i k \phi}\right)^{2}}{2}+\left(\frac{\left.e^{2 i k \phi}+e^{-2 i k \phi}\right)^{2}}{2}+\ldots+\right.\right. \\
& +\frac{e^{(T-1) i k \phi}+e^{-(T-1) i k \phi}}{2} . \\
& S=1+\frac{1}{4}\left[e^{2 i k \phi}+e^{-2 i k \phi}+e^{4 i k \phi}+e^{-4 i k \phi}+\ldots+e^{2(T-1) i k \phi}+e^{-2(T-1) i k \phi_{+}}\right. \\
& +2(T-1)\rceil \\
& S=\frac{1}{2}+\frac{T}{2}+\frac{1}{4}\left[e^{2 i k \phi}+e^{4 i k \phi}+\ldots+e^{2(T-1) i k \phi}+e^{-2 i k \phi}+e^{-4 i k \phi}+\ldots+\right. \\
& \left.+e^{-2(T-1) i k \phi}\right]
\end{aligned}
$$

Aplicando a förmula da soma de termos da progressão geomētrica obtém-se: 
.134.

$$
\begin{aligned}
S & =\frac{1}{2}+\frac{T}{2}+\frac{1}{4}\left[\frac{e^{2(T-1) i k \phi} \cdot e^{2 i k \phi}-e^{2 i k \phi}}{e^{2 i k \phi}-1}+\right. \\
& \left.+\frac{e^{-2(T-1) i k \phi} \cdot e^{-2 i k \phi}-e^{-2 i k \phi}}{e^{-2 i k \phi}-1}\right] \\
S & =\frac{1}{2}+\frac{T}{2}+\frac{1}{4}\left[\frac{e^{2 i k \phi}\left(e^{2(T-1) i k \phi}-1\right)}{e^{2 i k \phi}-1}+\frac{e^{-2 i k \phi}\left(e^{-2(T-1) i k \phi}-1\right)}{e^{-2 i k \phi}-1}\right]
\end{aligned}
$$

Multiplicando o primeiro termo do colchete o numerador e o denominador por $e^{-i k \phi} e^{-(T-1) i k \phi}$ e multiplicando o numerador e o denominador do segundo termo do colchete por $e^{i k \phi} e^{(T-1) i k \phi}$ tem-se :

$$
\begin{aligned}
S & =\frac{1}{2}+\frac{T}{2}+\frac{1}{4}\left[\frac{e^{2 i k \phi} e^{-i k \phi} e^{-(T-1) i k \phi}\left(e^{2(T-1) i k \phi}-1\right)}{e^{-(T-1) i k \phi} e^{-i k \phi}\left(e^{2 i k \phi}-1\right)}+\right. \\
& \left.+\frac{e^{-2 i k \phi} e^{i k \phi} \cdot e^{(T-1) i k \phi}\left(e^{-2(T-1) i k \phi}-1\right)}{e^{(T-1) i k \phi} e^{i k \phi}\left(e^{-2 i k \phi}-1\right)}\right] \\
S & =\frac{1}{2}+\frac{T}{2}+\frac{1}{4}\left[\frac{e^{i k \phi}\left(e^{(T-1) i k \phi}-e^{-(T-1) i k \phi}\right)}{e^{-(T-1) i k \phi}\left(e^{i k \phi}-e^{-i k \phi}\right)}+\right. \\
& \left.+\frac{e^{-i k \phi}\left(e^{-(T-1) i k \phi}-e^{(T-1) i k \phi}\right)}{e^{(T-1) i k \phi}\left(e^{-i k \phi}-e^{i k \phi}\right)}\right]
\end{aligned}
$$

Dividindo-se por 2 i tem-se 


$$
\begin{aligned}
& S=\frac{1}{2}+\frac{T}{2}+\frac{1}{4}\left[e^{i k \phi} e^{(T-1) i k \phi} \frac{\frac{\left(e^{(T-1) i k \phi}-e^{-(T-1) i k \phi}\right)}{\frac{\left(e^{i k \phi}-e^{-i k \phi}\right)}{2 i}}}{\frac{2 i}{i}}+\right. \\
& \left.+e^{-i k \phi} \cdot e^{-(T-1) i k \phi} \frac{\frac{\left(e^{(T-1) i k \phi}-e^{-(T-1) i k \phi)}\right.}{2 i}}{\frac{\left(e^{i k \phi}-e^{-i k \phi}\right)}{2 i}}\right] \\
& S=\frac{1}{2}+\frac{T}{2}+\frac{1}{4}\left[e^{T i k \phi} \frac{\operatorname{sen}(T-1) k \phi}{\operatorname{senk} \phi}+e^{-T i k \phi} \frac{\operatorname{sen}(T-1) k \phi}{\operatorname{sen} k \phi}\right] \\
& S=\frac{1}{2}+\frac{T}{2}+\frac{1}{2} \cdot\left[\frac{e^{T i k \phi}+e^{-T i k \phi}}{2} \cdot \frac{\operatorname{sen}(T-1) k \phi}{\operatorname{sen} k \phi}\right] \\
& \mathrm{S}=\frac{1}{2}+\frac{\mathrm{T}}{2}+\cos \mathrm{Tk} \phi \cdot\left(\frac{\operatorname{sen}(\mathrm{T}-1) \mathrm{k} \phi}{2 \operatorname{senk} \phi}\right)
\end{aligned}
$$$$
\text { No caso T impar, tem-se }
$$$$
\phi=\frac{2 \pi}{\mathrm{T}} \quad \mathrm{k}=\frac{(\mathrm{T}-1)}{2}
$$$$
S=\frac{1}{2}+\frac{T}{2}+\left(\frac{\operatorname{sen}(T-1) \frac{(T-1)}{2} \cdot \frac{2 \pi}{T}}{2 \operatorname{sen} \frac{(T-1)}{2}-\frac{2 \pi}{T}} \cdot \cos T \frac{(T-1)}{2} \cdot \frac{2 \pi}{T}\right)
$$$$
\left.\mathrm{S}=\frac{1}{2}+\frac{\mathrm{T}}{2}+\frac{\operatorname{sen}(\mathrm{T}-1) \frac{(\mathrm{T}-1)}{\mathrm{T}} \Pi}{2 \operatorname{sen} \frac{(\mathrm{T}-1)}{\mathrm{T}} \cdot \Pi} \cdot \cos (\mathrm{T}-1) \cdot \Pi\right)
$$ 


$$
\begin{aligned}
& \mathrm{S} \cdot=\frac{1}{2}+\frac{\mathrm{T}}{2}+\frac{\operatorname{sen}\left[(\mathrm{T}-2) \Pi+\frac{\pi}{\mathrm{T}}\right]}{2 \operatorname{sen}\left(\Pi-\frac{\pi}{\mathrm{T}}\right)} \\
& \mathrm{S}=\frac{1}{2}+\frac{\mathrm{T}}{2}+\frac{\operatorname{sen}(\mathrm{T}-2) \Pi \cos \frac{\pi}{\mathrm{T}}+\operatorname{sen} \frac{\pi}{\mathrm{T}} \cdot \cos (\mathrm{T}-2) \Pi}{2\left(\operatorname{sen} \Pi \cdot \cos \frac{\Pi}{\mathrm{T}}-\cos \Pi \cdot \operatorname{sen} \frac{\Pi}{\mathrm{T}}\right)} \\
& \mathrm{S}=\frac{1}{2}+\frac{\mathrm{T}}{2}+\frac{-\operatorname{sen} \frac{\pi}{\mathrm{T}}}{2 \operatorname{sen} \frac{\Pi}{\mathrm{T}}} \\
& \mathrm{S}=\frac{\mathrm{T}}{2}
\end{aligned}
$$$$
\text { No caso de T par, tem-se }
$$$$
\mathrm{k}=\frac{\mathrm{T}}{2} \quad \phi=\frac{2 \pi}{\mathrm{T}}
$$$$
S=\sum_{t=0}^{T-1} \cos ^{2} k \phi t
$$$$
S=\sum_{t=0}^{T-1} \cos ^{2} \frac{T}{2} \cdot \frac{2 \pi}{T} t
$$$$
S=\sum_{t=0}^{T-1} \cos ^{2} \pi t
$$$$
S=\cos ^{2} 0 \pi+\cos ^{2} \pi+\cos ^{2} 2 \pi+\ldots+\cos ^{2}(T-1) \Pi
$$$$
\mathrm{S}=\mathrm{T}
$$

De maneira análoga para os demais somatórios. 